إستفادة الريفيات من المشروعات الصغيرة بمحافظتى المنوفية و الثرقية أموره حسن أبو طالب أبريز

CrossMark قسم بحوث نرشيد المر أة الريفية ـ معهد بحوث الإرشاد الزر اعي و التتمية الريفية ـ مركز البحوث الزر اعية Received on: 12/12/2019

إستهدف البحث التعرف على مستوى استفادة المبحوثات الريفيات من المشرو عات الصغيرة

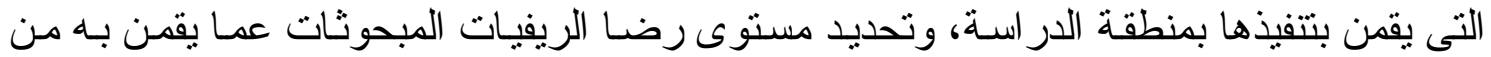

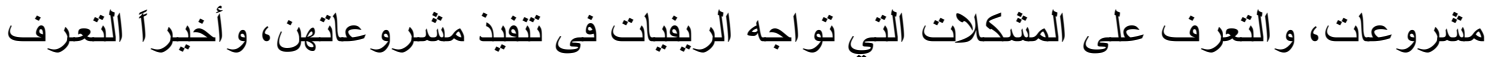

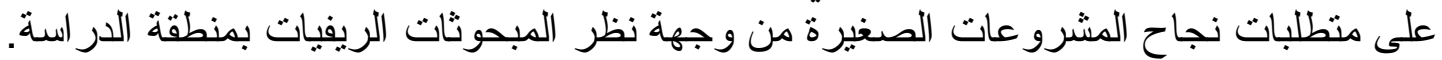

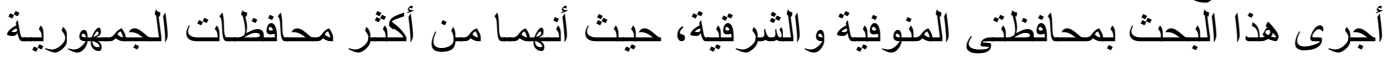

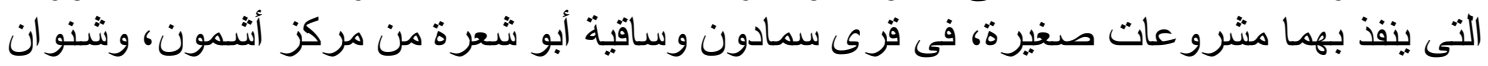

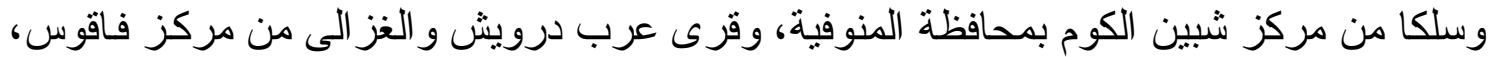

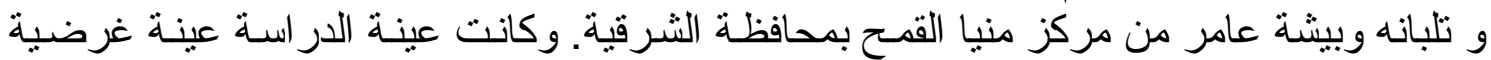
اعتمـادا على الاخبـاريين Purposive Sample

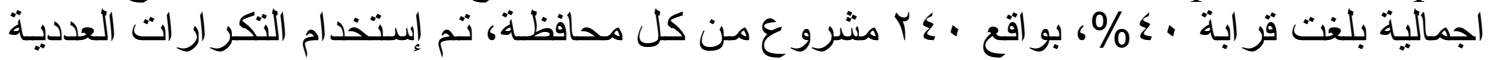

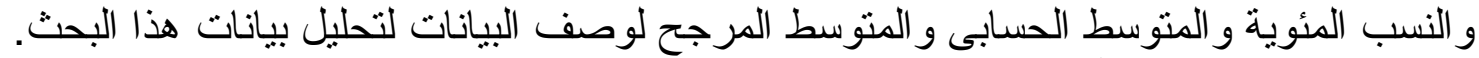

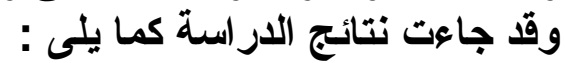

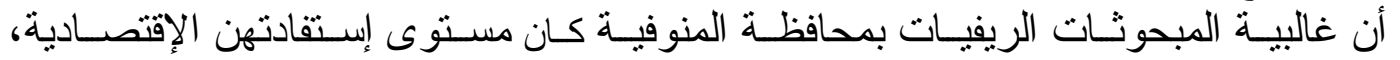

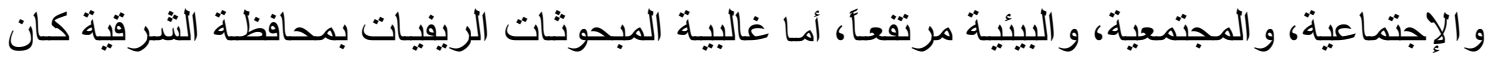

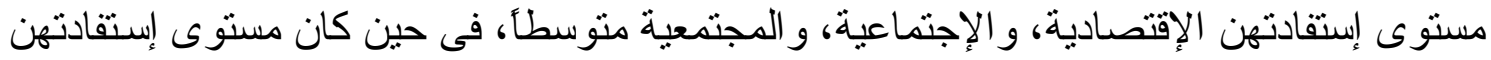
البيئية منخفضئ. أن مستوى رضـا المبحوثات الريفيـات عن المشـرو عات الصـغيرة بمحافظتى الدر اسـة كـان متوسطا.

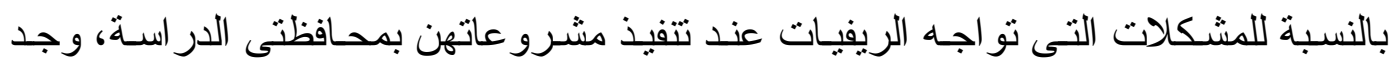

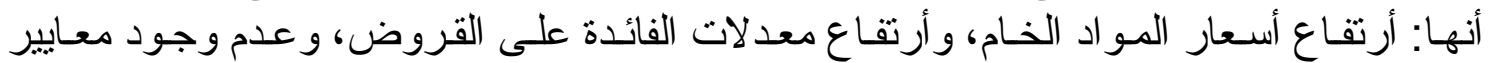

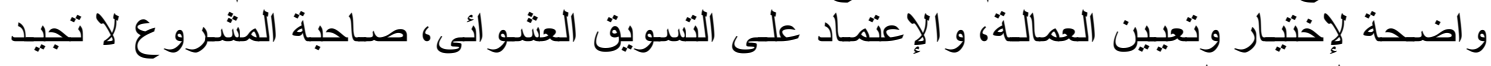
بالنسبة لمتطلبات نجاح المشرو عات الصغية الصنابة بمحافظتى الدر اسة، وجد أن أهمها: أن تكون مهار ات الرقابة و المتابعة.

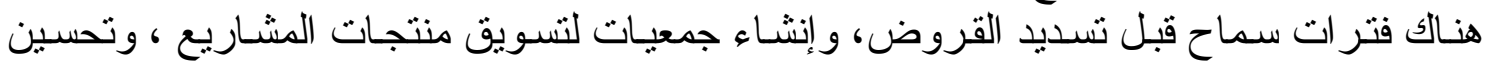

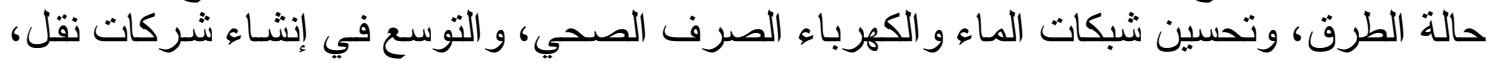

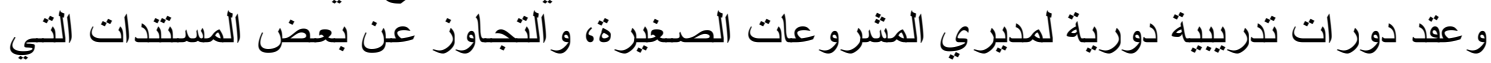

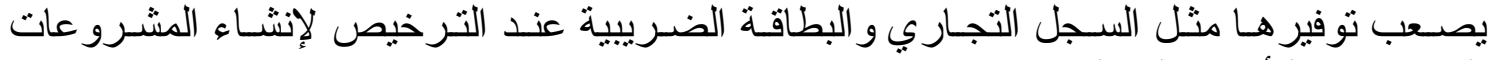

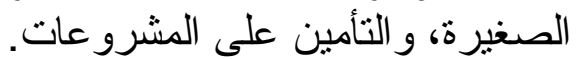
الكلمات المفتاحيّة: الريفيات، المشروعة المثروعات الصغيرة، البطالة.

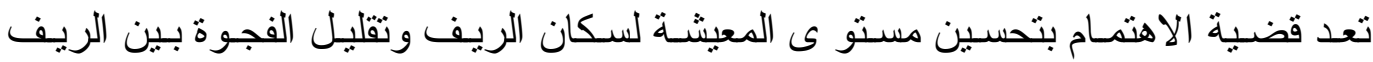

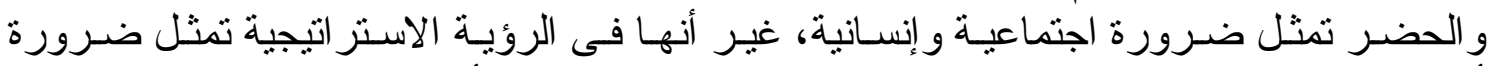

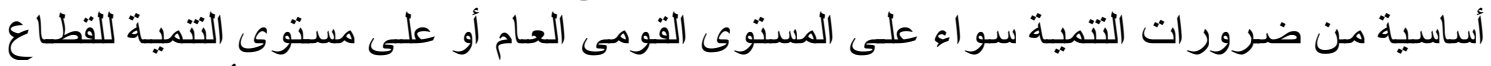

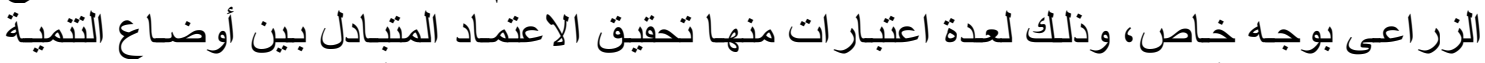

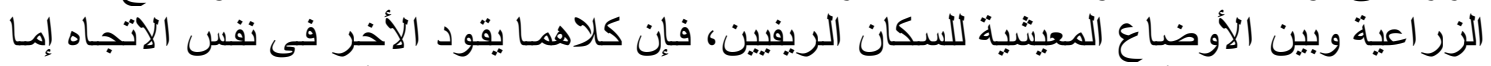

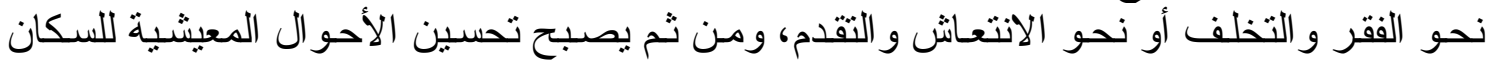




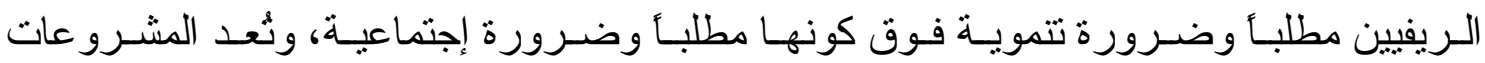

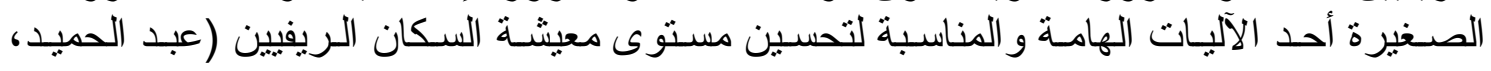

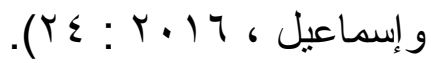

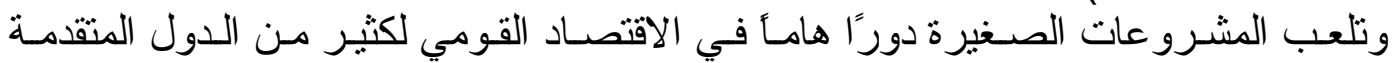

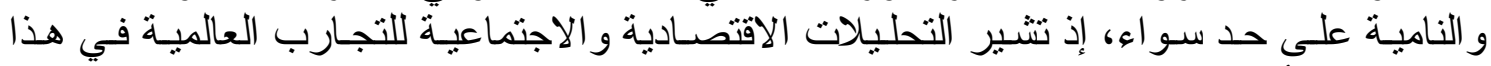

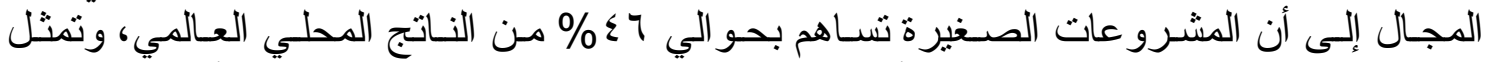

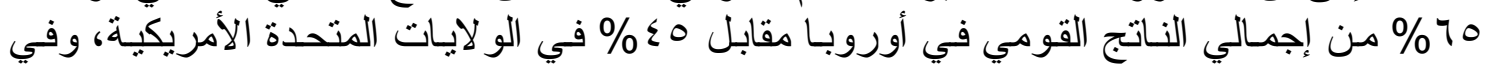

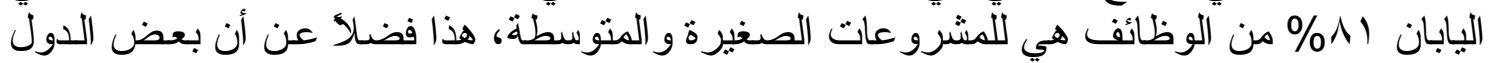

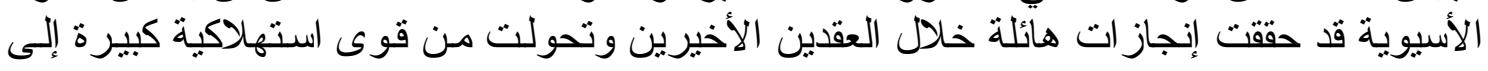

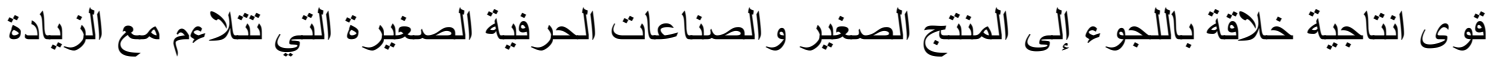

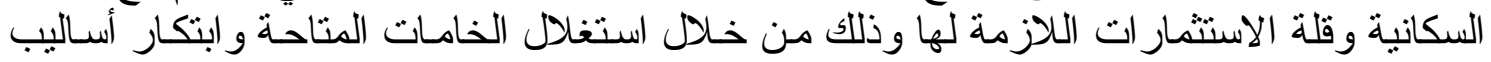

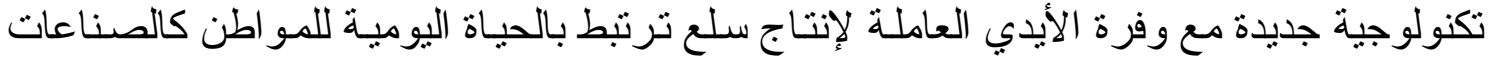

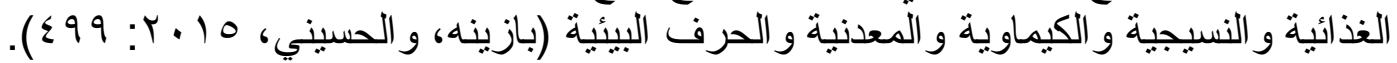

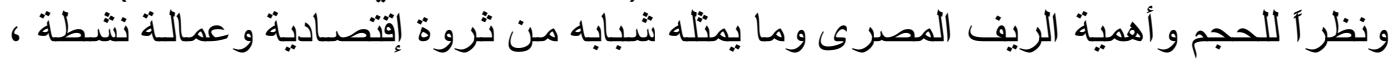

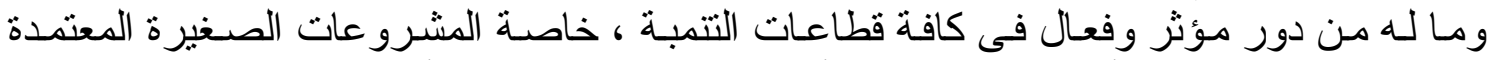

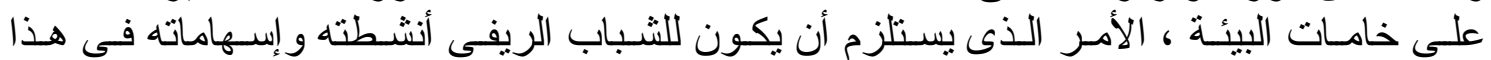

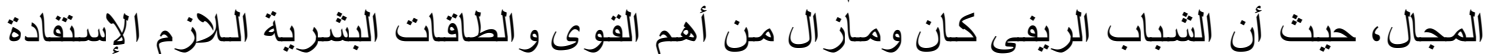

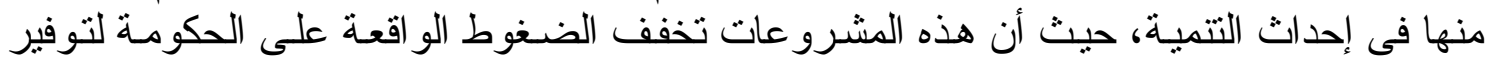

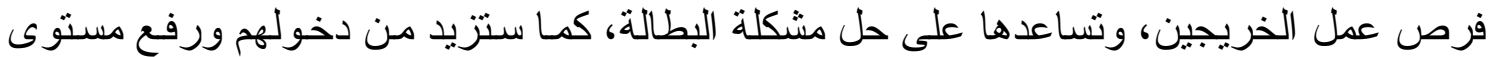

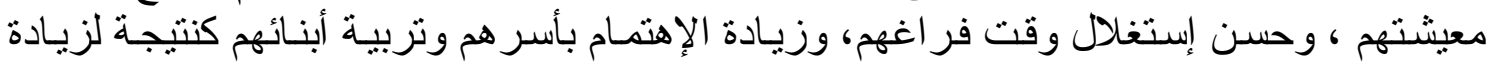

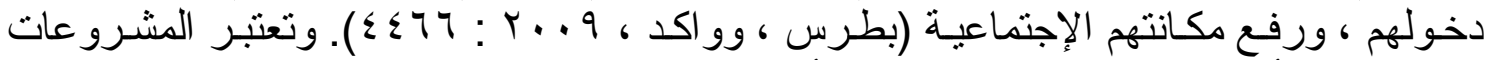

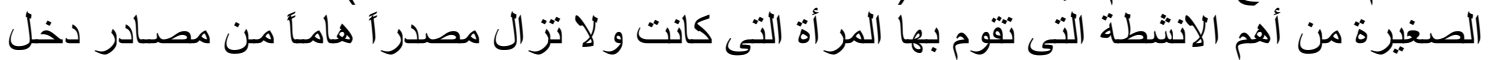

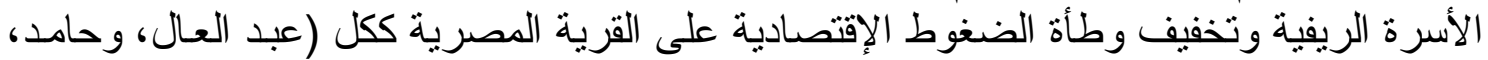

(r: $r \cdot 17$

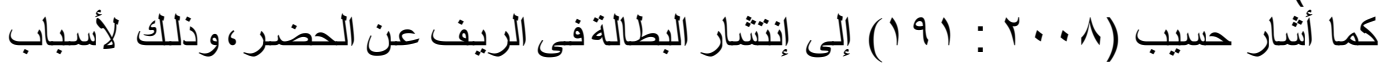

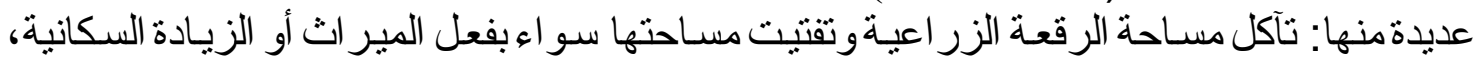

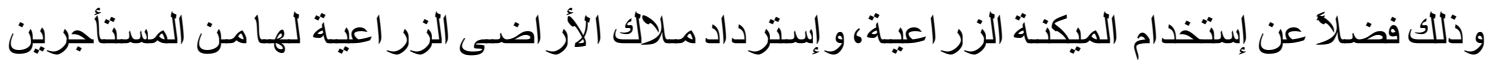

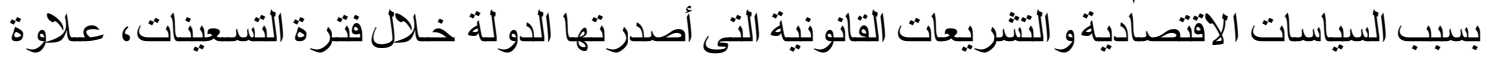

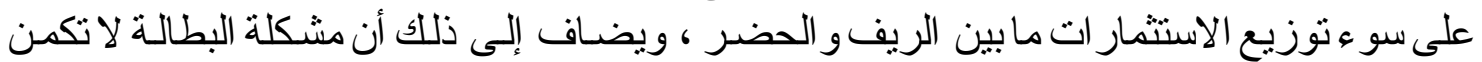

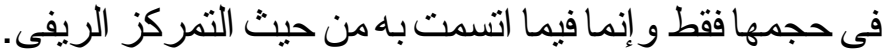

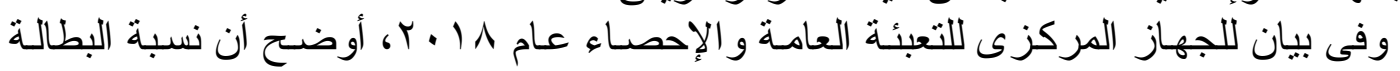

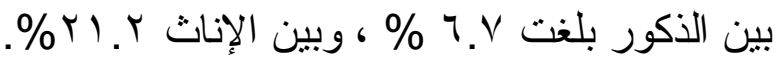

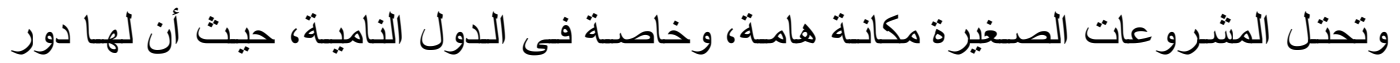

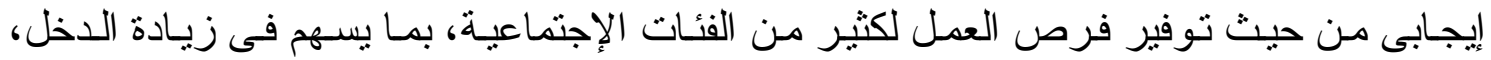

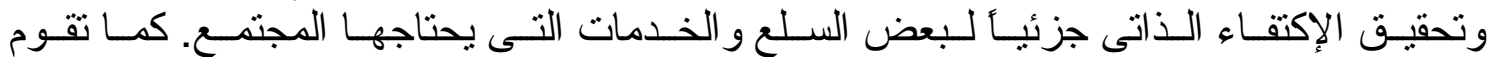

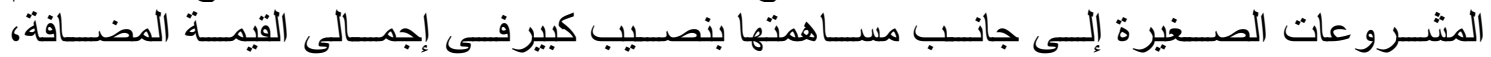

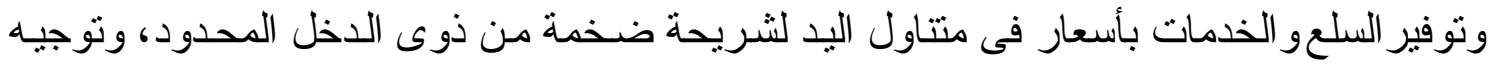

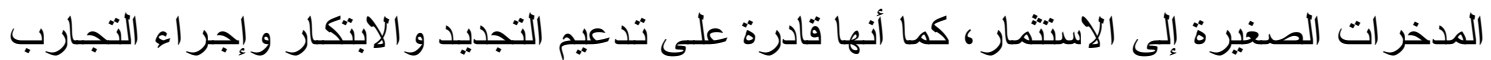

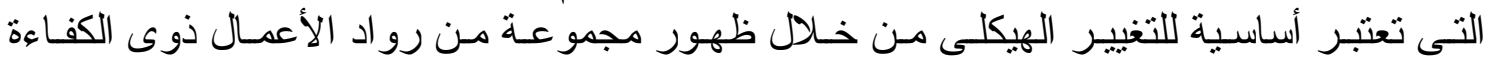

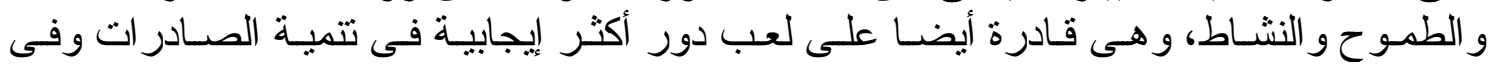

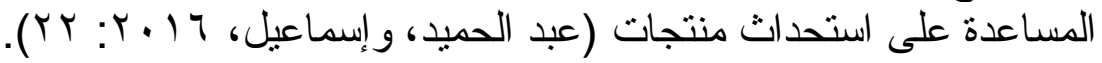


كمـا أن الصـناعات الصـغيرة لهـا القدرة على التشـغيل الـذاتي لمحدودي الـدخل وخريجي

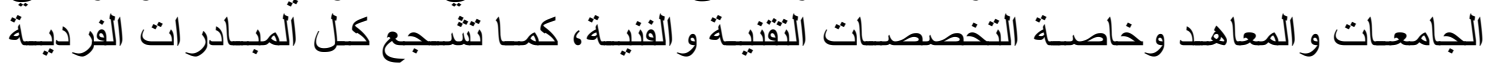

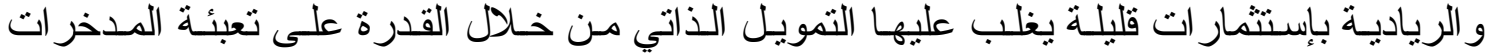

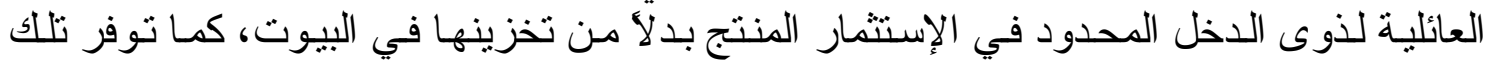

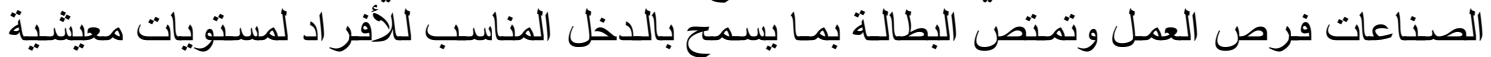

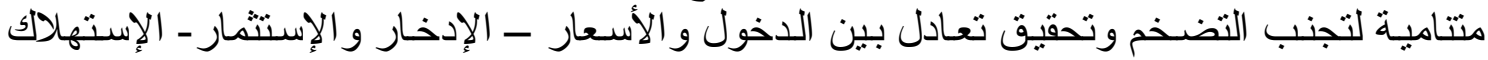

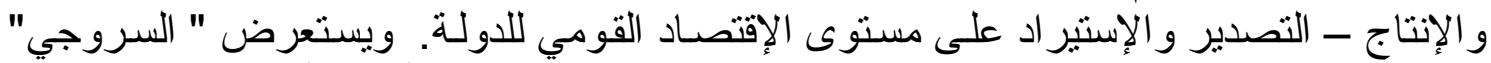

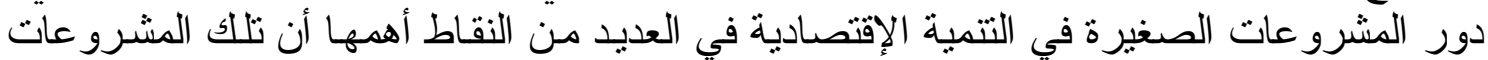

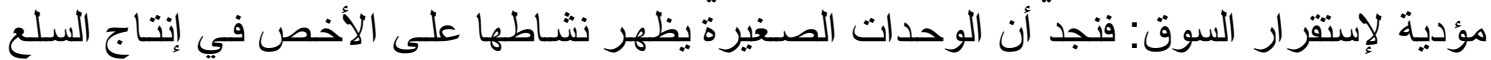

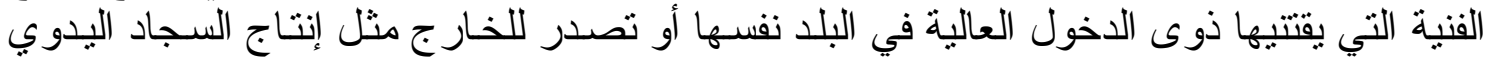

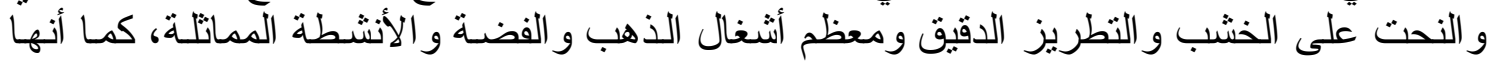
تعدـل على تحسـين ميـز ان التبـادل التجـاري الخـارجي، حيـث يسـاعد تسـويق المنتجـات السـابقة

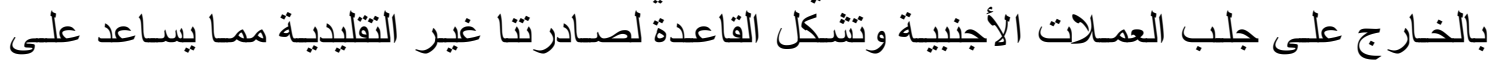

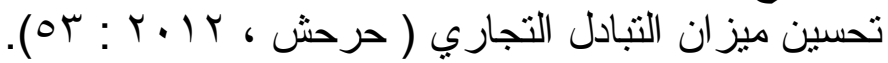

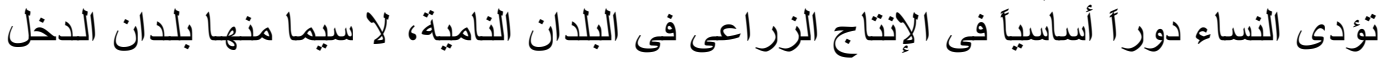

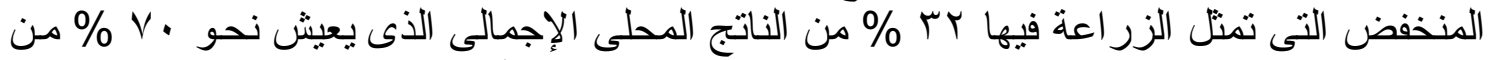

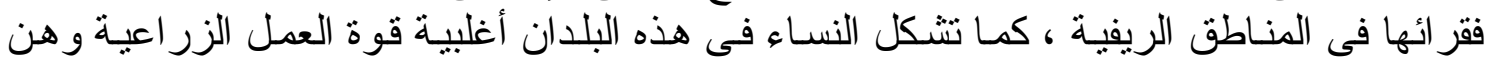

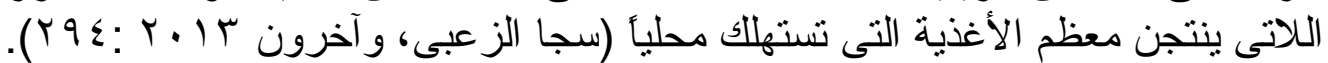

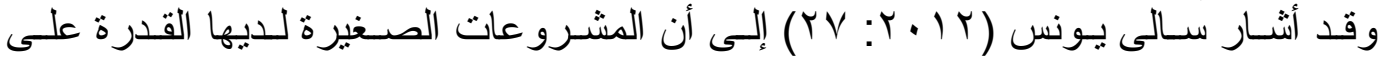

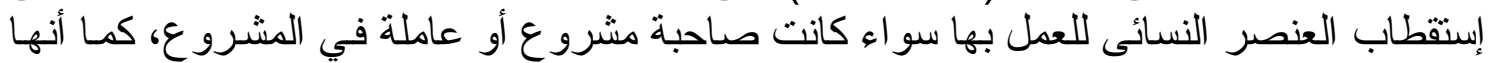

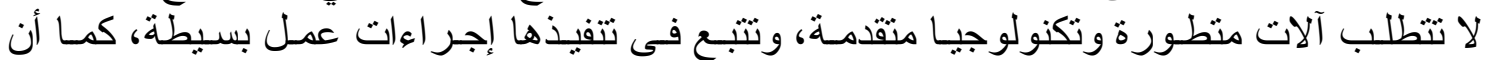

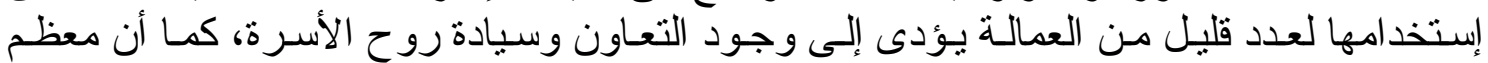

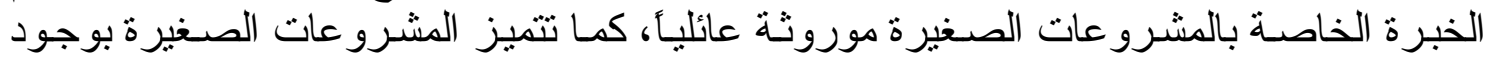

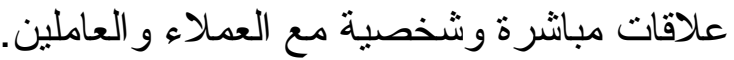

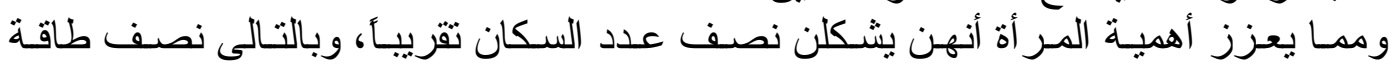

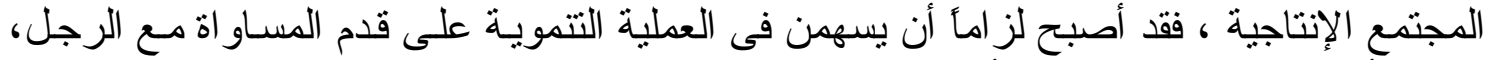

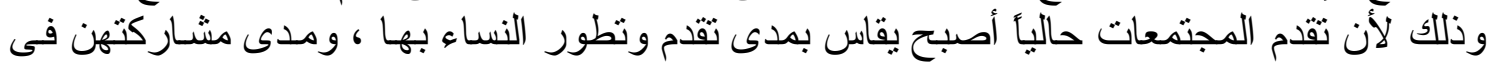

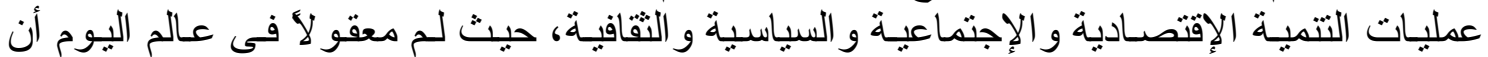

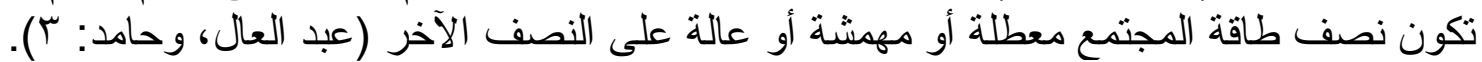

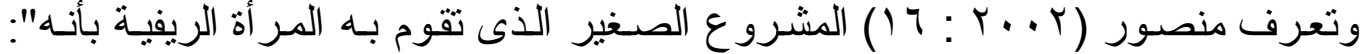

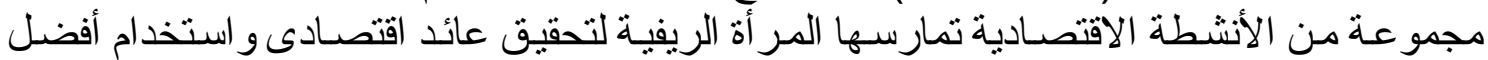

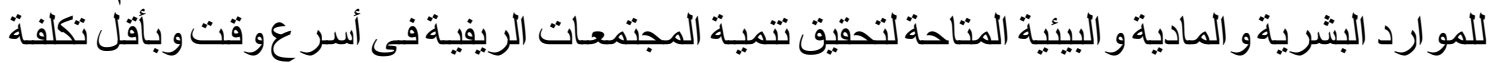

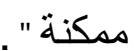

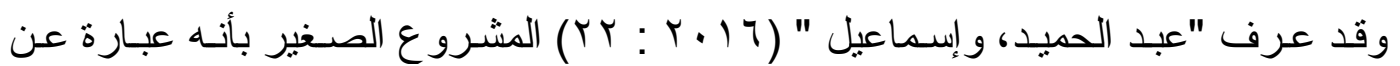

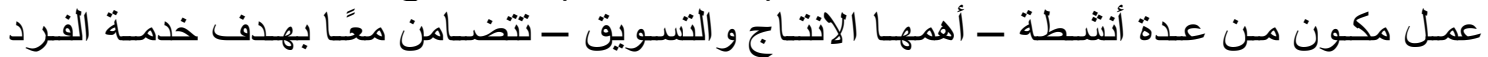

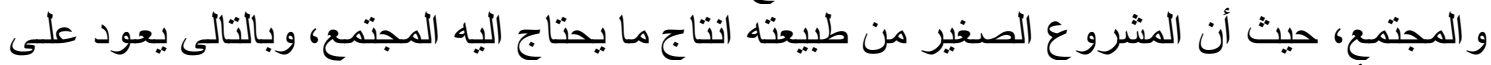
جميع الأفر اد بتوفير الخدمات ويعود الفئرو على صناحبه بالربح و الفائدة.

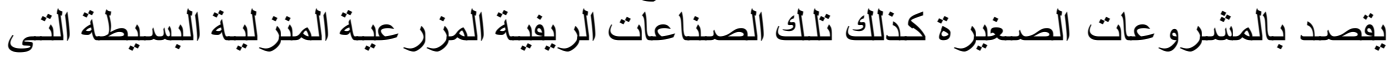

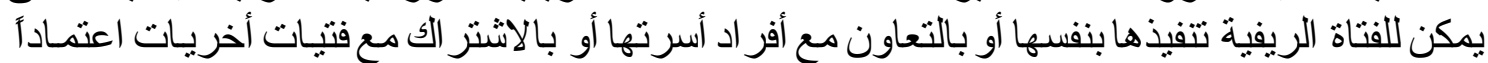

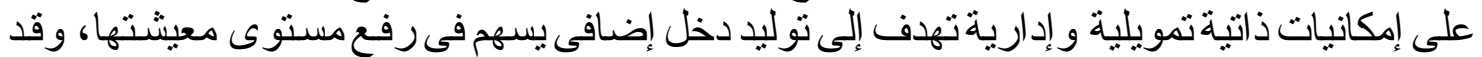

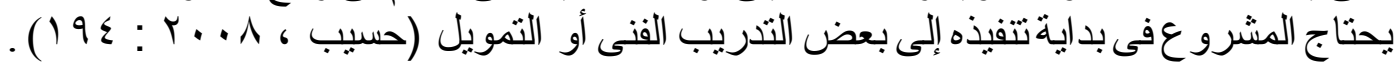




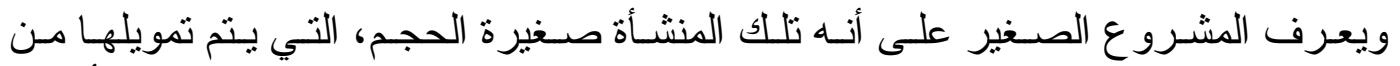

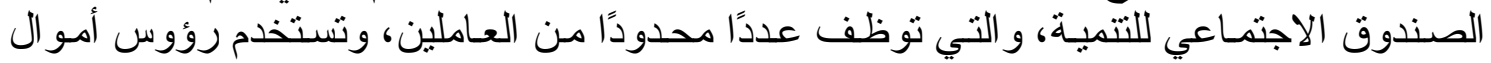

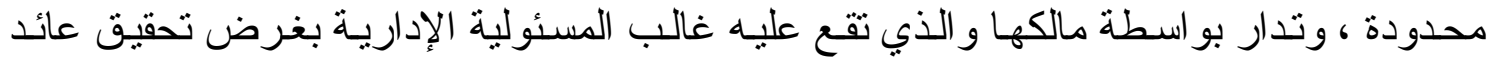

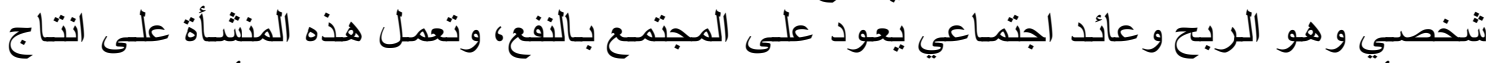

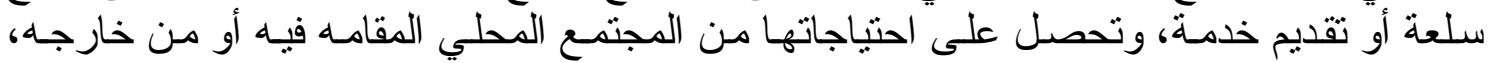

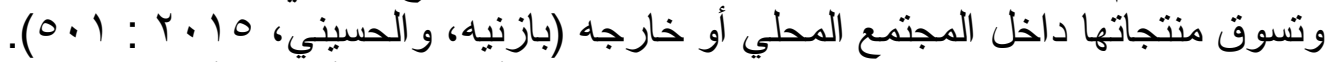

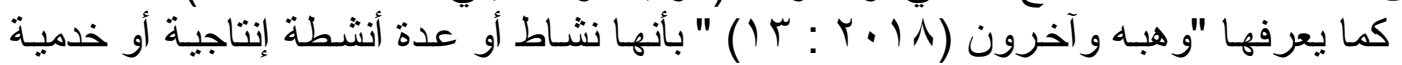

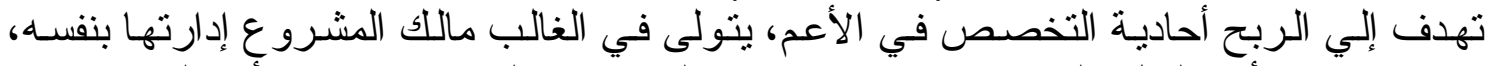

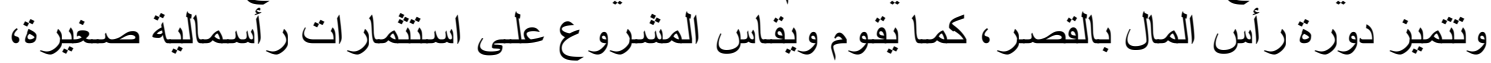

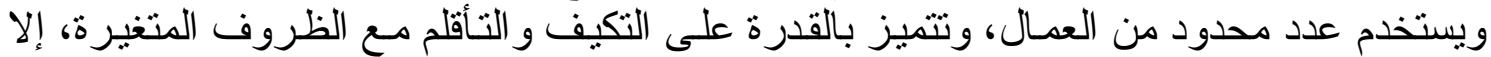

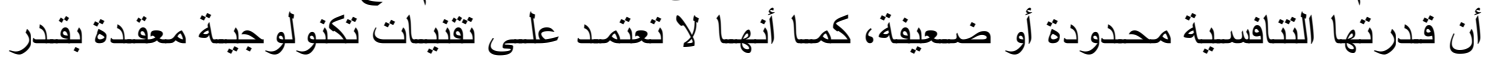
إعتمادها على الخبر ات الحرفية و التطبيقية.

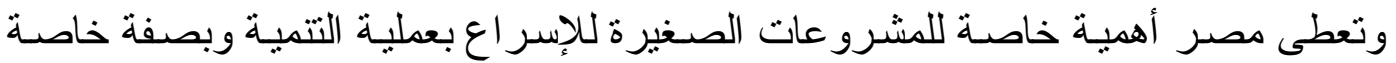

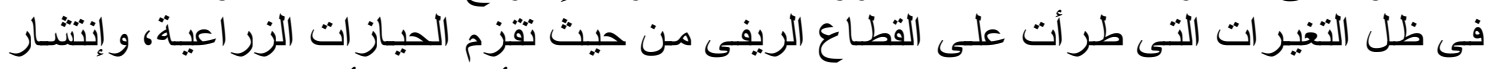

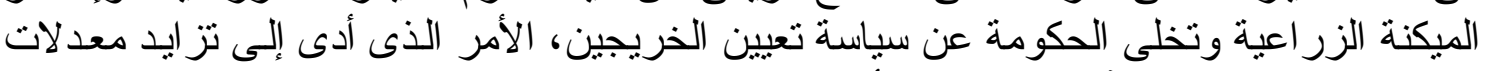

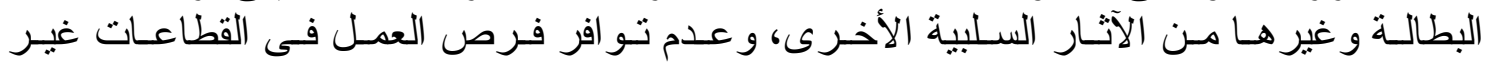

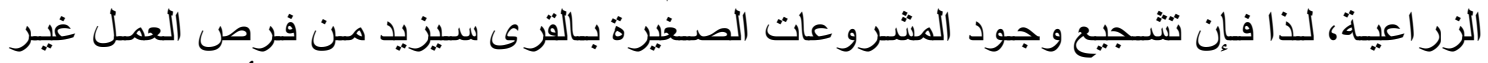

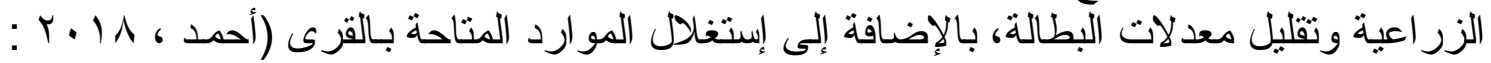

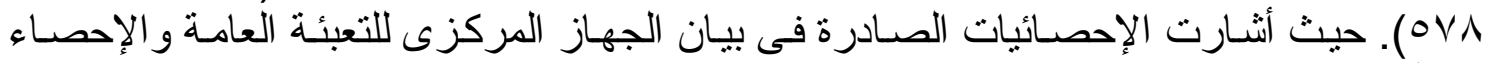

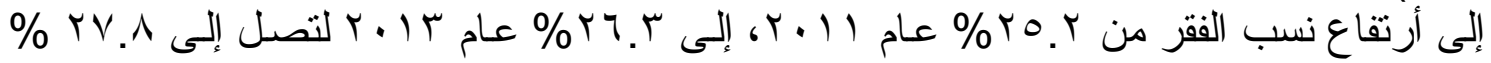

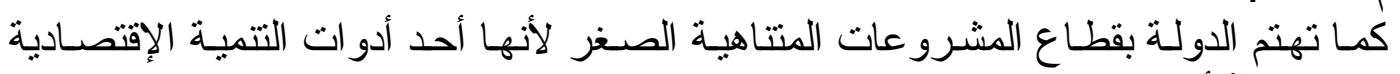

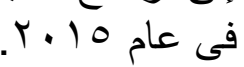

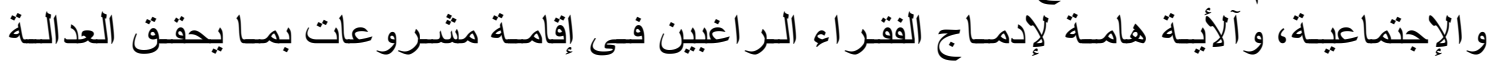

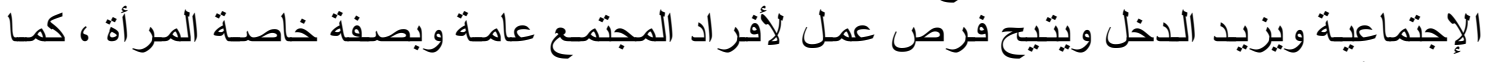

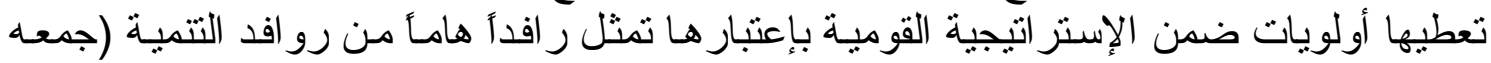

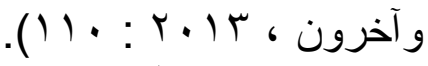

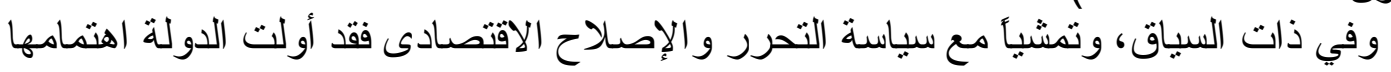

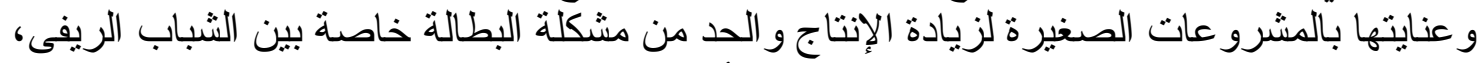

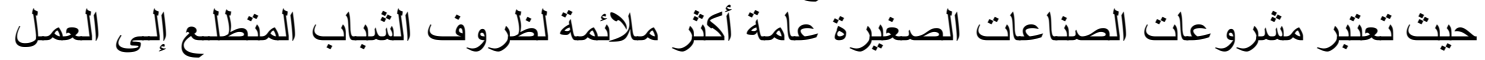

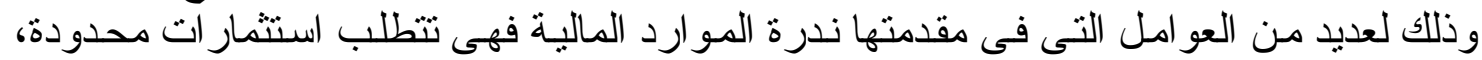

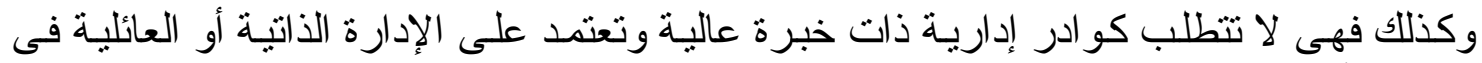

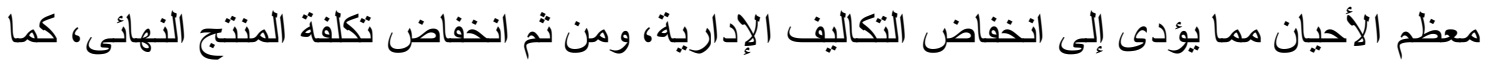

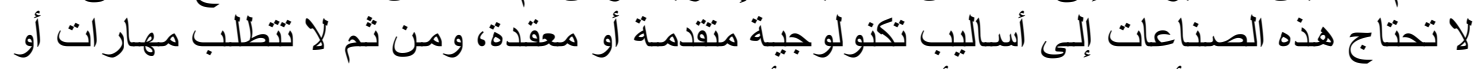

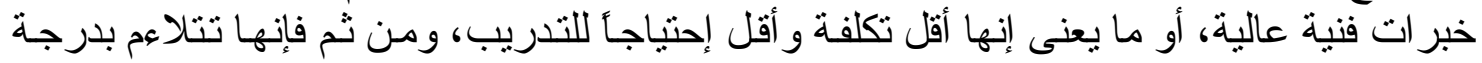

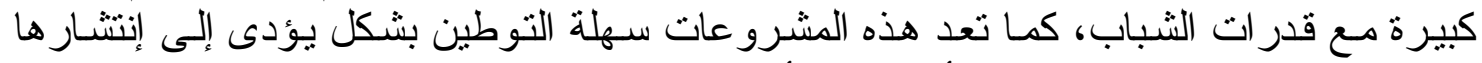

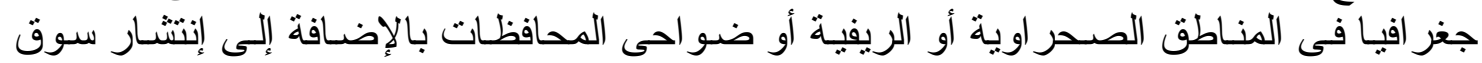

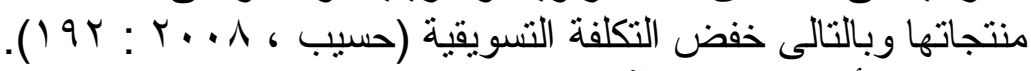

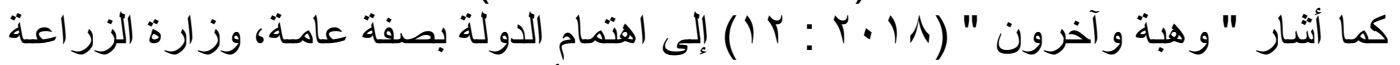

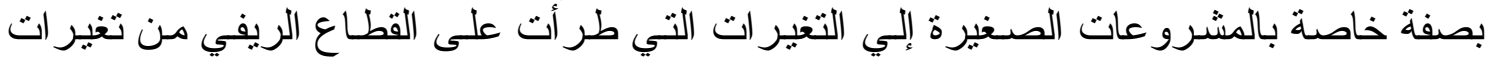

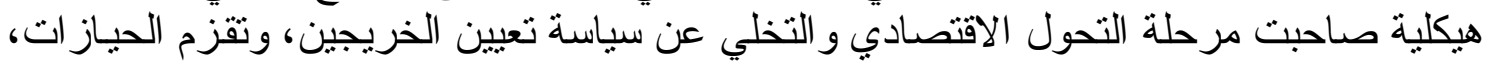

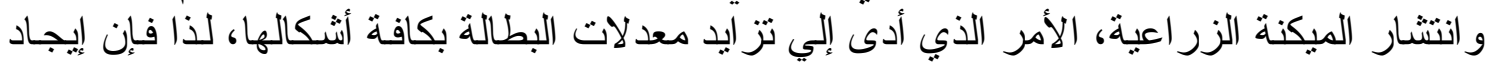


المشروعات الصغيرة بالريف سيزيد من فرص العمل ويحد كثير أ من الاثار السلبية لهذه التغيرت الهيكلية.

كما أهتم جهاز تتمية المشرو عات الصغيرة فى مصر بتمويل المشرو عات متتاهية الصغر

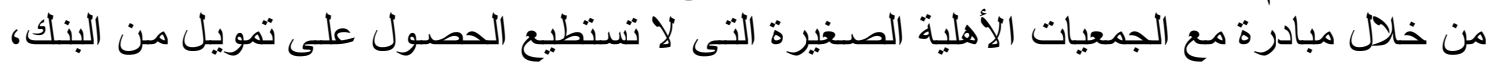

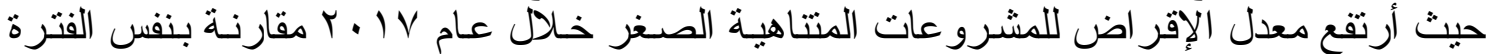

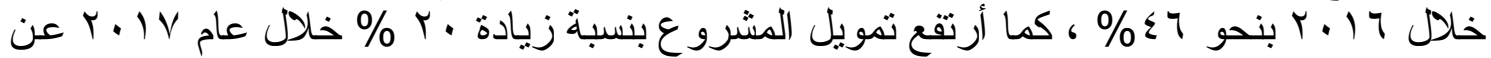

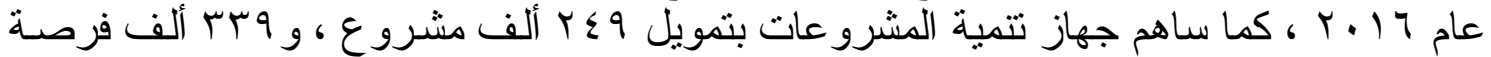

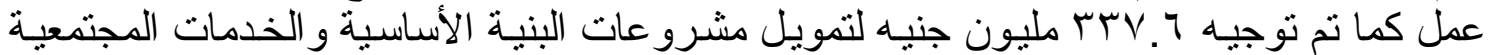

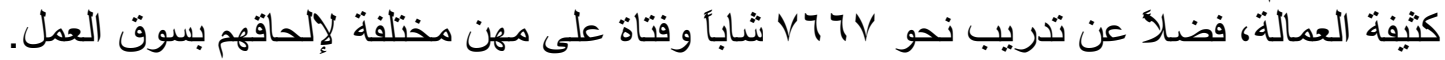

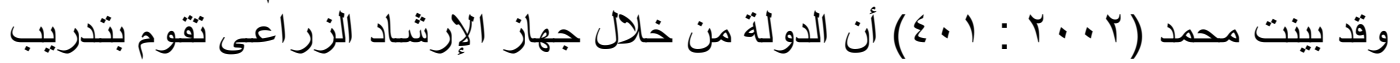

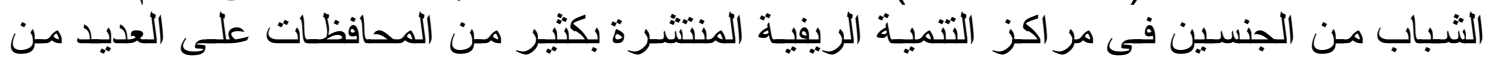

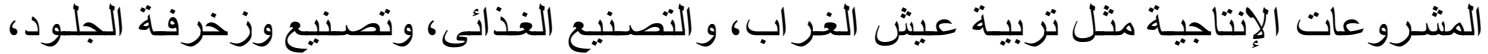

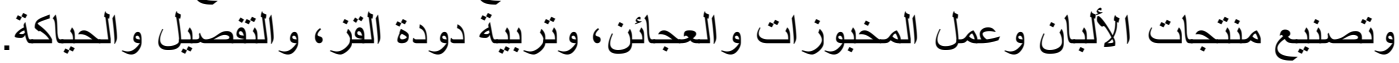

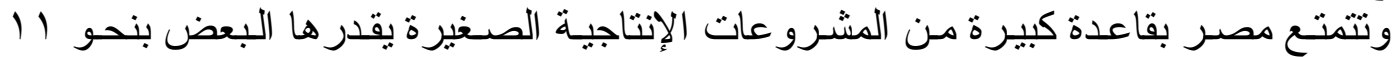

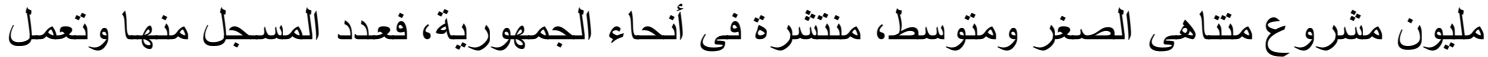

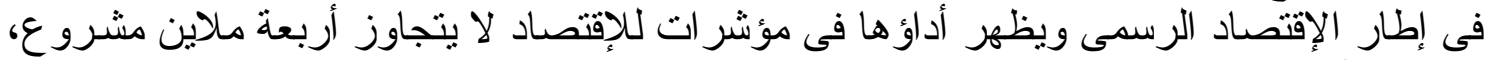

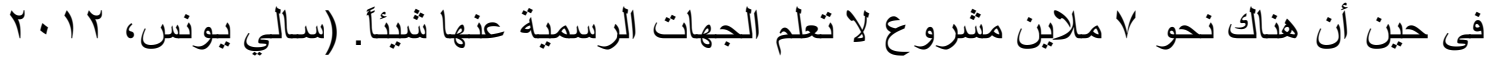

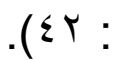

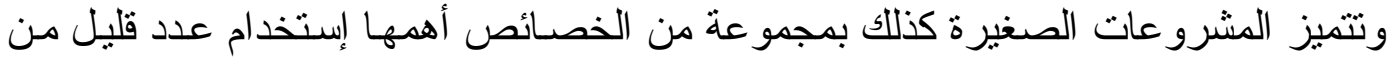

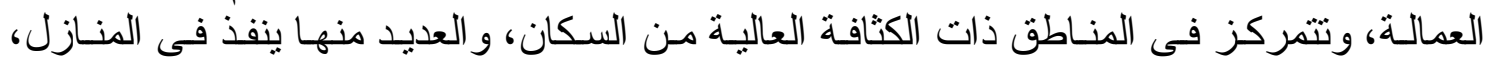

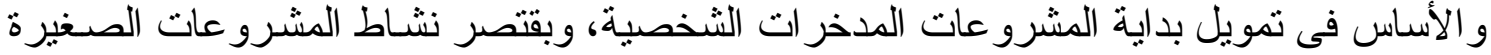

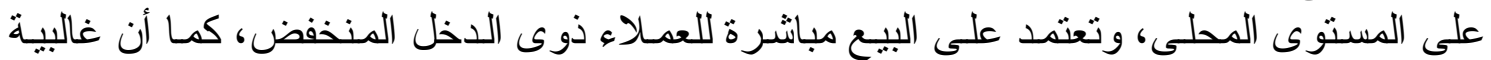

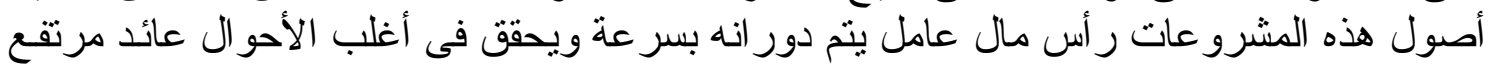

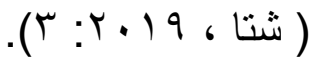

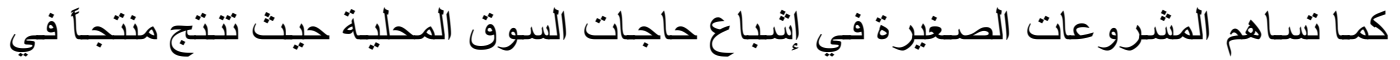

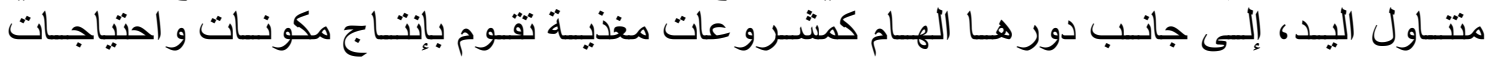

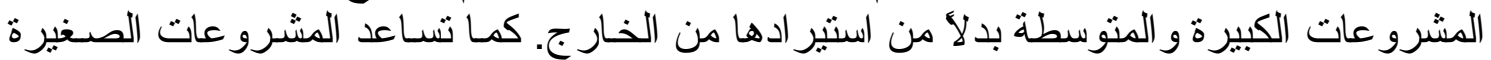

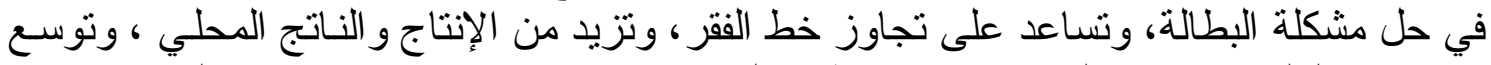

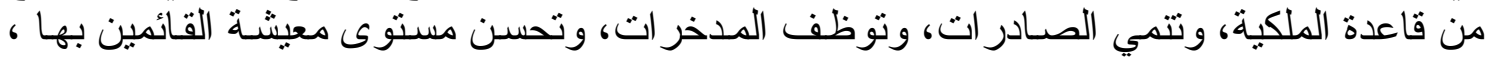

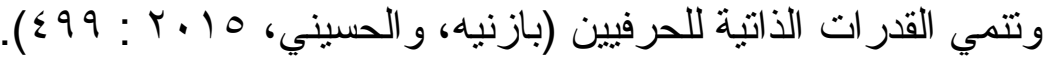

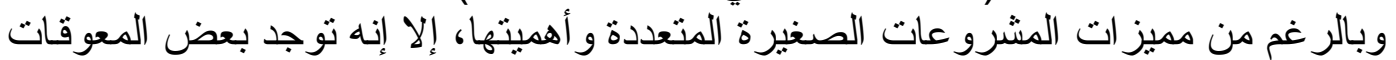

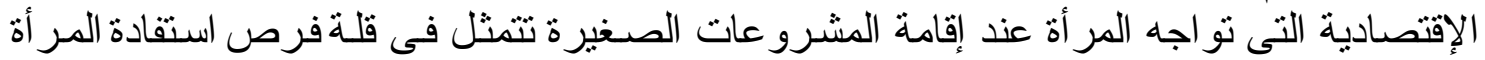

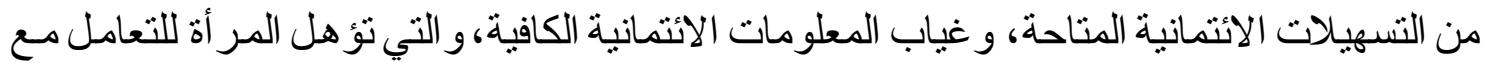

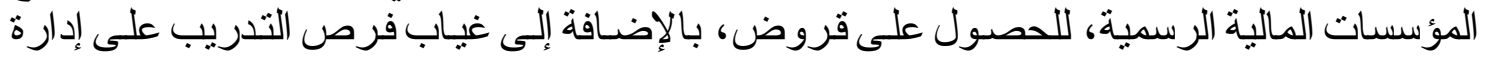

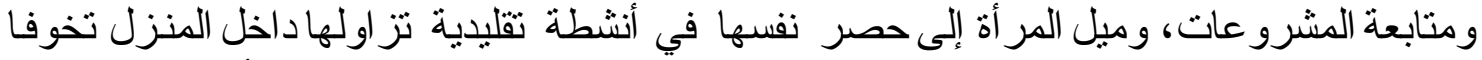

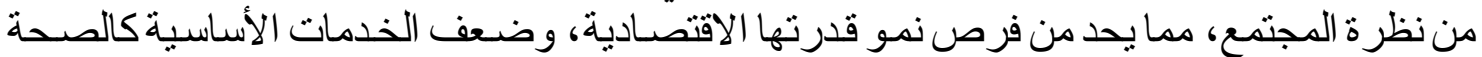

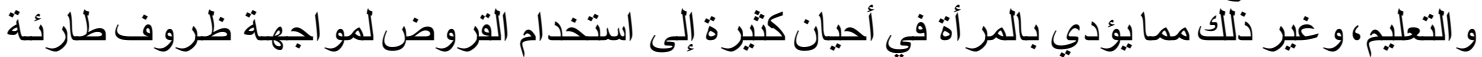

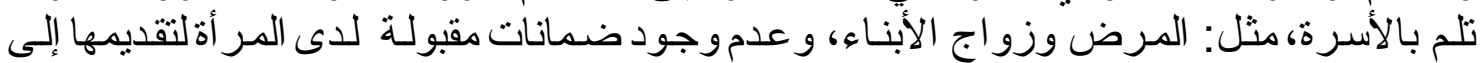

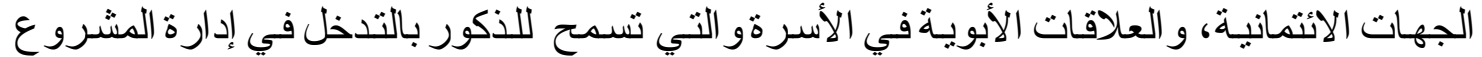

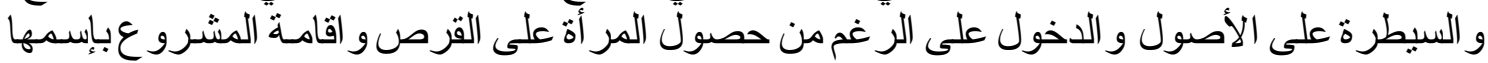

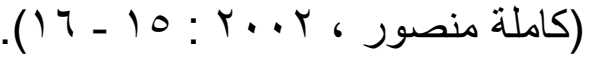




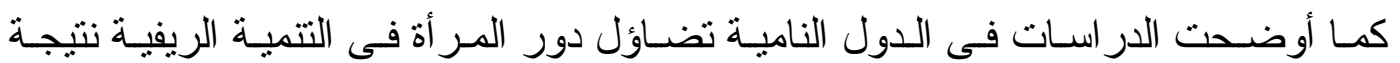

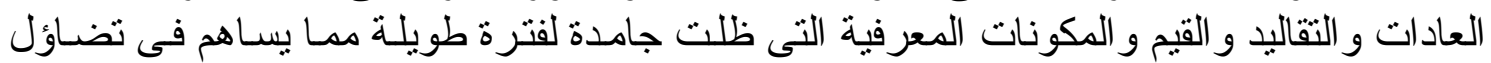

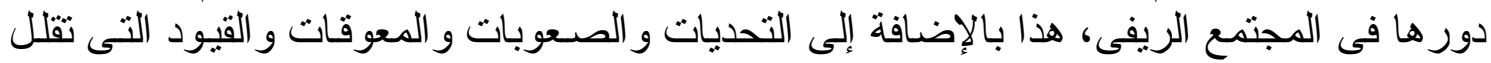

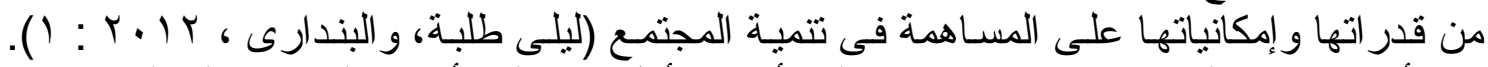

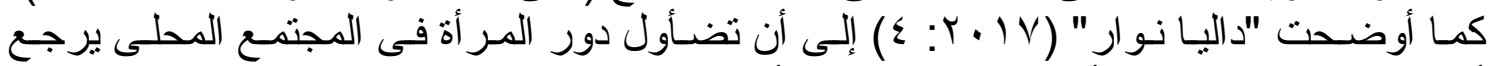

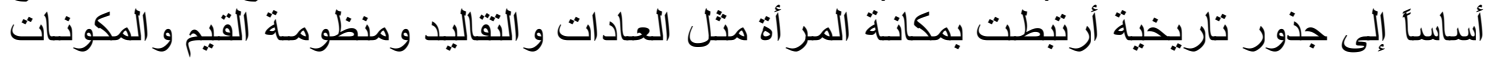

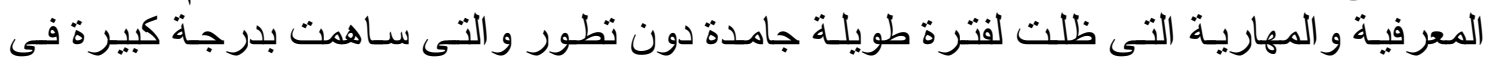
تضاؤل دور ها فى المجتمع الريفى الرئ.

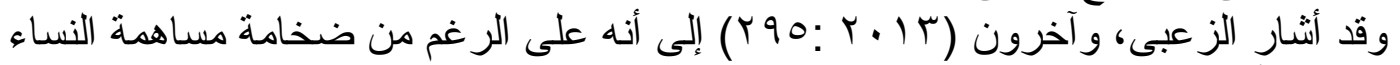

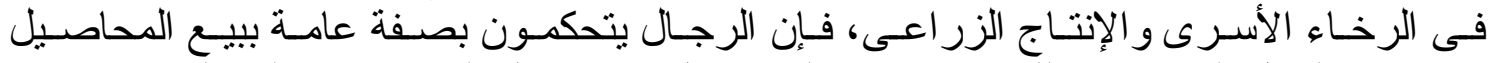

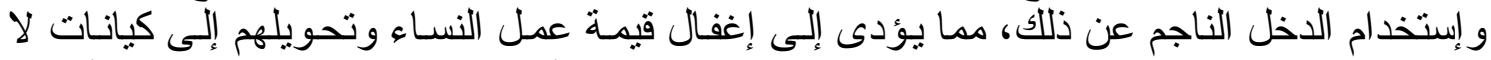

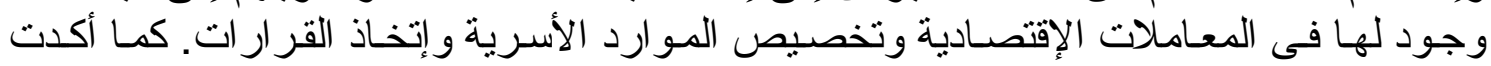

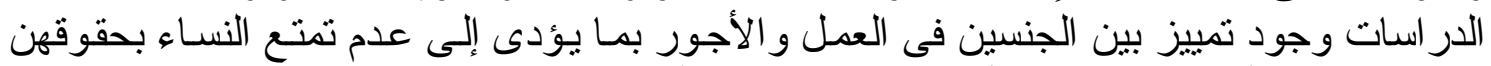

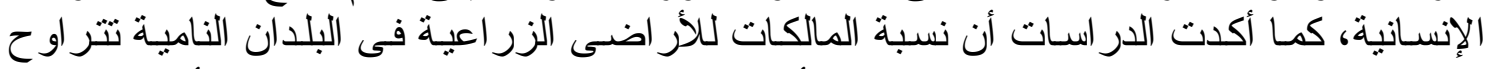

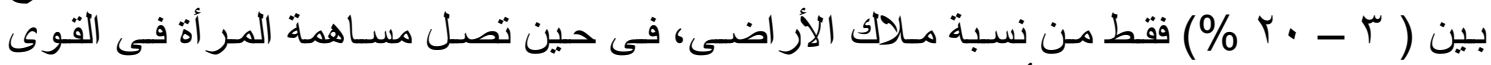

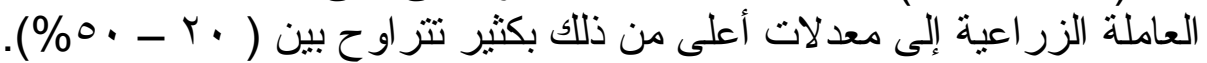

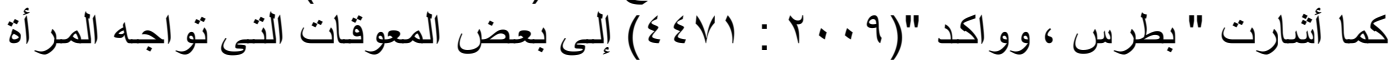

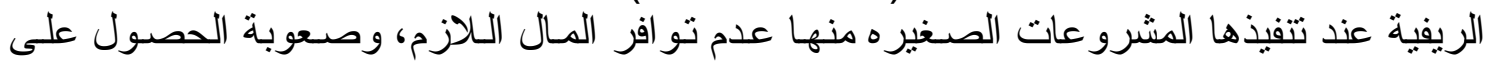

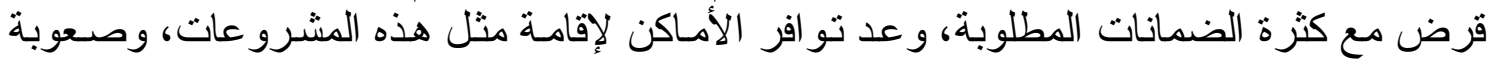

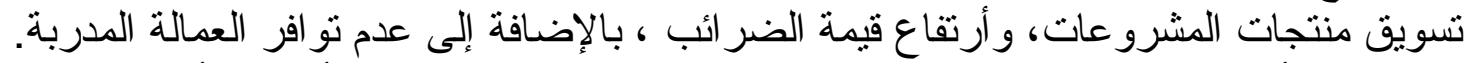

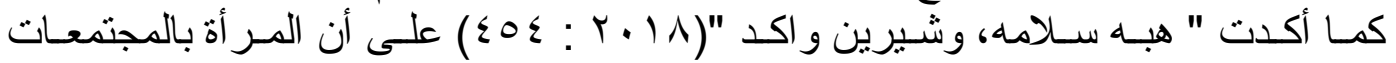

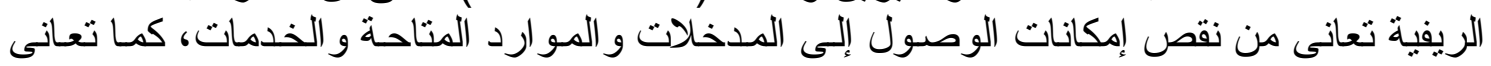

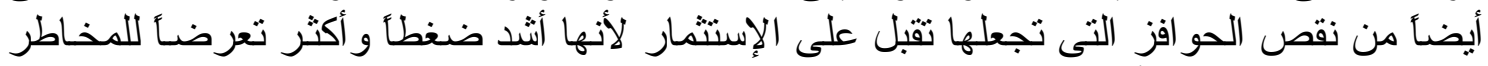

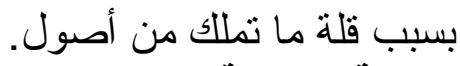

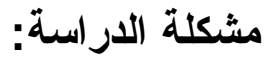

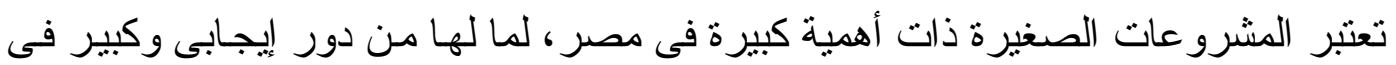

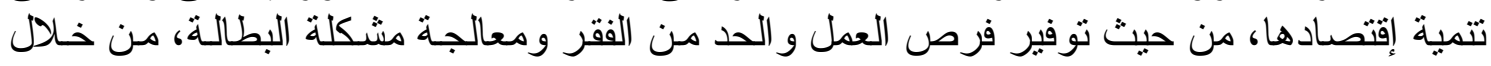

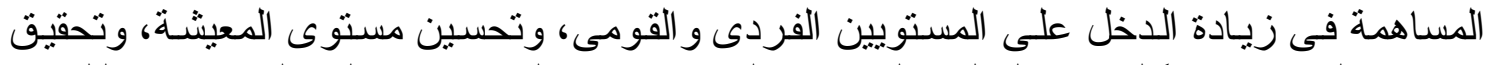

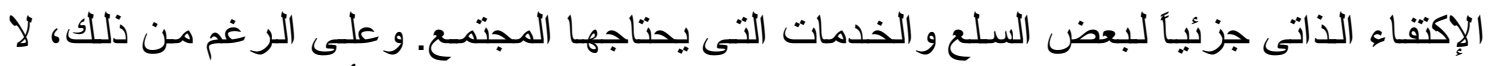

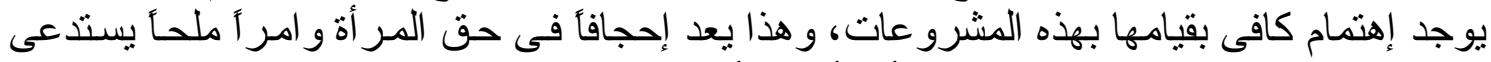

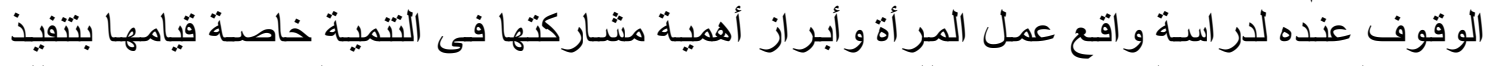

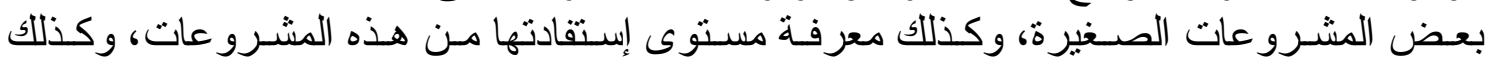

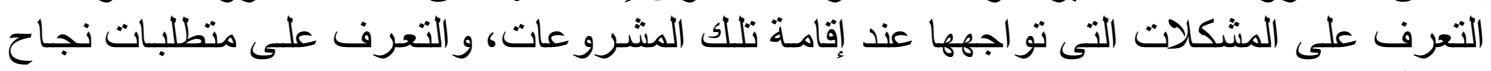
هذه المشرو عات. أهداف الار استة:

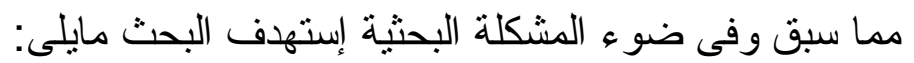

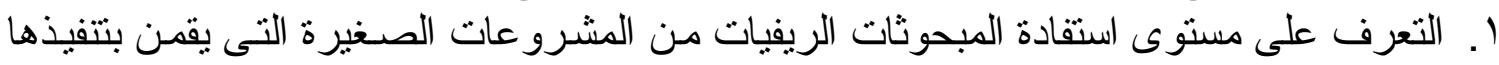
بمنطقة الدر اسة.

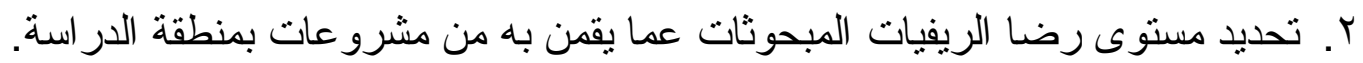

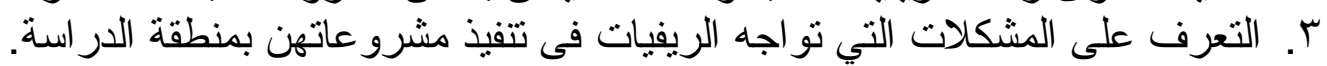
ع. . التعرف على متطلبات نجاح المشرو عات الصغيرة من وجهة نظر المبحوثات الريفيات بمنطقة 
أجرى هذا البحث بمحافظتى المنوفية و الثرقية، حيث أنهما من أكثر محافظـات الجمهوريـة

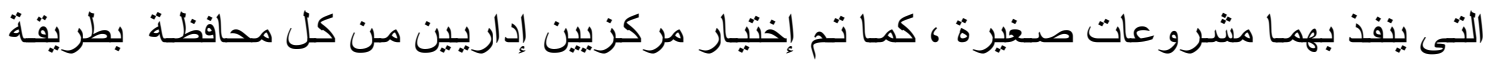

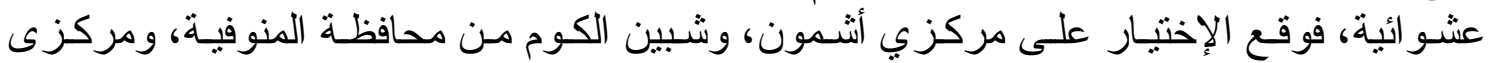

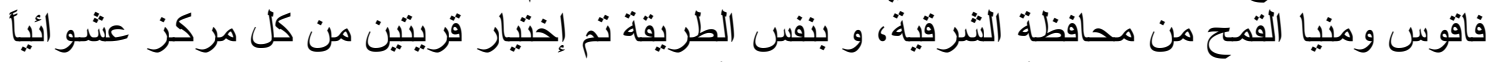

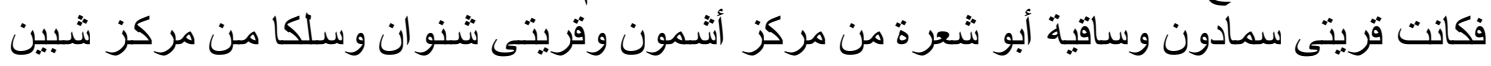

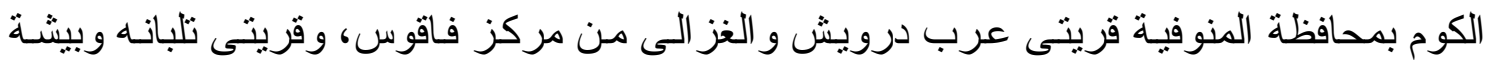
عامر من مركز منيا القمح بمحافظة الشرقية.

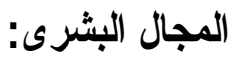

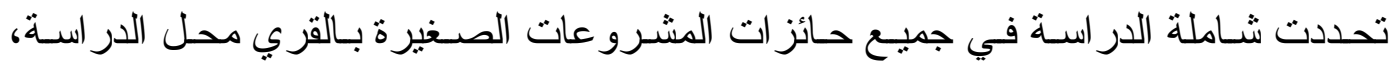

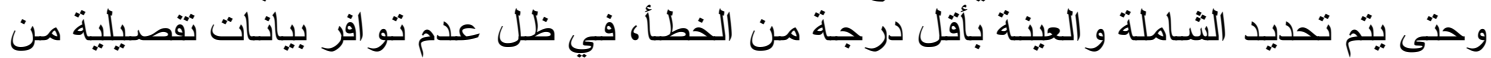

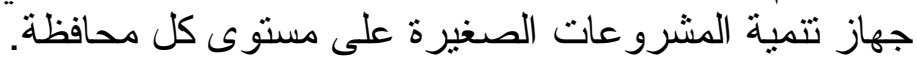

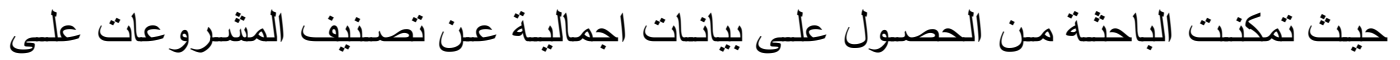

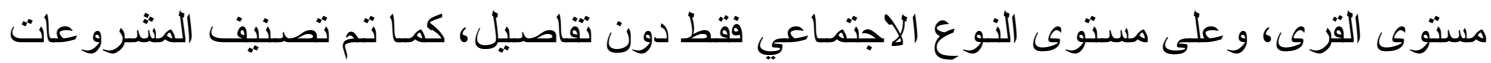

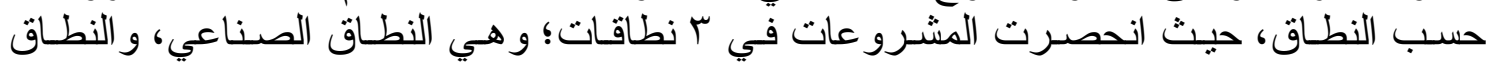

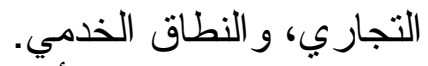

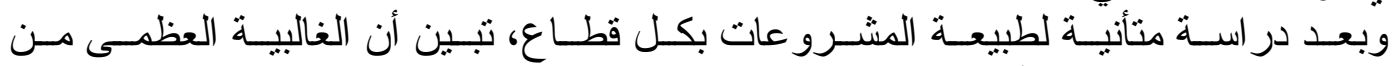

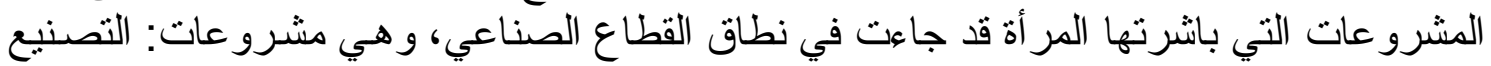

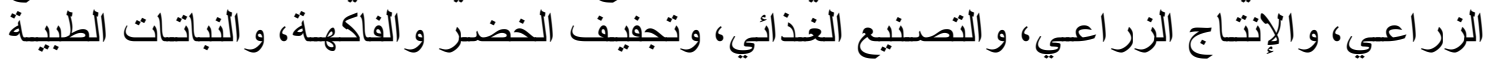

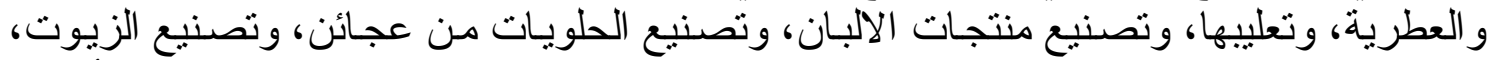

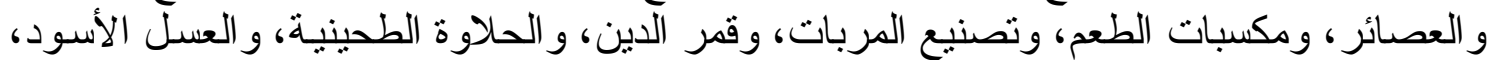

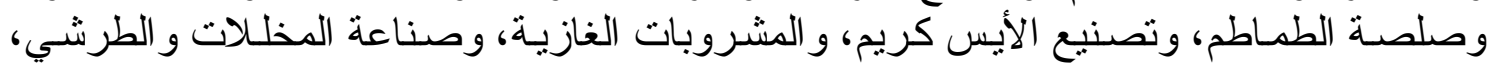

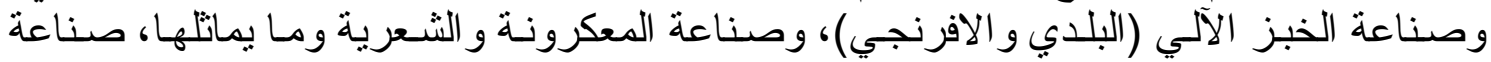

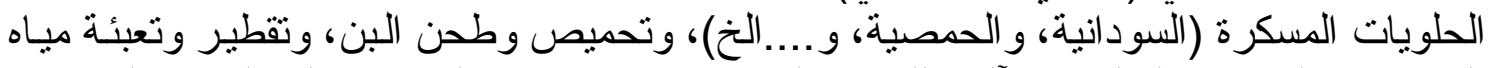

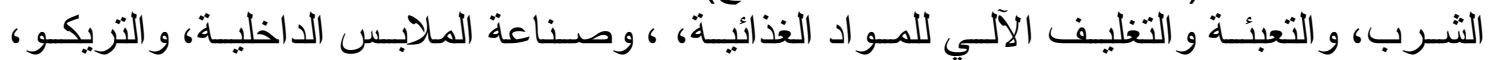

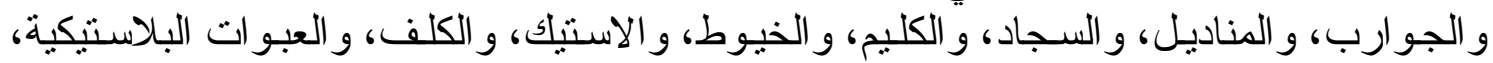

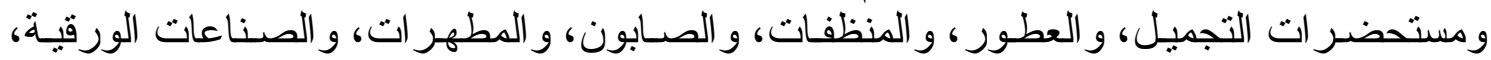

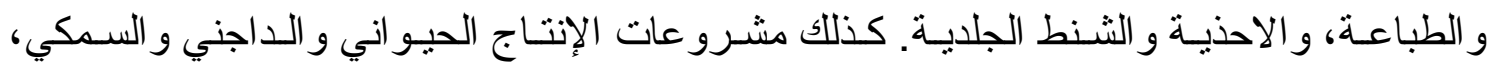

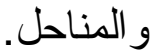

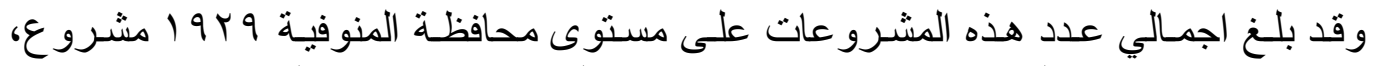

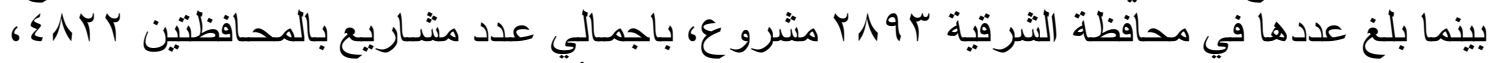

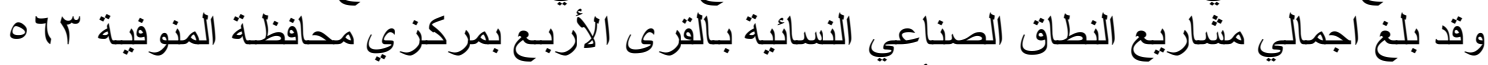

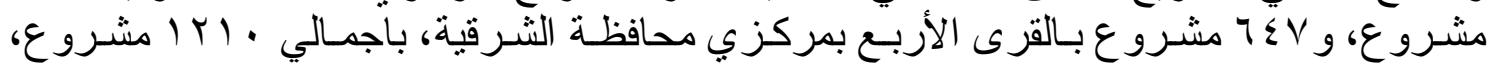

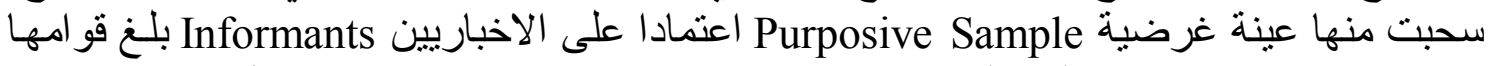

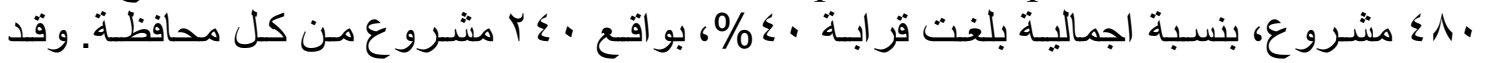

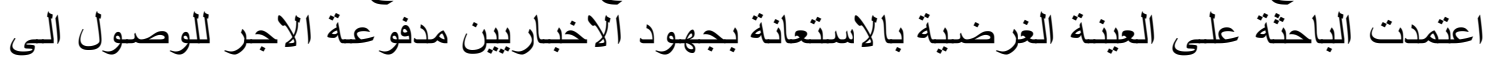

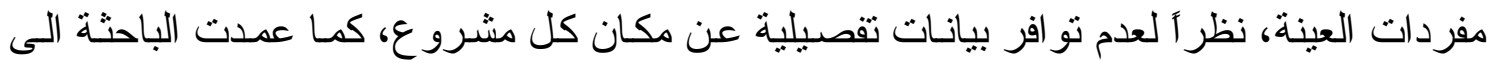

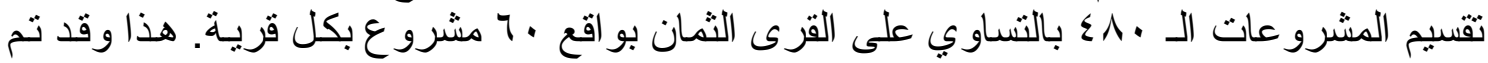

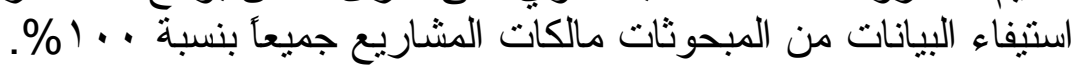

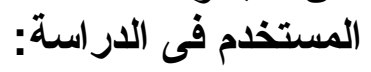

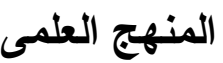
اعتمدت الباحثة على المنهج الوصفى لإجر اءه هذه الدر اسة. 
جمعت البيانات بإستخدام إستمارة إستنبيان بالمقابلـة الشخصية، وقد تم جمع البيانـات خـلال

\section{جمع البيانات:}

$$
\begin{aligned}
& \text { شهري يوليه و أغسطس عام } 9 \text { 1 ـ ب. } \\
& \text { متغير ات الار اسة: }
\end{aligned}
$$

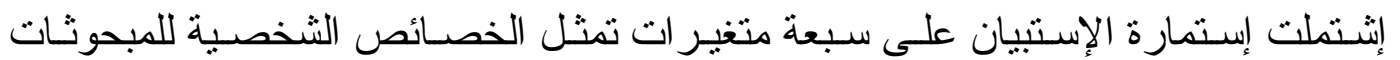

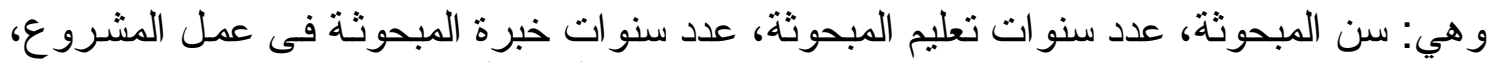
الحالة الاجتماعية للمبحوثة، الحالة العملية للمبحوثة، عدد أفر اد أسرة المبحوثة الثة، الدخل الشههرى

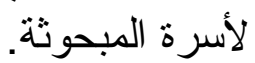

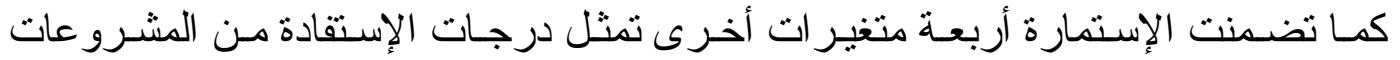

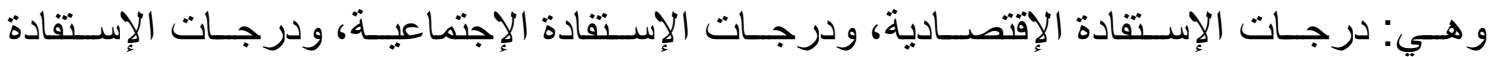

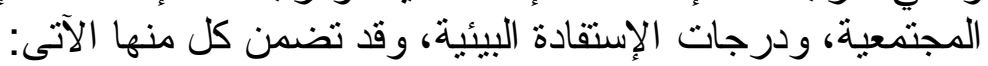
أ - درجات الإستفادة ودرات الإقتصادية:

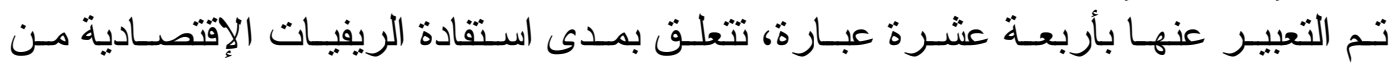

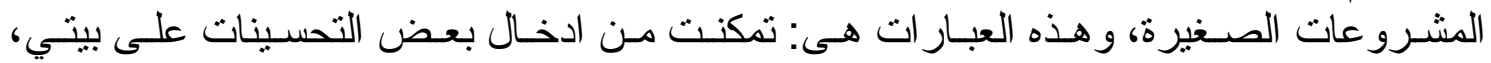

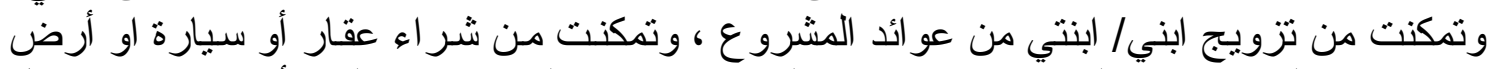

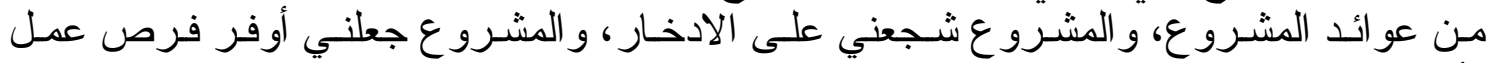

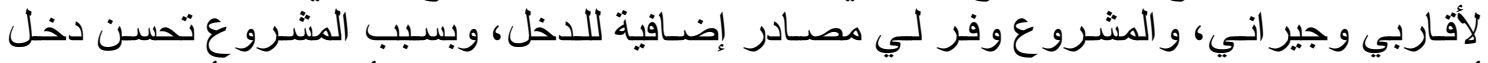

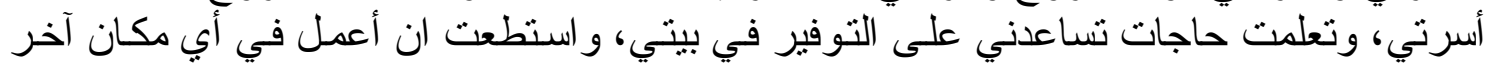

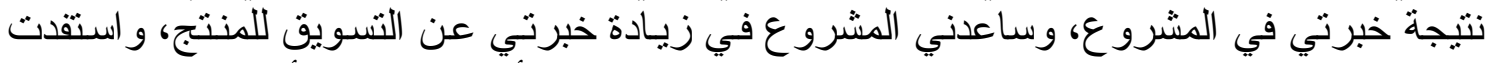

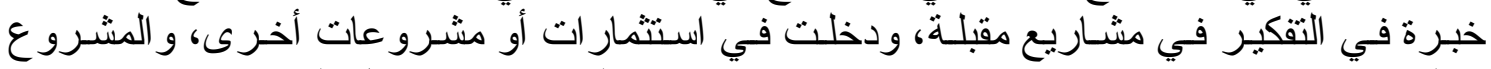

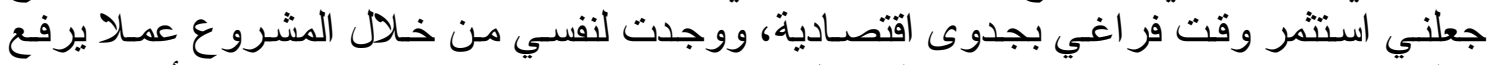

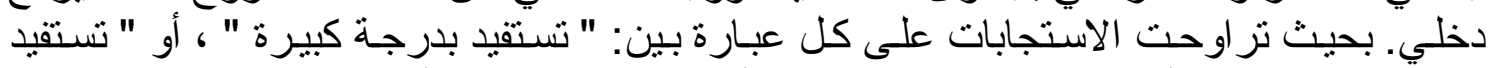

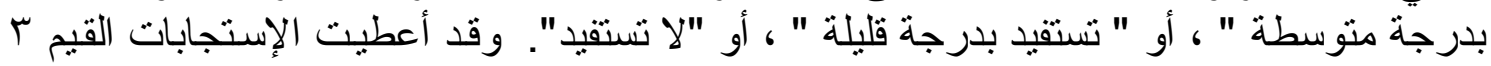

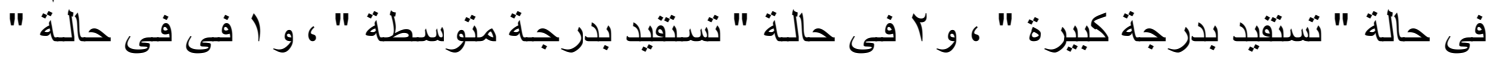

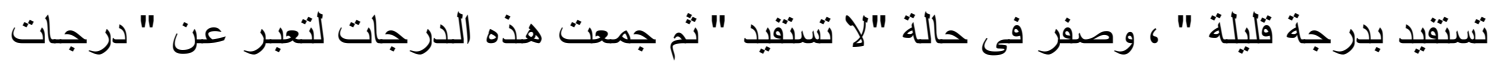

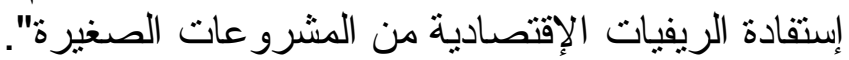
ب - درجات الإستفادة الإجتماعية:

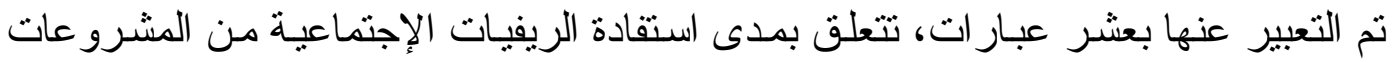

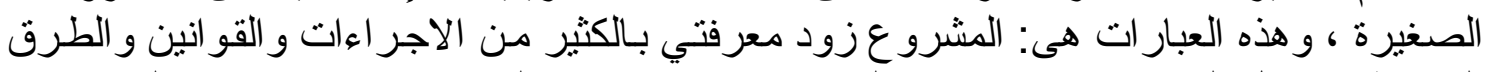

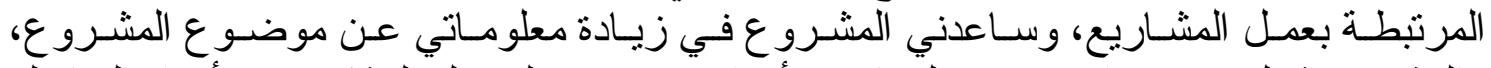

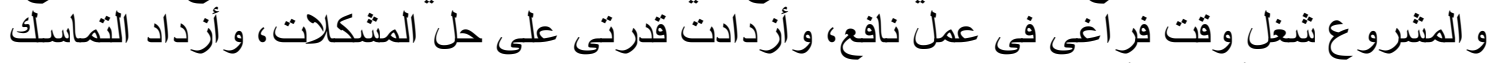

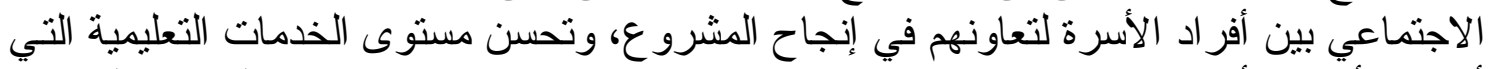

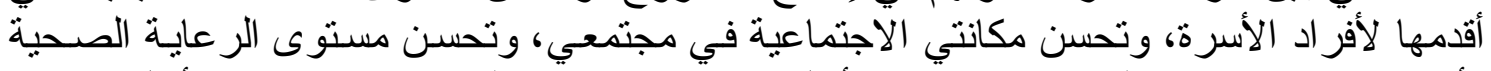

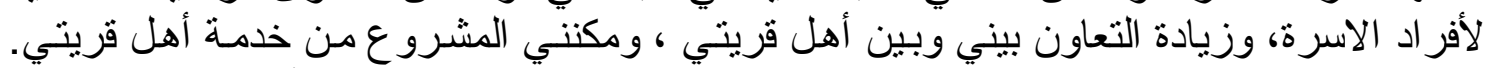

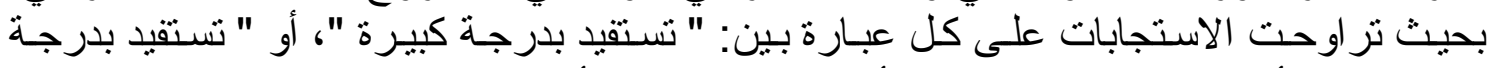

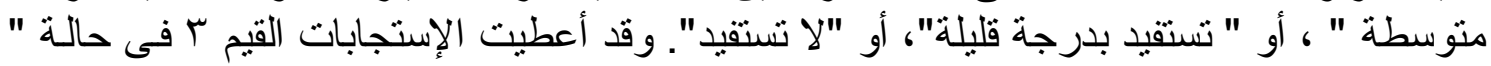

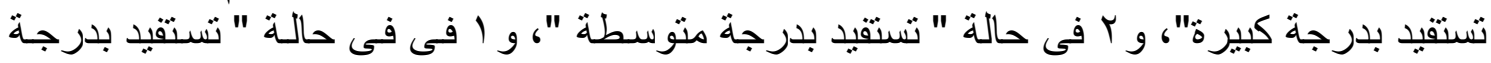

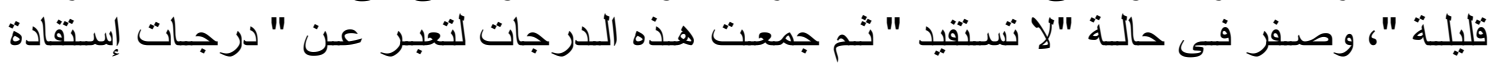

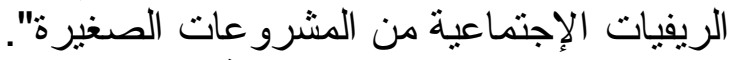

ه - درجات الإستفادة المجتمعية:

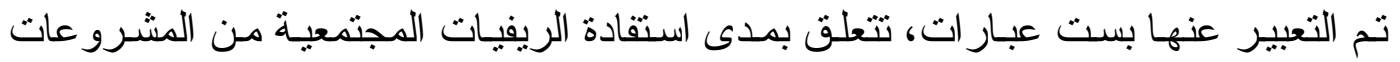

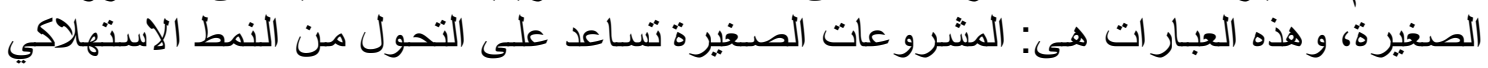




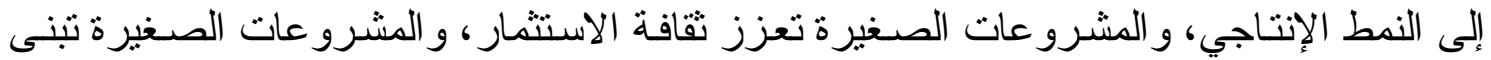

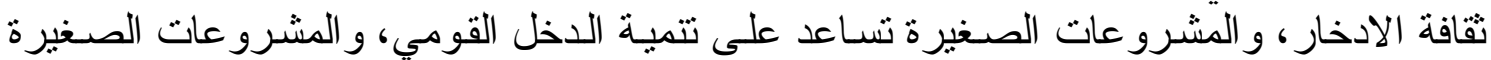

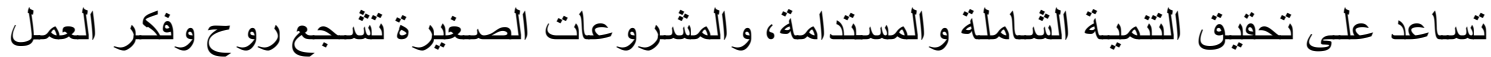

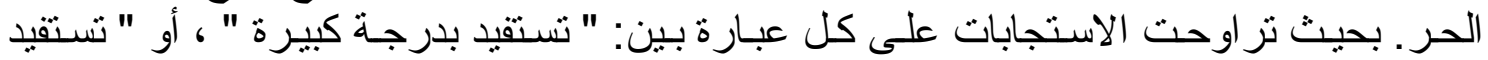

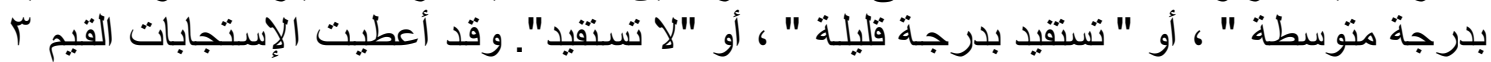

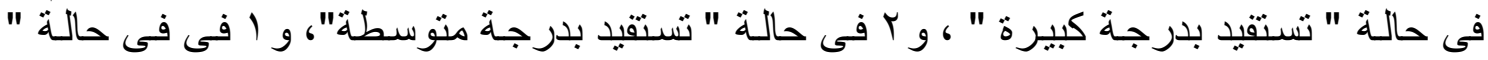

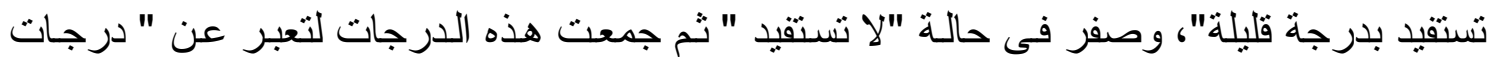

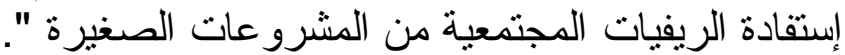
د - درجات الإستفادة البيئية:

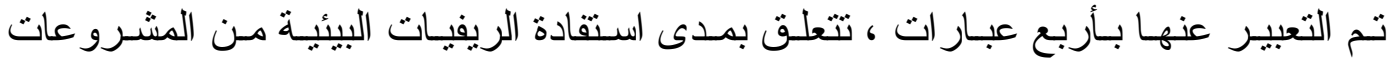

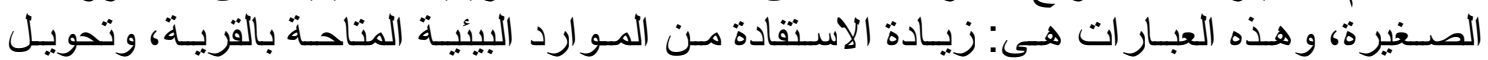

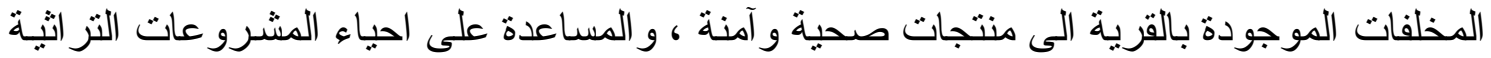

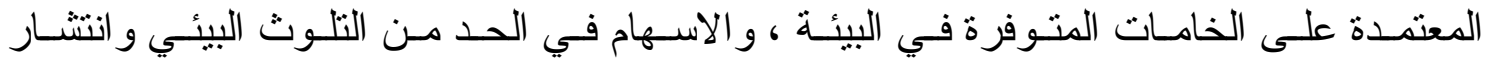

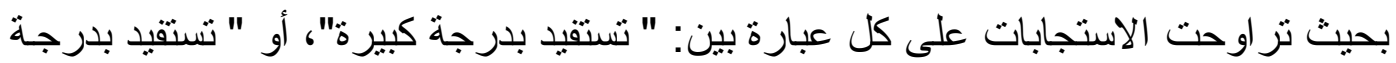

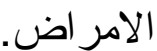

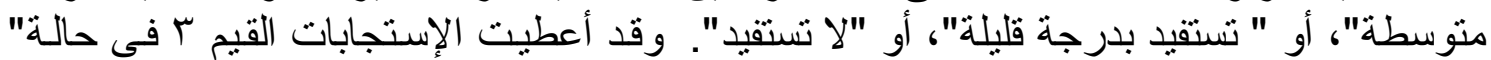

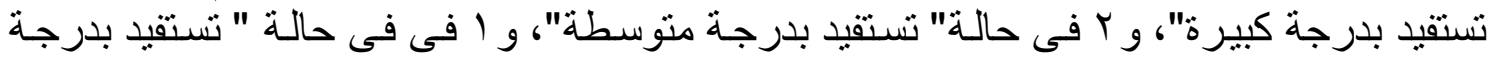
قليلة"، وصفر فى حالة "لا تستقيد " ثم جمعت هذه الدرجات لتعبر عن " درجات إستقادة الريفيات البيئبة من المشرو عات الصغيرة".

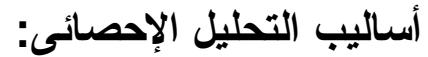

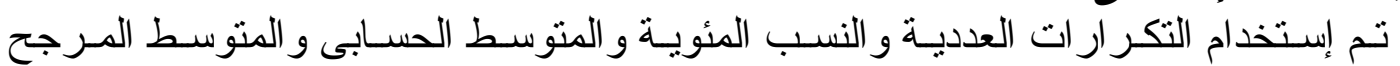
لوصف البيانات. وصف عينة الار اسة:

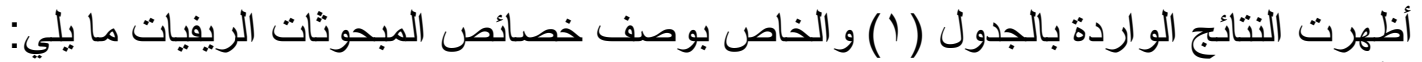

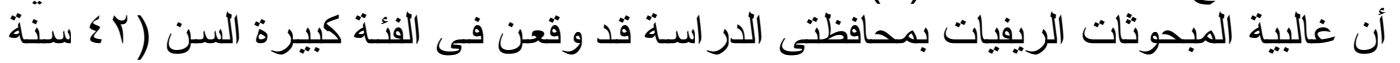

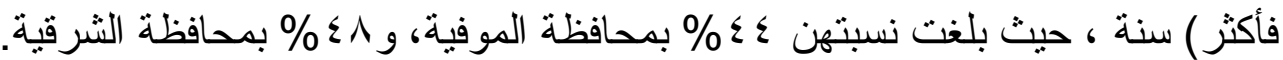

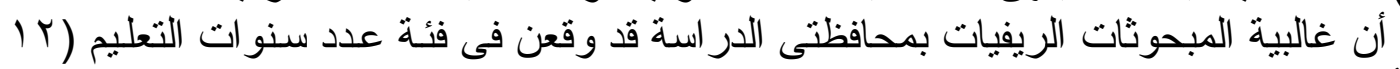

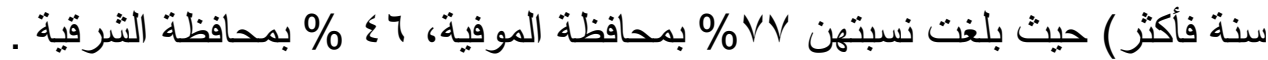

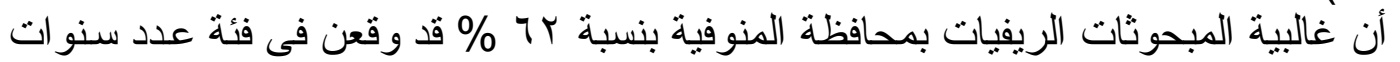

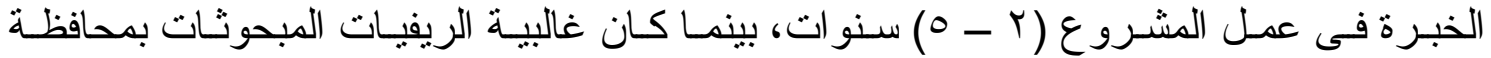

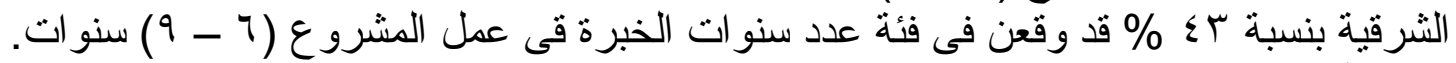

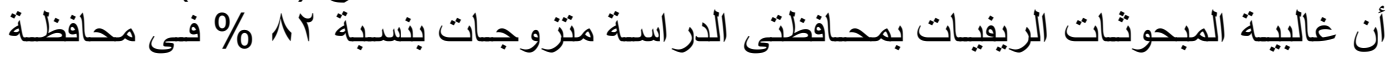

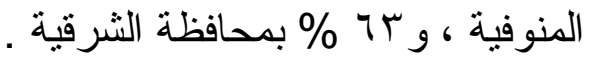

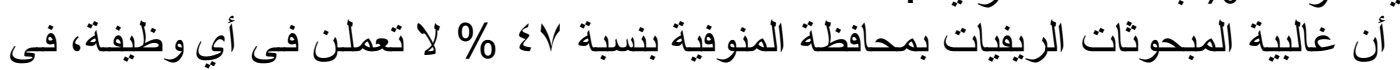

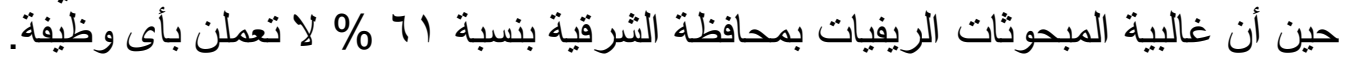

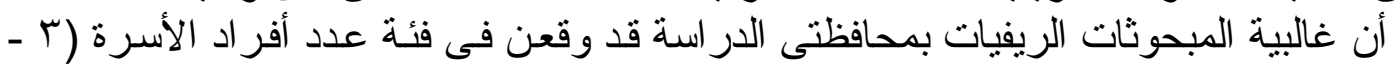

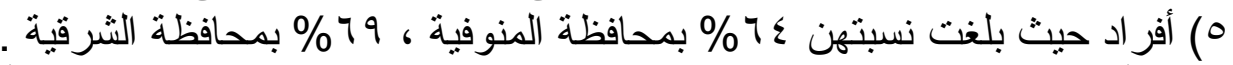

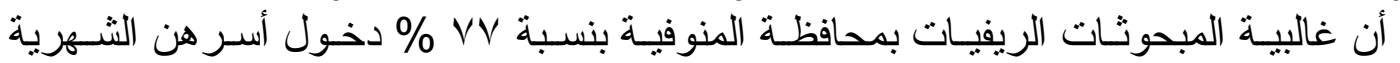

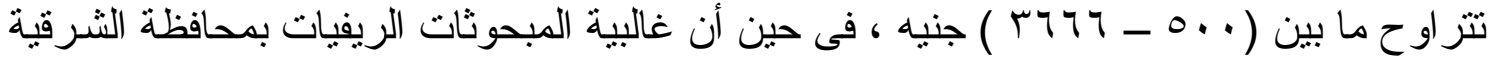

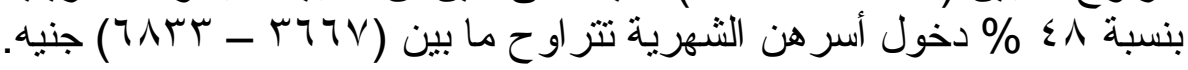


جدول 1. التوزيع العددى والنسبى للخصائص الشخصية والاجتماعية والاقتصادية المبحوثات الريفيات

\begin{tabular}{|c|c|c|c|c|}
\hline \multicolumn{2}{|c|}{ محافظة الشرقية } & \multicolumn{2}{|c|}{ محافظة المنوفية } & \multirow{2}{*}{ خصائص المبحوثات الريفيات } \\
\hline$\%$ & 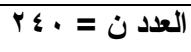 & $\%$ & العدد ن = • § ب & \\
\hline \multicolumn{5}{|r|}{ سن المبحوثة } \\
\hline 9 & T) & IV & $\varepsilon$. & l \\
\hline$\varepsilon r$ & 1.4 & r9 & $9 \varepsilon$ & ( \\
\hline$\sum \Lambda$ & 117 & $\varepsilon \varepsilon$ & 1.7 & ( ) ( سنة فأكثر ( ) \\
\hline \multicolumn{5}{|r|}{ تعليم المبحوثة } \\
\hline T) & VT & 11 & rT & ( صفر - 0 ) سنوات \\
\hline Tr & 07 & IT & rA & (11- 1) \\
\hline$\sum 7$ & 111 & VV & 1117 & ( r ( سنة فأكثر () \\
\hline \multicolumn{5}{|r|}{ عدد سنوات خبرة المبحوثةة فى عمل المشروع } \\
\hline rq & $9 \varepsilon$ & TY & $1 \leqslant \Lambda$ & (ن- (0) \\
\hline$\varepsilon r$ & $1 \cdot \varepsilon$ & rT & 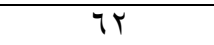 & (9-7) سنة \\
\hline 11 & $\varepsilon r$ & IT & $r$. & ( · · سنو ات فأكثر ) \\
\hline \multicolumn{5}{|r|}{ الحالة الإجتماعية للمبحوثةة } \\
\hline 1. & tr & 1. & $T \Sigma$ & عزباء \\
\hline$\pi$ & 10. & AT & 197 & 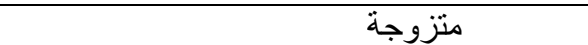 \\
\hline Tr & 07 & 7 & 10 & أرملة \\
\hline$\varepsilon$ & 11 & r & 0 & 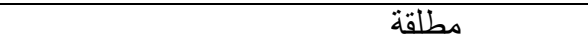 \\
\hline \multicolumn{5}{|r|}{ الحالة العملية للمبحوثة : } \\
\hline 7 & $1 \leqslant V$ & $\varepsilon V$ & $11 \mathrm{~T}$ & لا تعمل \\
\hline ro & 7. & 10 & m & 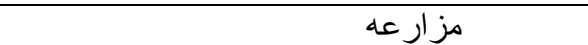 \\
\hline $1 \varepsilon$ & $r$. & 11 & $\varepsilon \varepsilon$ & تعمل في وظيفة حكو مبة \\
\hline . & . & r. & $\sum \Lambda$ & تعمل فى قطاع خاص \\
\hline \multicolumn{5}{|r|}{ عدد أفراد أسرة المبحوثةة : } \\
\hline 10 & TV & ro & 89 & (Y-1) فرد \\
\hline 79 & 170 & $7 \varepsilon$ & 104 & (أفراد \\
\hline 17 & rA & 11 & rA & ( 7 أفر اد فأكثر ) ( \\
\hline \multicolumn{5}{|r|}{ الاخل الشهرى لأسرة المبحوثة : } \\
\hline 19 & $\leqslant 0$ & VV & 110 & ( ) ( \\
\hline$\leqslant \Lambda$ & $11 \varepsilon$ & 11 & $\varepsilon r$ & 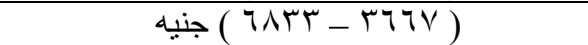 \\
\hline TT & NI & 0 & $1 \pi$ & 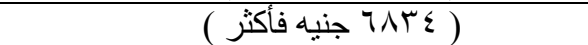 \\
\hline
\end{tabular}

وبـالنظر إلى النتائج السـابقة و الخاصـة بوصف المبحوثات الريفيـات أفر اد عينـة الدر اسـة تبين مـا

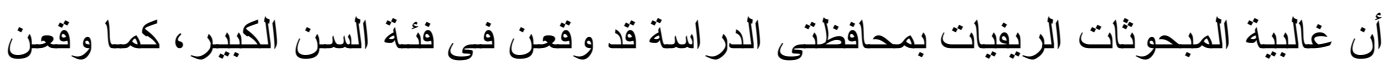

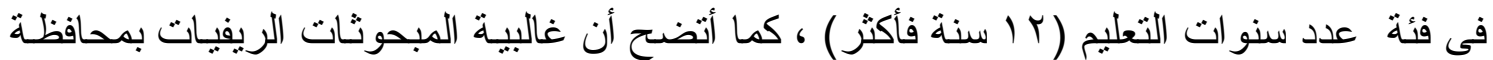

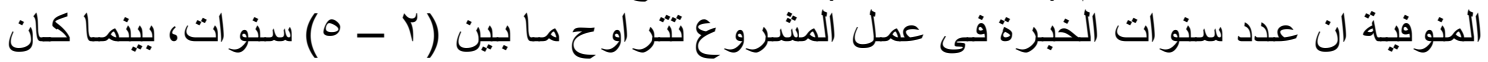

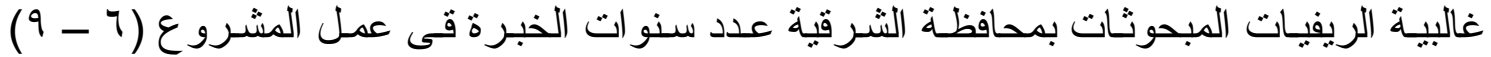

كـــا تبـين أن غالبيــة المبحوثـات الريفيـات بمحسافظتى الدر اســة متزوجـات، و وأن غالبيــة سنو ات

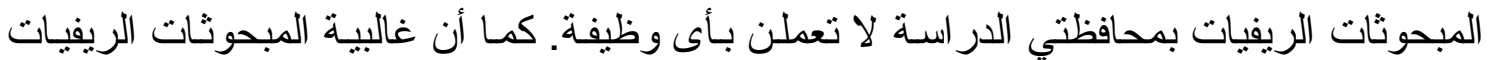

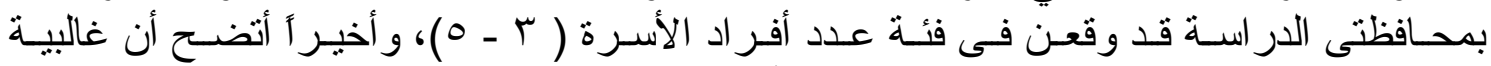

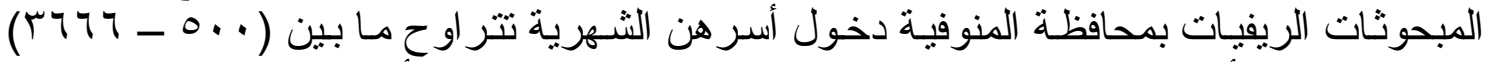

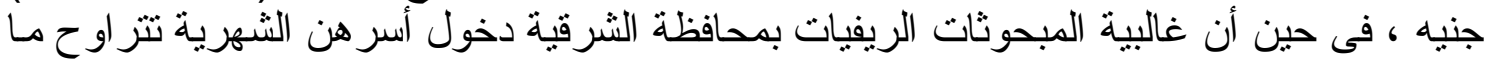
بين (VT ( 


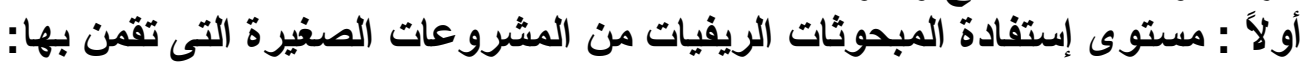

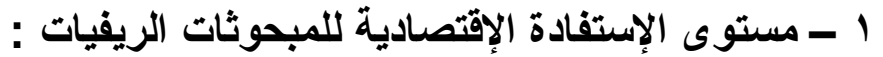

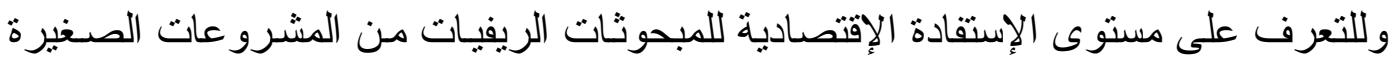

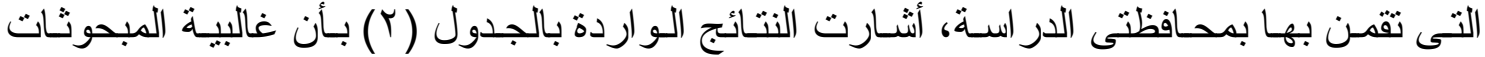

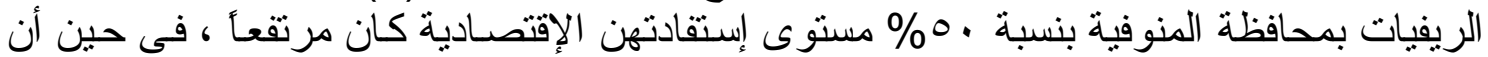

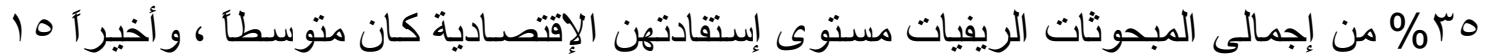

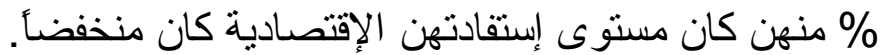

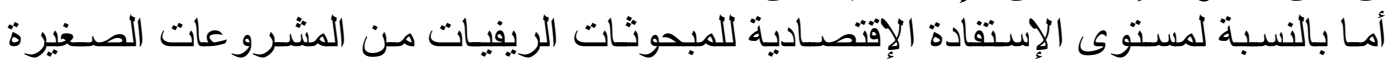

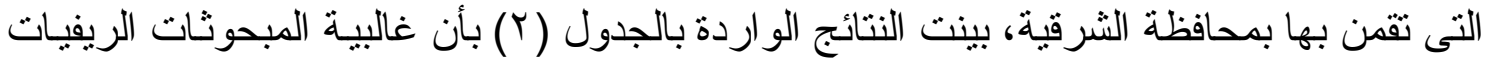

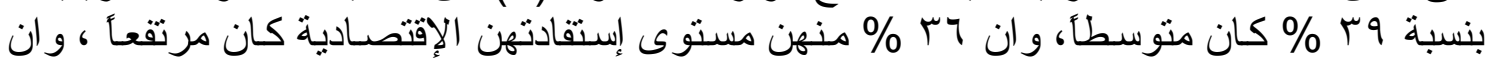

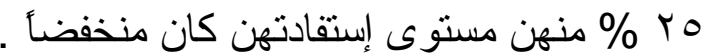

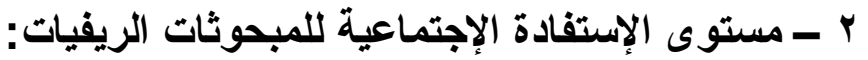

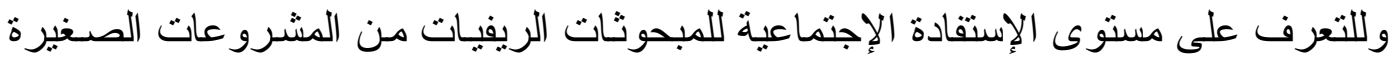

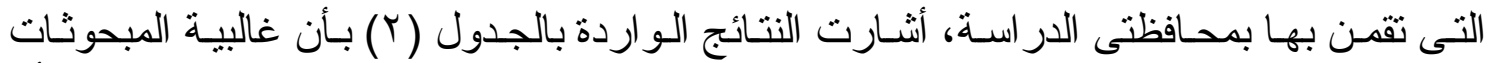

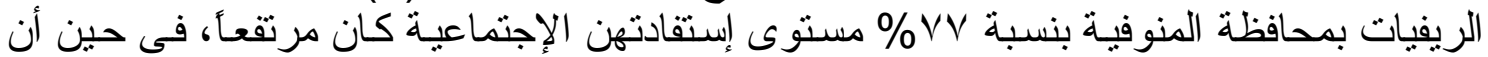

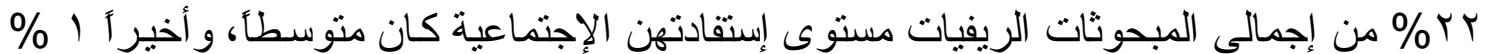

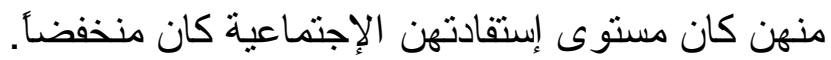

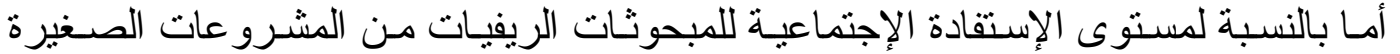

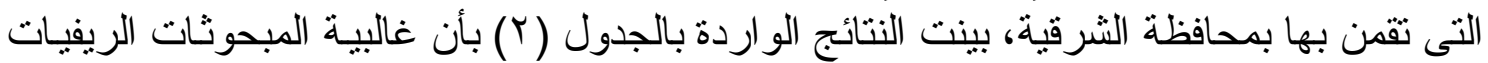

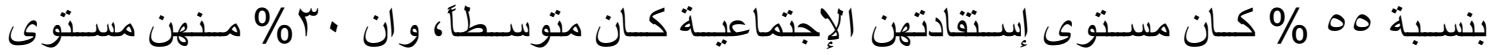

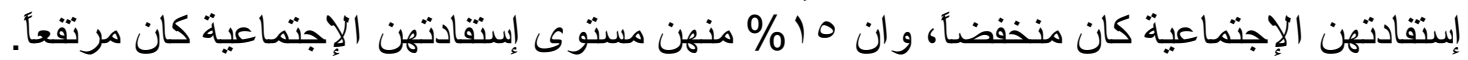
r - مستوى الإستفادة المجتمعية للمبحوثات الرئات الريفيات:

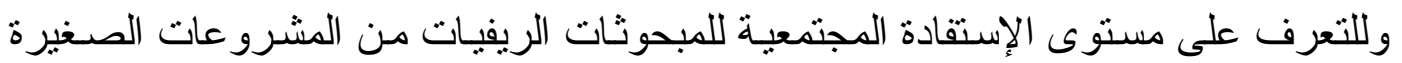

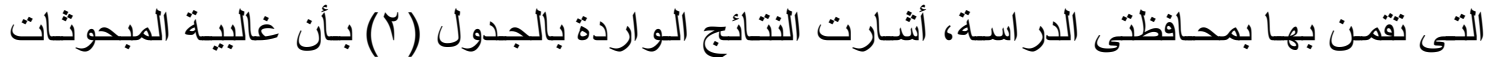

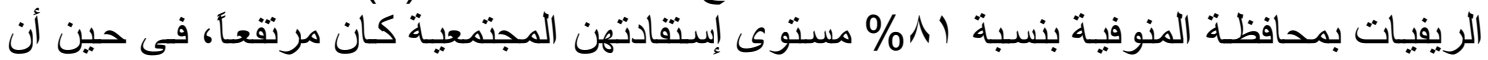

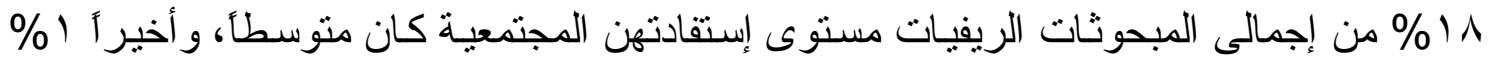

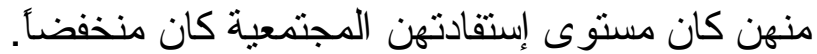

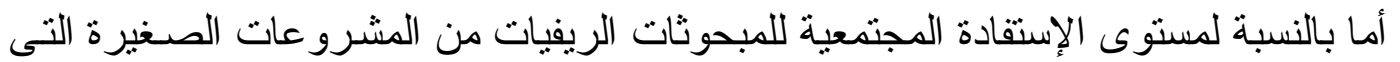

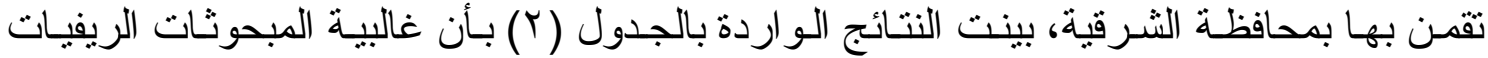

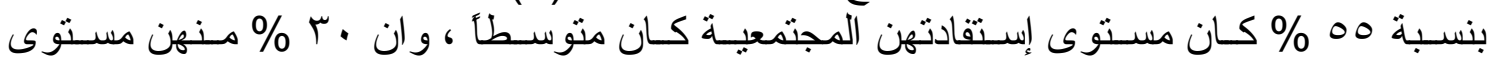
إستفادتهن المجتمعية كان منخفضأ، و وان 10 \% \% منهن مستوى إستفادتهن المجتمعية كان مرتفعاً. ع - مستوى الإستفادة البيئية :

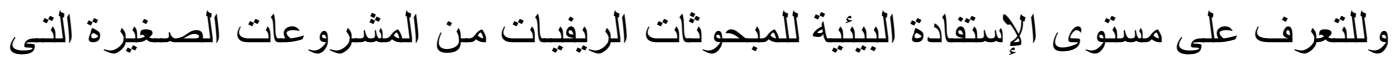

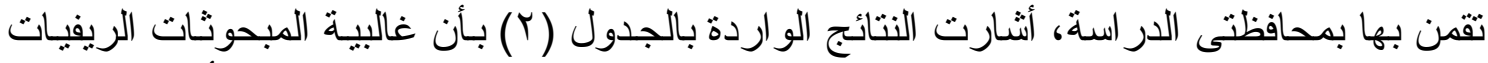

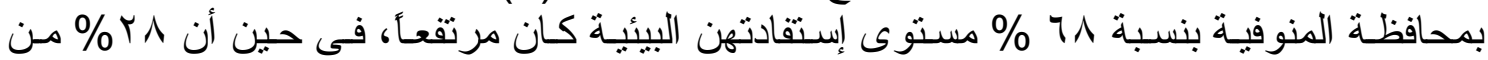

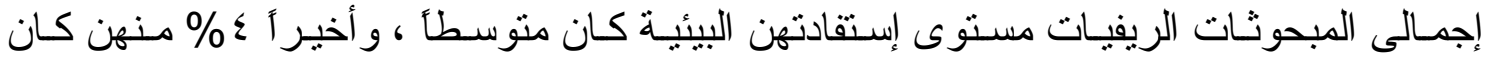
مستوى إستفادتهن البيئية كان منخفضاً.

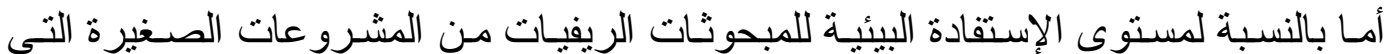

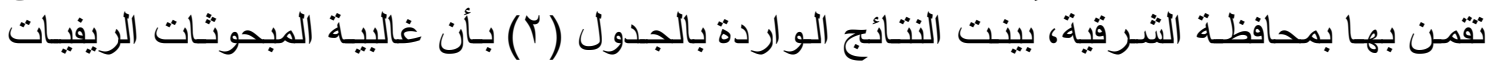

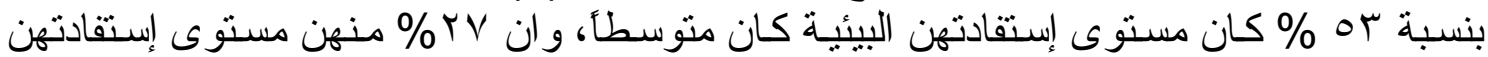
البيئية كان مرتفعاً ، و ان • r\% منهن مستوى إستفادتهن البيئية كان منخفضأ. 


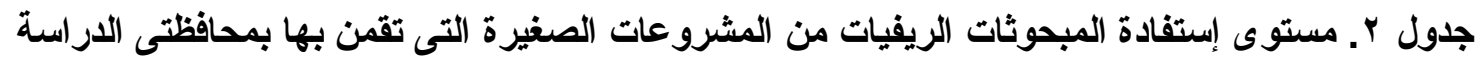

\begin{tabular}{|c|c|c|c|c|}
\hline \multicolumn{2}{|c|}{ محافظة الثرقية } & \multicolumn{2}{|c|}{ محافظة المنوفيةة } & \multirow{2}{*}{ الصنيرة إنتىفادة المبحوثنات الريفيات من المشروعات } \\
\hline$\%$ & عدد & $\%$ & عدد & \\
\hline & & & & 1 - الاستفادة الاقتصادية : \\
\hline TO & 09 & 10 & TV & منخفض ( \& \\
\hline rq & 94 & ro & NT & متوسط ( KM -1؛ ) درجة \\
\hline rq & $\mathrm{NA}$ & 0 . & $\pi$ T. & مرتفع ( بـ درجة فأكثز ) \\
\hline & & & & r - الإستفادة الإجتماعبة : \\
\hline$r$. & $\mathrm{ve}$ & 1 & $r$ & منخفض ( • (19 19 ) درجة \\
\hline 00 & Tाז & TY & or & 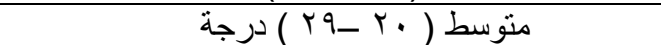 \\
\hline 10 & rV & VV & 110 & مرتفع ( •ץ درجة فأكثر) \\
\hline & & & & r ـ الإستفادة المجتمعية : \\
\hline$r$ r. & VT & 1 & r & منخفض ( آ- 11 ) درجة \\
\hline 00 & Tr. & 11 & $\varepsilon r$ & متوسط (Y IV_ IV_) درجة \\
\hline 10 & TV & NI & 190 & مرتفع ( ^ا درجة فأكثز ) \\
\hline & & & & ـ ـ الإستفادة البيئية : \\
\hline$r$. & $\varepsilon \wedge$ & $\varepsilon$ & 9 & منخفض ( ₹- V ) درجات \\
\hline or & TY & TA & TV & متوسط ( ^ -11 ) درجة \\
\hline TV & 77 & 71 & $17 \varepsilon$ & مرتفع ( r ( درجة فأكثر) \\
\hline
\end{tabular}

المصدر: إستمارة الإسنبيان

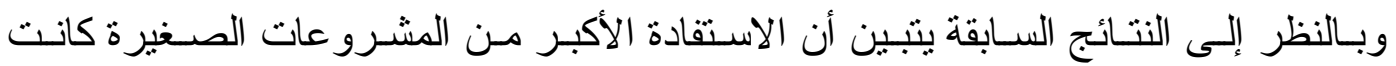

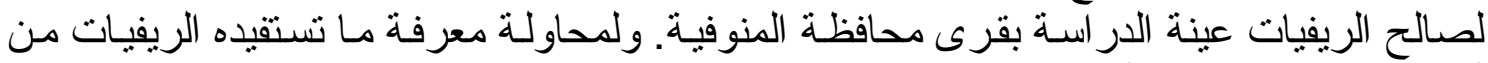

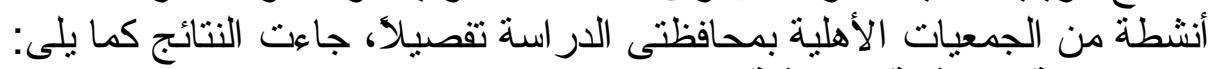

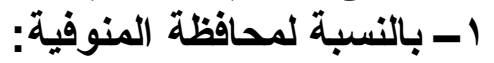

أ أل الإستفادة الإقتصادية:

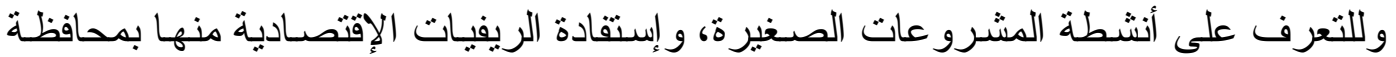

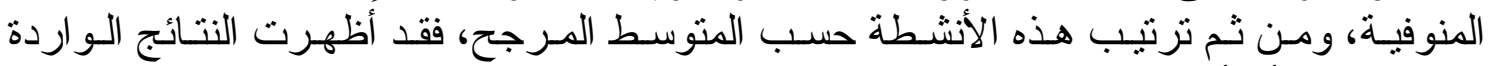

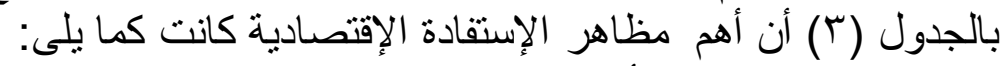

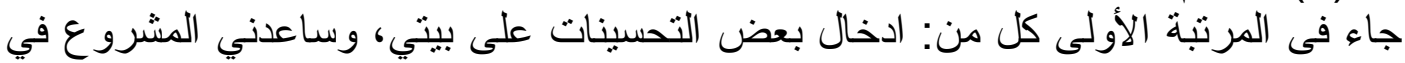

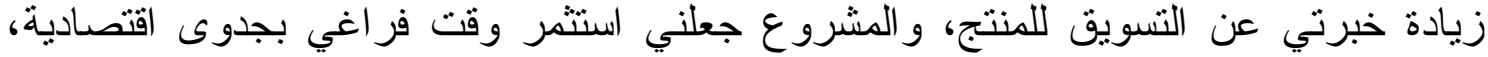

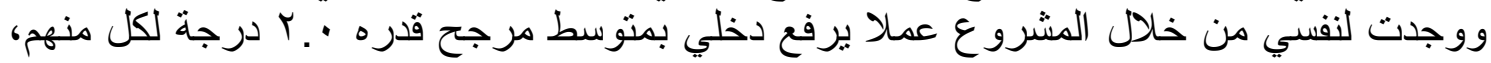

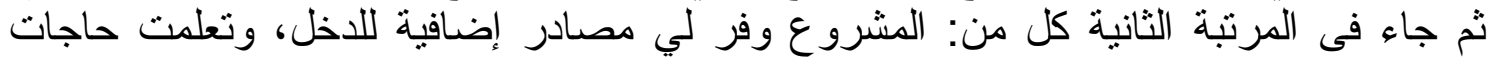

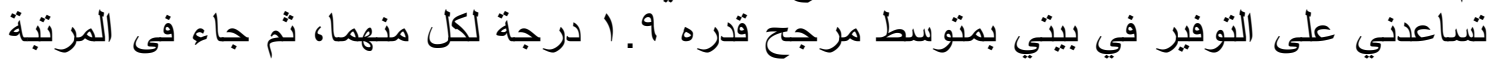

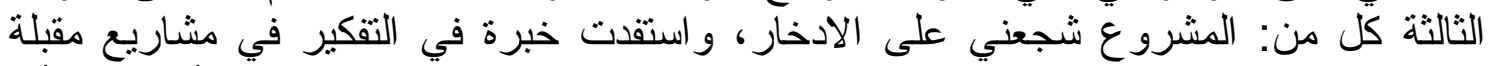

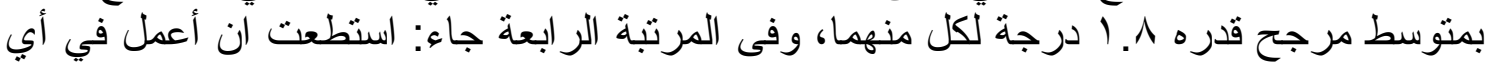

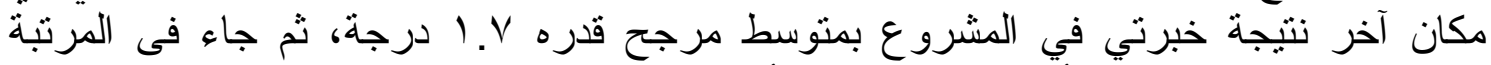

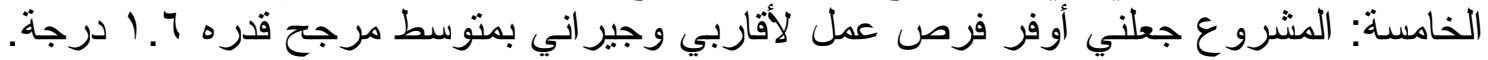

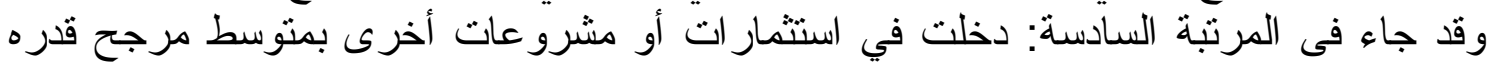

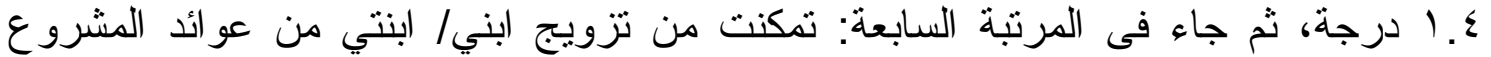

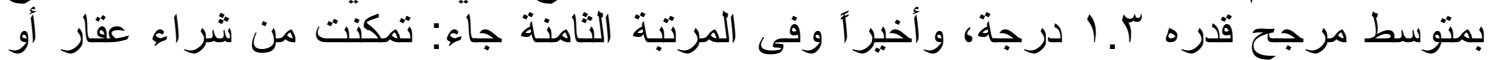

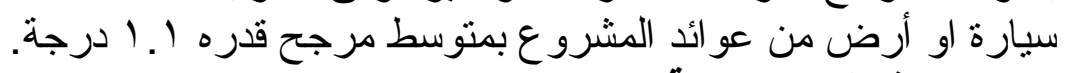

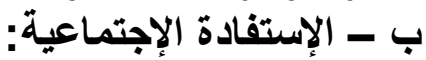

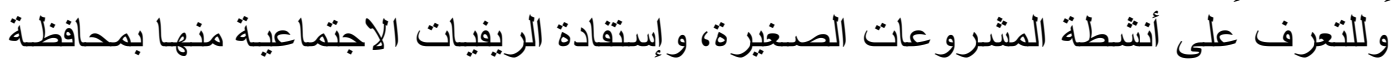

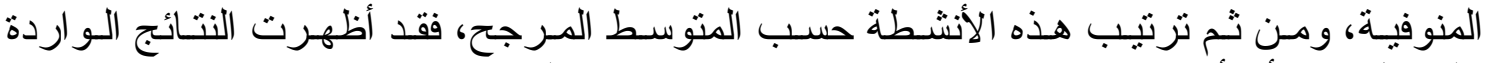
بالجدول (T) أن أهم مظاهر الإستفادة الاجتماعية كانت كما يلى الئ: 


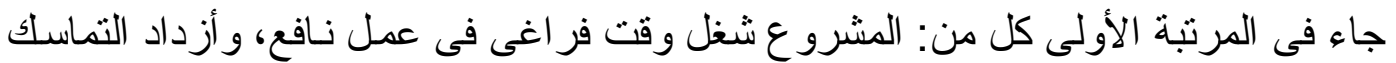

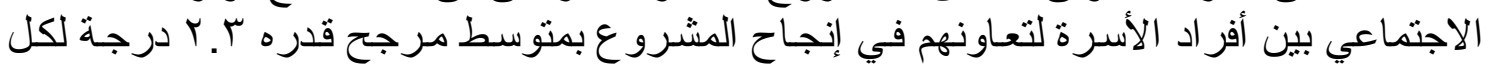

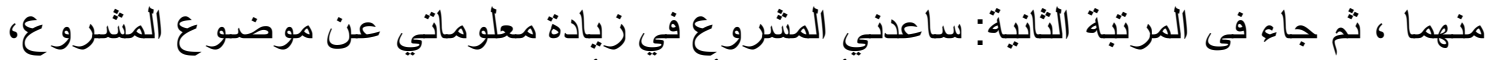

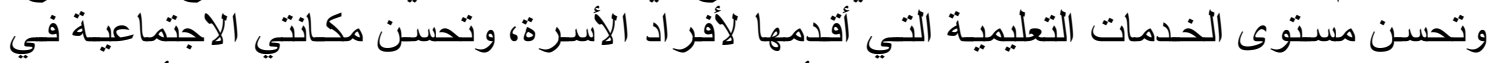

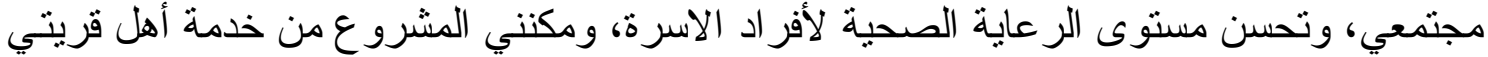

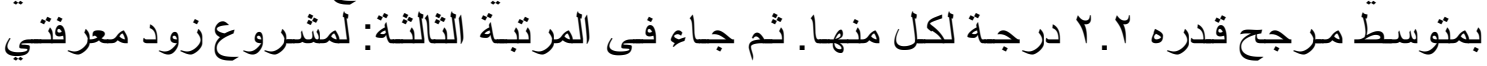

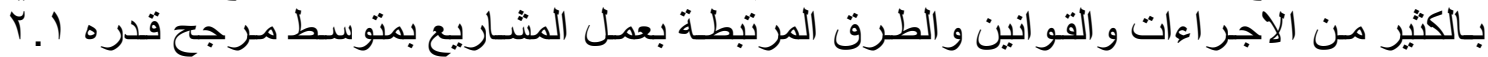

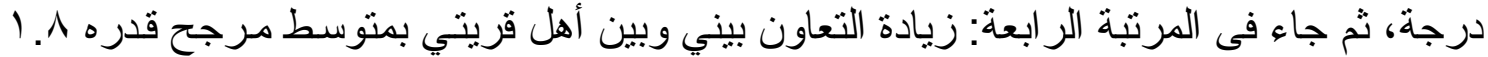

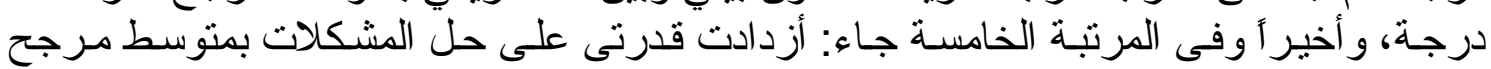

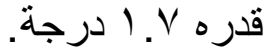

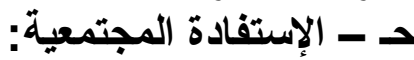

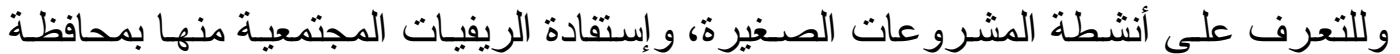

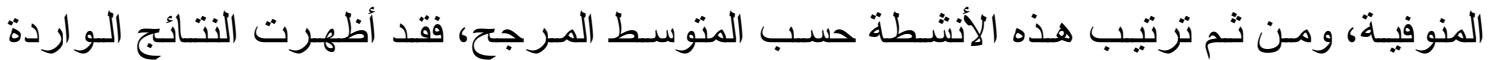

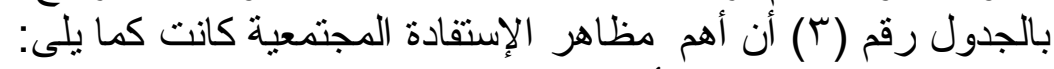

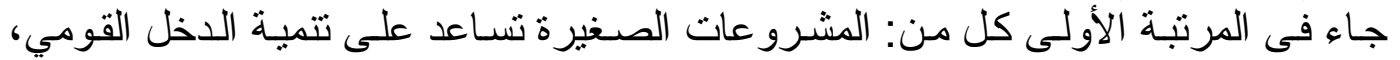

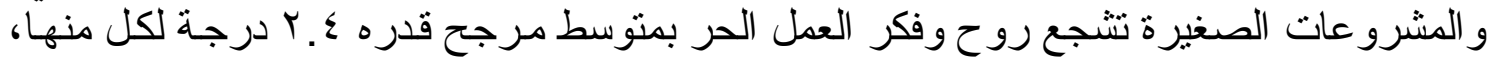

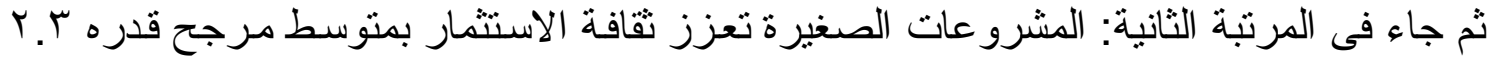

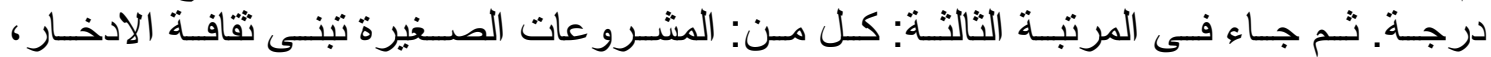

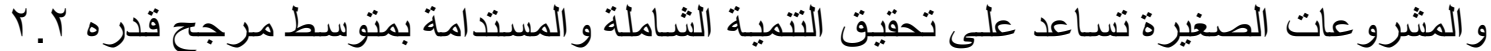

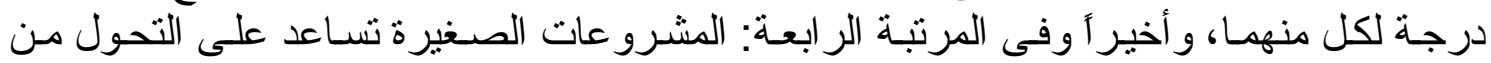

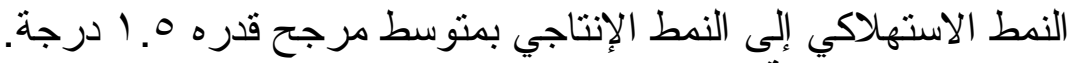

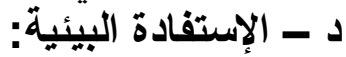

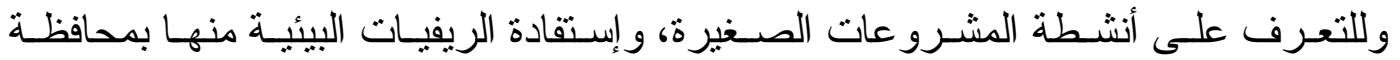

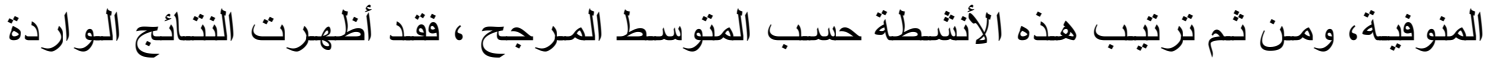

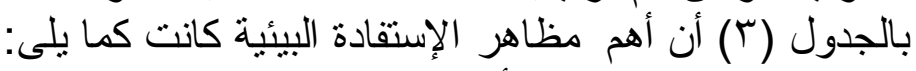

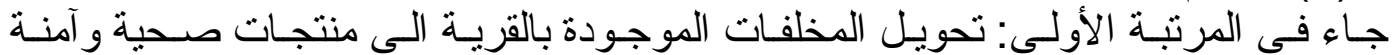

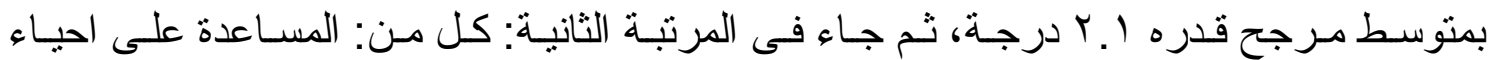

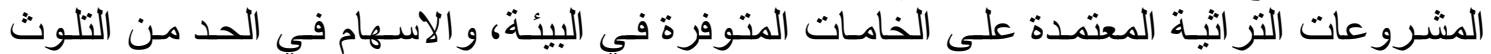

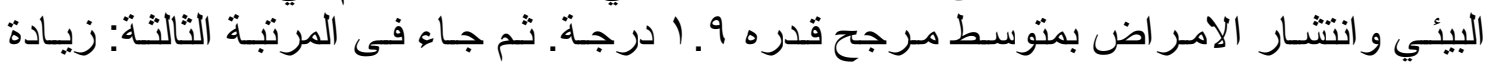

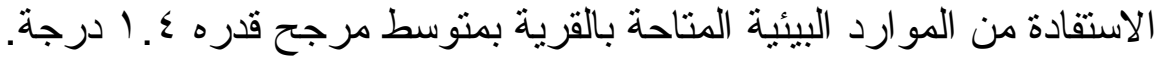


Doi: 10.21608/ajas.2019.66218

http://ajas.journals.ekb.eg/

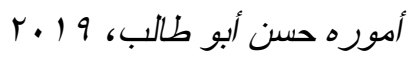

جدول r. توزيع المبحوثات الريفيات وفقاً لإستفادتهن من المشروعات الصغيرة بمحافظة المنوفية

\begin{tabular}{|c|c|c|c|c|c|c|c|c|c|c|}
\hline \multirow[t]{2}{*}{ 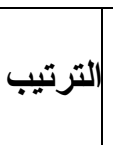 } & \multirow{2}{*}{ المتوسط } & \multicolumn{2}{|c|}{ لا تستفيد } & \multicolumn{2}{|c|}{ إستفادة بلرجة } & \multicolumn{2}{|c|}{ إستفادة بلرجة متوسطة } & \multicolumn{2}{|c|}{ |إستفادة بلرجة| } & \multirow[t]{2}{*}{ إستفادة الريفيات المشروعات الصغيرة } \\
\hline & & $\%$ & العدد & $\%$ & 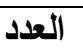 & $\%$ & العدد & $\%$ & العدد & \\
\hline & & & & & & & & & & |ستفادة اقتصادية : \\
\hline 1 & r.e. & $r$ & 0 & $r \cdot$ & $\varepsilon \wedge$ & $\varepsilon r$ & $1 \cdots$ & ru & AV & مكنت من ادخال بعض التحسينات على بيتي \\
\hline $\mathrm{V}$ & $1 . r$ & T & $\Lambda V$ & Tr & r. & $\lceil\wedge$ & $7 V$ & r & 07 & مكنت من تزويج ابني/ ابنتي من عوائد المشروع \\
\hline$\wedge$ & 1.1 & $\leqslant 0$ & $1 \cdot 1$ & Tו & 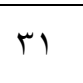 & $r \leq$ & 09 & 11 & $\varepsilon r$ & |لمشنت من شر اء عقار أو سبارة او أرض من عوائد \\
\hline$r$ & 1.1 & $\mathrm{~V}$ & 17 & $r \cdot$ & Vo & ry & $\Lambda V$ & $r 7$ & $7 Y$ & |لمشروع شجعني على الادخار \\
\hline 0 & 1.7 & Tร & OV & 19 & $\leqslant 0$ & r. & $\overline{V T}$ & TV & 70 & لمشروع جعلني أوفر فرص عمل لأقاربي وجير اني \\
\hline$r$ & 1.9 & $r$ & 0 & $r \varepsilon$ & 71 & $\varepsilon \varepsilon$ & $1 \cdot 7$ & rA & $7 \wedge$ & لالمشروع وفر لي مصادر إضافية للدخل \\
\hline 1 & r.. & r & 0 & rT & $0 \leqslant$ & $\sum V$ & $M T$ & rA & 79 & بسبب المشروع تحسن دخل أسرتي \\
\hline r & 1.9 & 0 & 11 & Yo & 71 & $\varepsilon r$ & $1 \cdots$ & rᄉ & 71 & لمعلمت حاجات تساعدني على التوفير في بيتي \\
\hline$\varepsilon$ & 1. $v$ & 0 & 11 & r & T纟 & r. & $v r$ & r & $\vee V$ & |المشتطعت ان أعمل في أي مكان آخر نتيجة خبرتي في \\
\hline 1 & r.e. & 7 & 10 & 19 & $\leqslant 0$ & $\sum Y$ & $1 \cdot 1$ & " מ & V9 & ساعدني المشروع في زيادة خبرتي عن التسويق للمنتج \\
\hline$r$ & 1.1 & $1 \cdot$ & rร & ry & $7 r$ & r & $\vee \wedge$ & ri & $V 7$ & ستفدت خبرة في التفكير في مشاريع مقبلة \\
\hline 7 & $1 . \varepsilon$ & Th & $\Lambda$. & $1 \varepsilon$ & Th & rq & 79 & T乏 & $0 \Lambda$ & لخلت في استثمار ات أو مشرو عات أخرى \\
\hline 1 & r.e & 7 & $1 \varepsilon$ & 11 & $\varepsilon \varepsilon$ & $\varepsilon \varepsilon$ & 1.0 & re & $\checkmark V$ & لمشروع جعلني استثمر وقت فر اغي بجدوى اقتصادية \\
\hline 1 & r.e & 0 & 11 & 11 & $\varepsilon r$ & $\sum Y$ & $1 \cdot 1$ & ro & 10 & رجدت لنفسي من خلال المشروع عملا يرفع دخلي \\
\hline & & & & & & & & & & |ستفادة اجتماعية \\
\hline r & r. 1 & $\varepsilon$ & 9 & 10 & re & $\leqslant 7$ & $11 \cdot$ & 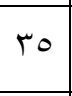 & $\Lambda \varepsilon$ & 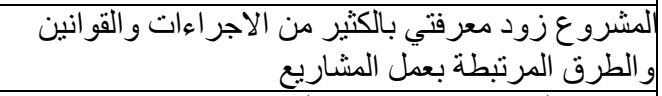 \\
\hline r & r. & 1 & r & it & $r \wedge$ & $\leqslant 9$ & 111 & rᄉ & 91 & شروع المشروع في زيادة معلوماتي عن موضوع \\
\hline 1 & r.r & $r$ & 0 & $1 \cdot$ & rT & $\sum Y$ & $1 \cdots$ & $\varepsilon 7$ & $11 Y$ & المشروع شغل وقت فر اغى فى عمل نافع \\
\hline 0 & $1 . \mathrm{V}$ & 0 & 11 & 11 & rV & $\sum r$ & $1 \cdot r$ & $\varepsilon 1$ & 99 & زددادت قدرتى على حل المشكلات \\
\hline 1 & r.r & r & 0 & 11 & TV & $\varepsilon$. & 97 & $\varepsilon V$ & 114 & 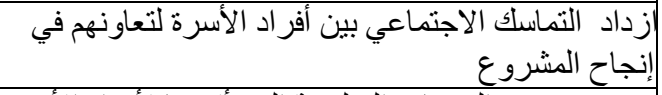 \\
\hline$r$ & r.t & $r$ & 7 & $1 \varepsilon$ & $r \varepsilon$ & $\varepsilon r$ & $1 \cdot \varepsilon$ & $\varepsilon \cdot$ & 97 & لحسن مستوى الخدمات التعليمية التي أقدمها لأفر اد الأسرة \\
\hline r & r.t & $r$ & V & 17 & rq & rN & 94 & $\varepsilon r$ & $1 \cdot r$ & تحسن مكانتي الاجتماعية في مجتمعي \\
\hline r & t. & r & $\varepsilon$ & IV & $\varepsilon$. & $\S$ & 99 & $\varepsilon \cdot$ & $9 V$ & تحسن مستوى الرعاية الصحية لأفر اد الاسرة \\
\hline$\varepsilon$ & 1.1 & r & $\mathrm{V}$ & 14 & $r \cdot$ & $\varepsilon$. & 90 & $\varepsilon 0$ & $1 \cdot 1$ & لزيادة التعاون بيني وبين أهل قريتي \\
\hline r & r. & 0 & Ir & 9 & rt & rᄉ & 91 & $\varepsilon \wedge$ & 110 & مكني المشروع من خدمة أهل قريتي \\
\hline & & & & & & & & & & |ستفادة المجتمعية \\
\hline$\varepsilon$ & 1.0 & 1 & $r$ & $\mathrm{~V}$ & IV & $\sum \wedge$ & 110 & $\varepsilon \varepsilon$ & 1.0 & 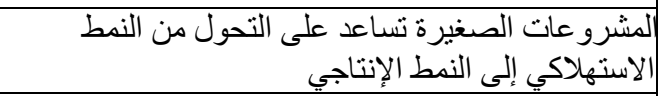 \\
\hline r & t.r & 1 & $r$ & it & rq & $\S$ & $9 \wedge$ & $\sum 7$ & 11. & المشرو عات الصغيرة تعزز ثقافة الاستثمار \\
\hline$r$ & r.t & 1 & $r$ & IT & rq & $\varepsilon r$ & $1 \cdot r$ & $\varepsilon \varepsilon$ & 1.7 & المشرو عات الصغيرة تبنى ثقافة الادخار \\
\hline 1 & T.乏 & $r$ & 0 & $1 \cdot$ & $T \varepsilon$ & T乏 & $\wedge 1$ & $0 \leqslant$ & $1 T \cdot$ & المشرو عات الصغيرة تساعد على تنمية الدخل القومي \\
\hline r & r. & r & $\checkmark$ & Ir & r. & $\varepsilon$. & 90 & $\leqslant 0$ & $1 \cdot 1$ & |و المستدروعة الصغيرة تساعد على تحقيق التنمية الثاملة \\
\hline 1 & r.乏 & r & $\varepsilon$ & 7 & $1 \varepsilon$ & $\S$ & 97 & or & $1 Y 7$ & المشروعات الصغيرة تشجع روح وفكر العمل الحر \\
\hline & & & & & & & & & & |لاستفادة البيئية \\
\hline$r$ & $1 . \varepsilon$ & $r$ & 0 & it & $r \wedge$ & $\varepsilon \Sigma$ & 1.7 & $\sum r$ & $1 \cdot 1$ & زيادة الاستفادة من الموارد البيئية المتاحة بالقرية \\
\hline 1 & r. 1 & 7 & 17 & 11 & $\varepsilon r$ & r & $\vee \varepsilon$ & $\leqslant 0$ & $1 \cdot 1$ & رو آحنة يل المخلفات الموجودة بالقرية الى منتجات صحية \\
\hline r & 1.9 & זו & r & 1. & $r \varepsilon$ & $\leqslant 1$ & 91 & רץ & $\Lambda_{7}$ & الخامات المتوفرة فياء المشئرو البيئة الميات التراثية المعتمدة على \\
\hline$r$ & 1.9 & $1 \varepsilon$ & r & 10 & דו & $r$. & $V T$ & $\sum 1$ & 91 & لالاسهام في الحد من التلوث البيئي وانتشار الامر اض \\
\hline
\end{tabular}

المصدر: إستمارة الإستبيان 


\section{r ا ب النسبة لمحافظة الثرقية:

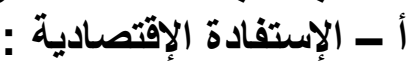

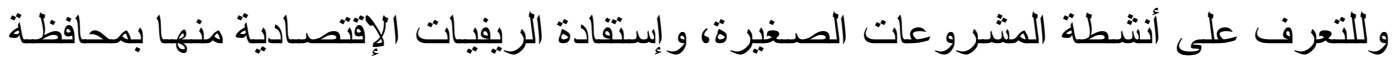

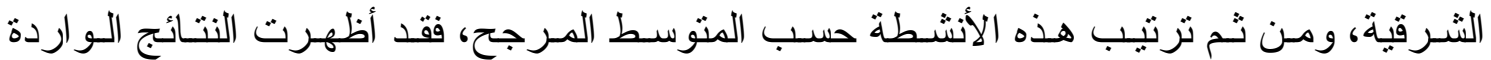

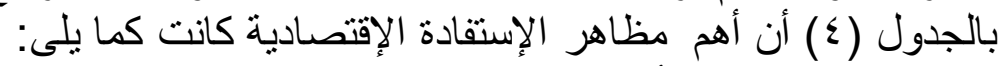

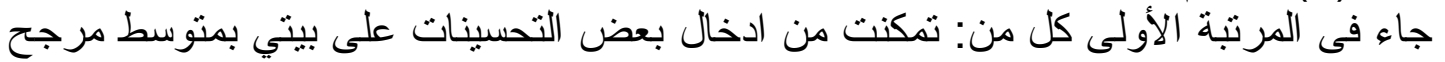

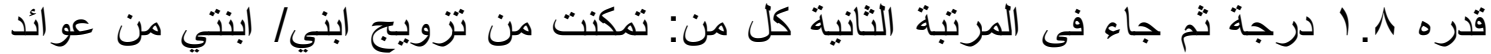

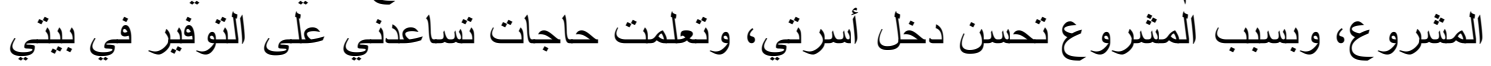

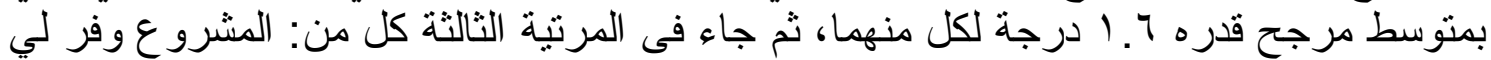

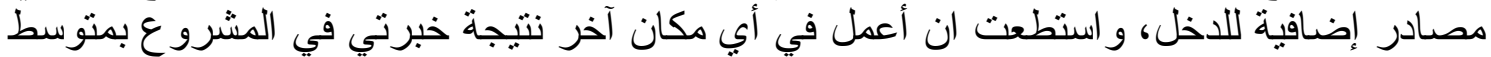

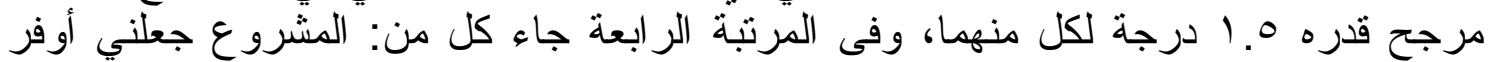

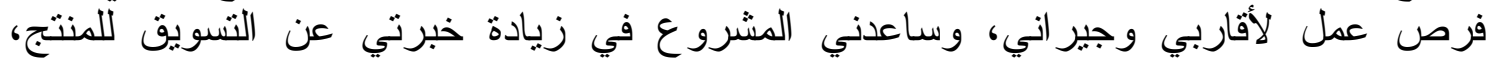

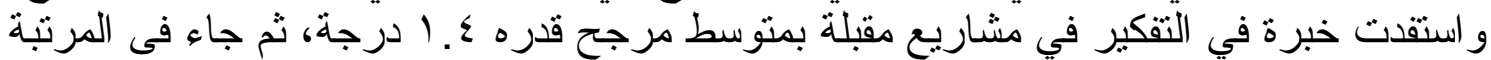

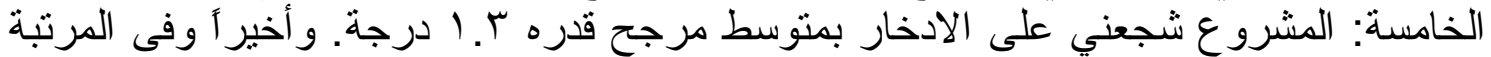

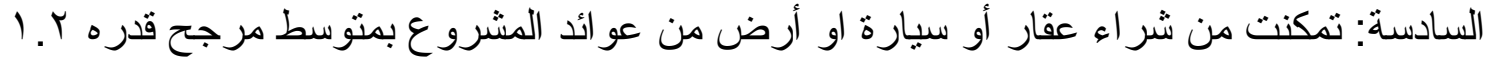

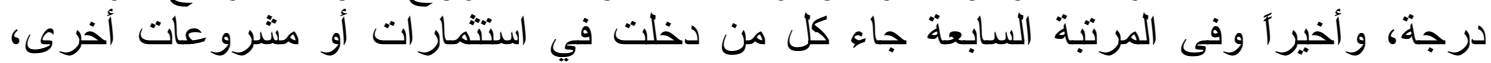

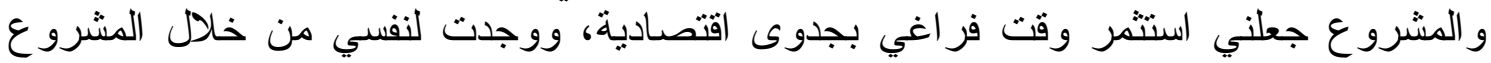

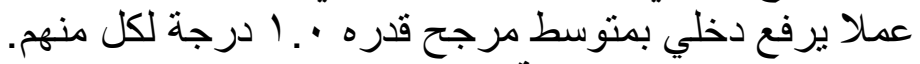

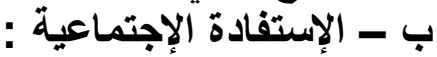

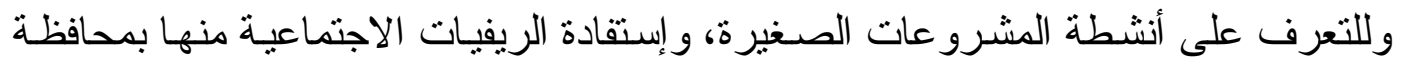

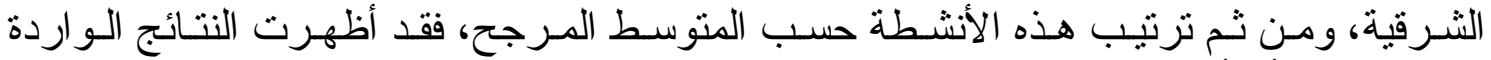

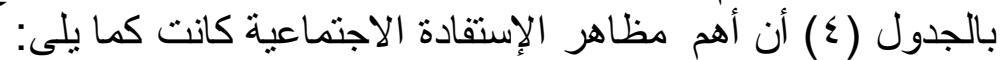

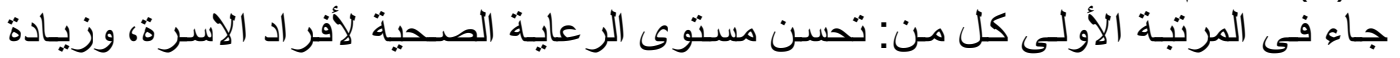

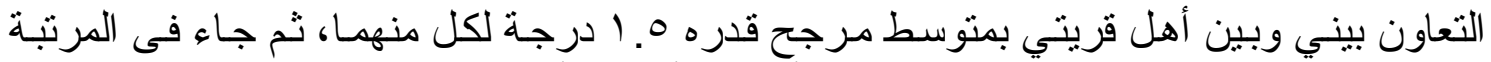

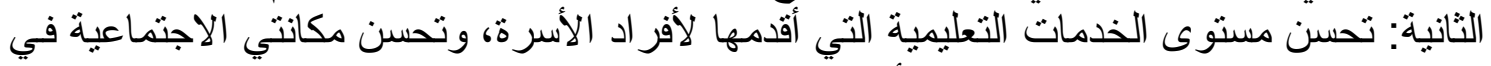

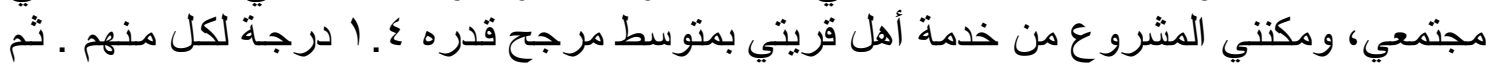

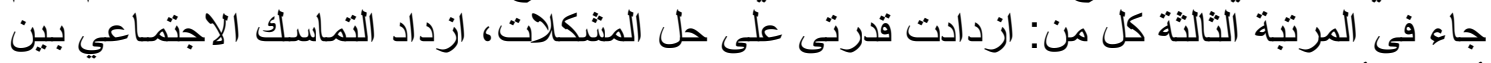

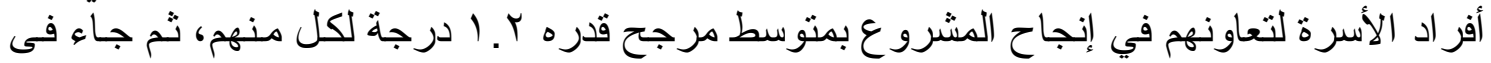

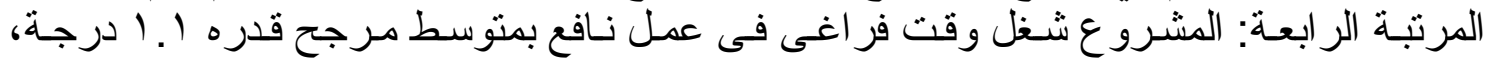

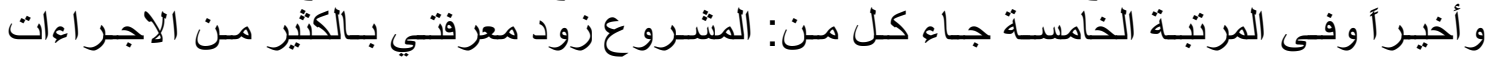

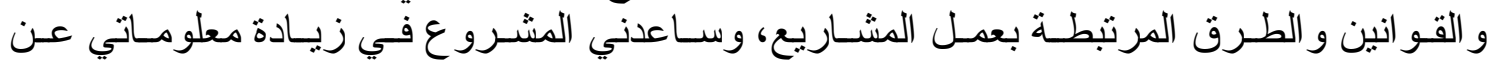

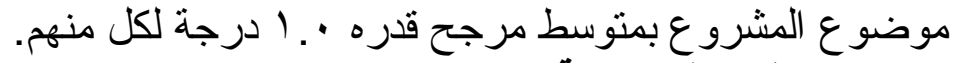
حـ - الإستفادة المجتمعية:

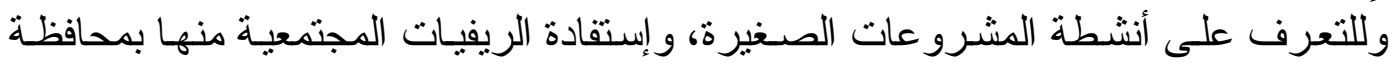

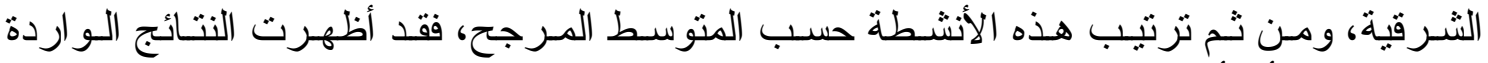

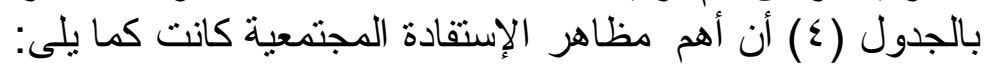

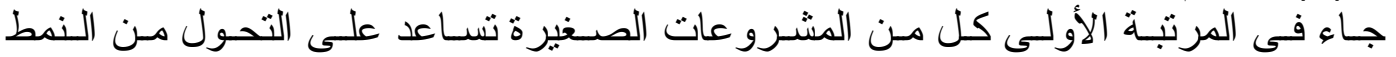

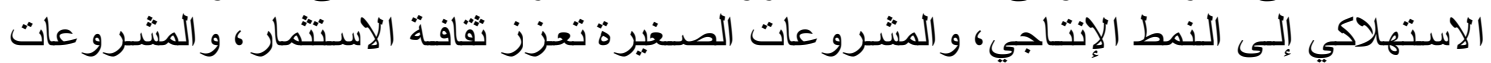

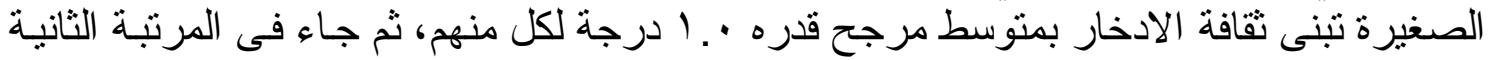

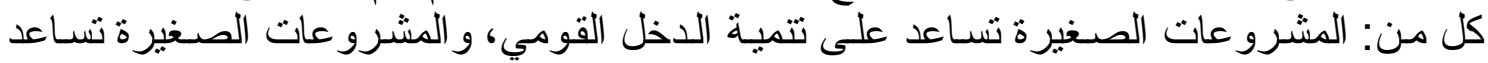

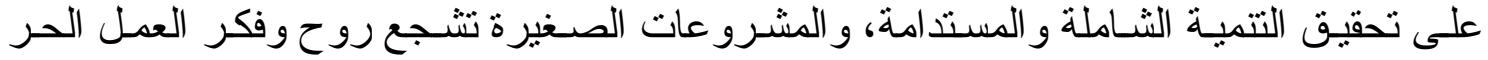
بمتوسط مرجح قدره 9 و · درجة. 


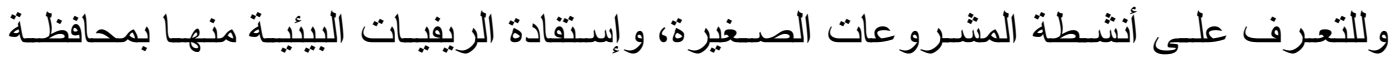

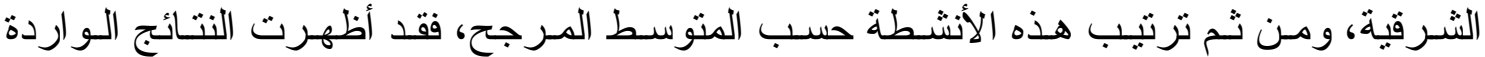

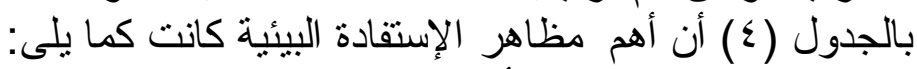

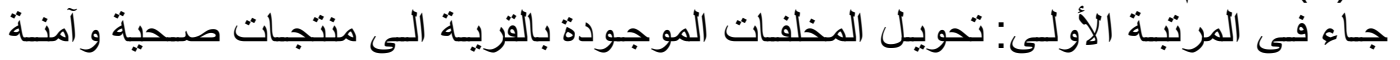

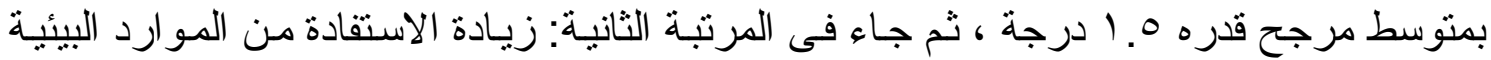

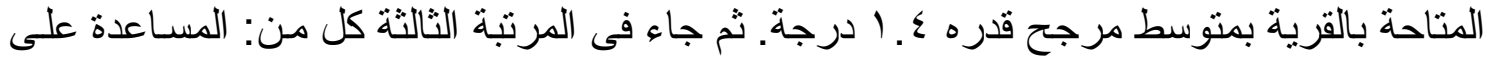

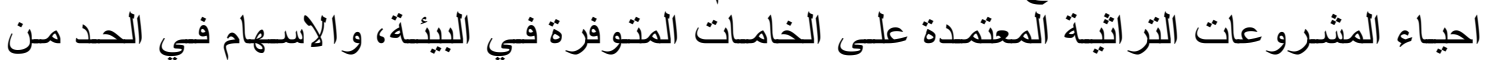
التلوث البيئي و انتشار الامر اض بمتوسط مرجح قدره درجة و احدة لكل منها. 
Assiut J. Agric. Sci., 50 (4) 2019 (265-291)

ISSN: 1110-0486

Website:www.aun.edu.eg/faculty_agriculture/journals_issues_form.php E-mail:ajas@aun.edu.eg

جدول § ـ توزيع المبحوثات الريفيات وفقاً لإستفادتهن من المشروعات الصغيرة بمحافظة الثرقية

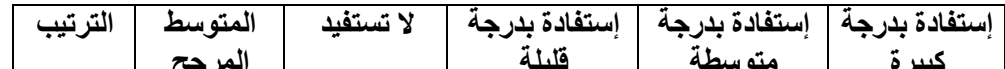

\begin{tabular}{|c|c|c|c|c|c|c|c|c|c|c|}
\hline & \multirow[t]{2}{*}{ المرجح } & & \multicolumn{2}{|c|}{ قليلة } & \multicolumn{2}{|c|}{ متوسطة } & \multicolumn{2}{|c|}{ كبيرة } & \multirow[t]{2}{*}{ إستفادة الريفيات المشرو عات الصغيرة } \\
\hline & & $\%$ & العدد & $\%$ & 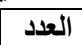 & $\%$ & العدد & $\%$ & العدد & \\
\hline & & & & & & & & & & |ستفادة اقتصادية : \\
\hline 1 & 1.1 & $r^{\prime}$ & 0 & ro & 71 & 01 & $1 \% 9$ & 10 & ro & تمكنت من ادخال بعض التحسينات على بيتى \\
\hline$r$ & 1.7 & IT & rq & ro & 09 & 0. & $|\pi|$ & $\pi$ & rI & تمكنت من تزويج ابني/ ابنتي من عوائد المشُروع \\
\hline 1 & $1 . r$ & זr & A. & 10 & ro & $\varepsilon r$ & $1 . r$ & 9 & rT & تعو ائد المشروع شراء عقار آو سيارة او أرض من \\
\hline 0 & 1.5 & 11 & $\varepsilon r$ & r9 & 79 & «0 & $1 \cdot 1$ & $\Lambda$ & $r$. & المشروع شجعني على الادخار \\
\hline$\varepsilon$ & $1 . \varepsilon$ & in & $\varepsilon \varepsilon$ & r. & v) & $\varepsilon \varepsilon$ & 1.0 & $\wedge$ & r. & |وجير |المشروع جعلني أوفر فرص عمل لآقاربي \\
\hline$r$ & 1.0 & 11 & rA & rT & $V \varepsilon$ & 0. & 119 & $\Lambda$ & 19 & المشرو ع وفر لي مصادر إضافية للاخل \\
\hline$r$ & 1.7 & $\mathrm{~V}$ & IV & rT & VV & $\varepsilon V$ & 115 & $T \varepsilon$ & $r \varepsilon$ & بسبب المشرو ع تحسن دخل أسرتي \\
\hline r & 1.7 & 7 & $1 \varepsilon$ & $r v$ & 19 & $\varepsilon r$ & $1 \cdot \varepsilon$ & $1 \varepsilon$ & Tr & تعلدت حاجات تساعدني على النوفير في بيتي \\
\hline r & 1.0 & 9 & ri & דו & AV & $\varepsilon r$ & $1 \cdot \varepsilon$ & ir & rA & في المشر و ع أعمل في أَي مكان آخر نتيجة خبرتي \\
\hline$\varepsilon$ & $1 . \varepsilon$ & 11 & r & rᄉ & qr & $\varepsilon r$ & $1 . r$ & $\wedge$ & 19 & سلتاّعني المشروع في زيادة خبرتي عن النشويق \\
\hline$\varepsilon$ & $1 . \varepsilon$ & 11 & YT & $r \Lambda$ & 94 & $\leqslant r$ & 1.5 & $\Lambda$ & 19 & استفدت خبرة في التفكبر في مشاريع مقبلة \\
\hline $\mathrm{V}$ & 1.5 & YA & TV & ri & $\mathrm{VT}$ & ro & 10 & 7 & 10 & دخلت في استثمارات أو مشرو عات أخرى \\
\hline $\mathrm{v}$ & $1 . r$ & r & 00 & ד & 14 & ro & $\wedge \varepsilon$ & 1 & 10 & |التصادية جعلني استثر وقت فراغي بجنوى \\
\hline $\mathrm{v}$ & $1 . r$ & r) & or & rN & 9. & $r \varepsilon$ & (1) & $\mathrm{v}$ & iv & وخلي لنفسي من خلال المشروع عملا يرفع \\
\hline & & & & & & & & & & |ستفادة اجتماعية \\
\hline o & 1. & $r \varepsilon$ & 1) & זr & vq & r & vo & r & ० & 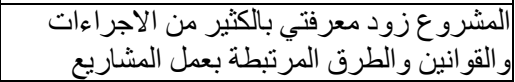 \\
\hline ० & 1. & rA & TV & rq & $q \pi$ & r & vo & r & 。 & سوضو ع المشرو ع عي زيادة معلوماتي عن \\
\hline$\varepsilon$ & 1.1 & $r \leqslant$ & 09 & $\Gamma \Lambda$ & 9. & $\mu$ & AV & r & $\varepsilon$ & المشرو ع شغل وقت فراغى فى عمل نافع \\
\hline$r$ & 1.5 & rT & 07 & rT & A. & $\leqslant r$ & $1 \cdots$ & r & $\varepsilon$ & ازدادت قدرتى على حل المشكلات \\
\hline r & $1 . r$ & in & «o & $\varepsilon$. & 97 & $\varepsilon$. & 90 & r & $\varepsilon$ & 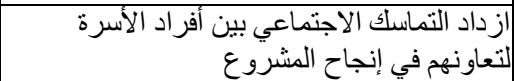 \\
\hline r & $1 . \varepsilon$ & ir & rq & ro & $\wedge \varepsilon$ & $\varepsilon \wedge$ & 117 & 。 & 11 & لافحر اد الأستوة الخدمات التعليمية التي أقدمها \\
\hline r & $1 . \varepsilon$ & 9 & rr & «o & $1 . \mathrm{V}$ & \&) & 99 & 0 & 11 & تحسن مكانتي الاجتماعية في مجتمعى \\
\hline 1 & 1.0 & 7 & 10 & ro & הT & $0 \xi$ & Tr. & 0 & TY & تحسن مستوى الرعاية الصحية لأفراد الاسرة \\
\hline 1 & 1.0 & 7 & 10 & ro & AT & $0 \xi$ & $1 \%$ & o & IT & زيادة التعاون بيني وبين أهل قريتي \\
\hline$r$ & $1 . \varepsilon$ & 14 & T1 & Tr & VV & 01 & TKY & $\varepsilon$ & 1. & مكنني المشروع من خدمة أهل قريتي \\
\hline & & & & & & & & & & |ستفادة المجتمعية \\
\hline 1 & 1. & r & זיד & « & 99 & rr & $\mathrm{V} 4$ & 1 & r & |النمطرو الاستهات الصي إلى النمط الإنتاجي النحول من \\
\hline 1 & $1 . \cdot$ & rT & Tr & 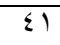 & 99 & rY & VV & 1 & r & المشرو عات الصغيرة تعزز ثقافة الآستثمار \\
\hline 1 & $1 . \cdot$ & TV & $T \varepsilon$ & $\varepsilon r$ & 1.1 & $r \cdot$ & $\mathrm{VT}$ & 1 & $r$ & المشرو عات الصغيرة تبنى ثقافة الادخار \\
\hline r & .9 & TV & TV & $0 \leqslant$ & 149 & 11 & $\leqslant r$ & 1 & r & |القوميرو عات الصغيرة تساعد على تنمية الدخل \\
\hline r & .9 & rq & (I) & «q & $11 \mathrm{~V}$ & r. & $\varepsilon \wedge$ & r & $\varepsilon$ & |الثشاملة و المستدامة الصغيرة تساعد على تحقيق التنمية \\
\hline r & .9 & T & $v \varepsilon$ & $\varepsilon \wedge$ & 117 & r) & 0 . & . & . & |الدر المرو عات الصغيرة تثجع روح وفكر العمل \\
\hline & & & & & & & & & & الاستفادة البيئية \\
\hline$r$ & $1 . \varepsilon$ & 0 & IT & $\leqslant 0$ & 1.9 & «o & $1 . \mathrm{V}$ & 0 & IT & زيادة الاستفادة من المو ارد الييئية المتاحة بالقرية \\
\hline 1 & 1.0 & 0 & ir & $\varepsilon_{0}$ & $1 \cdot 1$ & $\leq 0$ & 1.1 & 0 & IT & |تحوية وآمنةلفات الموجودة بالقرية الى منتجات \\
\hline r & 1. & Tr & $\mathrm{vA}$ & $\varepsilon$. & 90 & rT & 07 & 0 & 11 & المعتمدة على الخامات المناء المشروة في البيئة الثية \\
\hline r & 1. & $\mu$ & vi & «1 & 99 & r & $0 \leqslant$ & 0 & 11 & |الاسهرام في الحد من التلوث البيئي و انتشار \\
\hline
\end{tabular}

المصدر : إستمارة الإسنبيان 


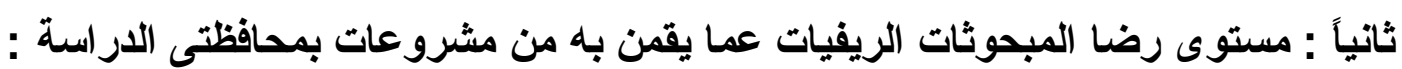

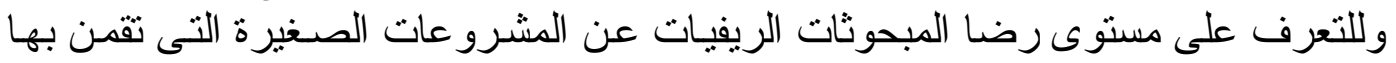

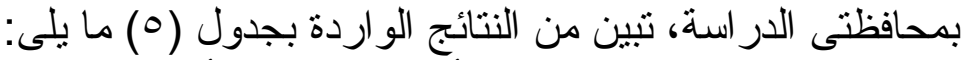

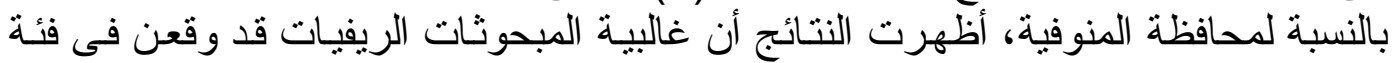

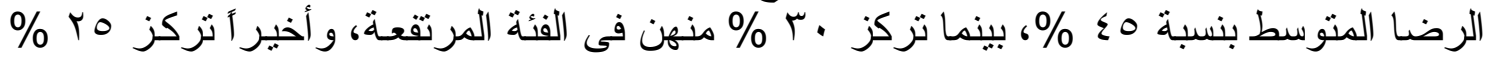

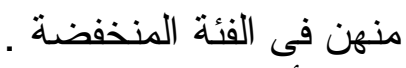
أما بالنسبة لمحافظة الشرقية بينت النتائج أن غالبية المبحوثات الريفيات قد وقعن فئ في الفئة

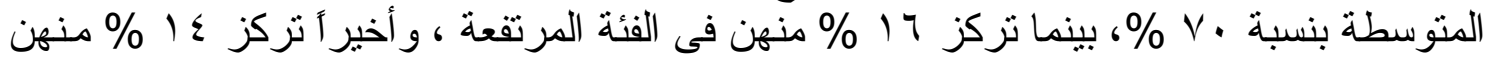

في الفئة المنخفضة. جدول هـ مستوى رضا المبحوثات الريفيات عن المشروعات الصغيرة التى تقمن بها بمحافظتى الدراسة

\begin{tabular}{|c|c|c|c|c|}
\hline \multicolumn{2}{|c|}{ محافظة الشرقية } & \multicolumn{2}{|c|}{ محافظة المنوفية } & مستوى رضا المبحوثات الريفيات عن \\
\hline$\%$ & ع عدد ن = r & $\%$ & عاد ن = • ع r & المشروعات الصغيرة التى تقمن بها \\
\hline $1 \leqslant$ & Tr & ro & 7. & منخفض ( V- I (I) درجة \\
\hline V. & $17 \mathrm{~V}$ & $\leqslant 0$ & 1.1 & متوسط ( Y IV_) درجة \\
\hline 17 & $\varepsilon$. & r. & VY & مرتفع ( ^ا درجة فأكثر ) \\
\hline
\end{tabular}

المصدر: إستمارة الإستبيان

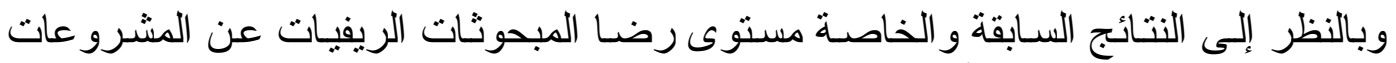

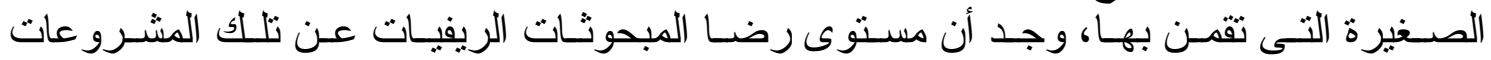

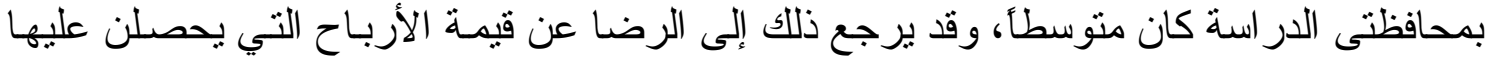

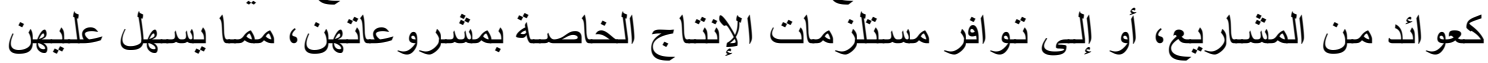

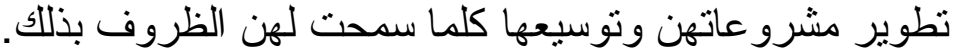

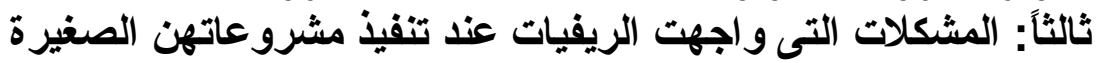

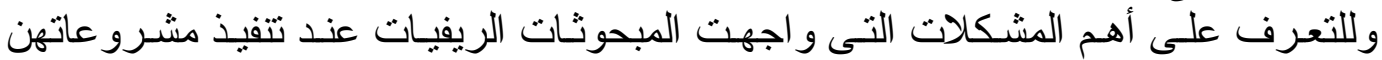

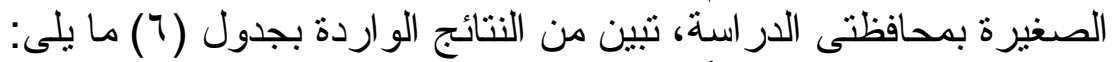
ا 1

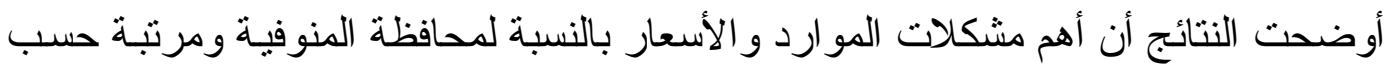

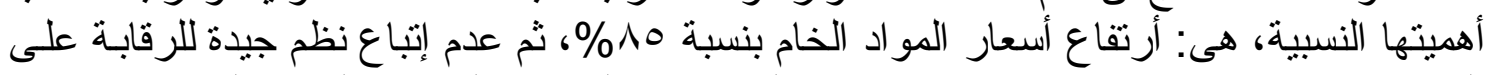

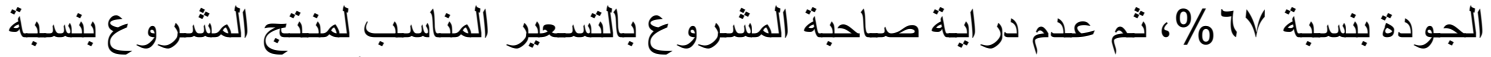

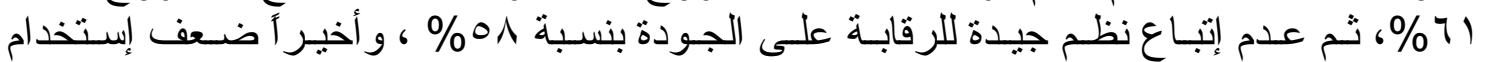

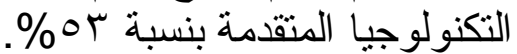

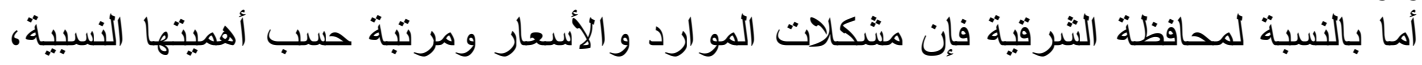

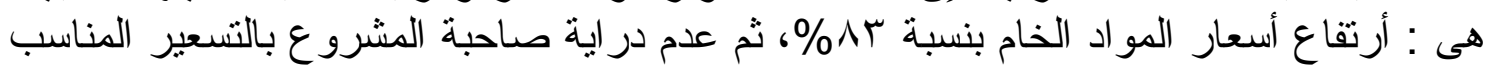

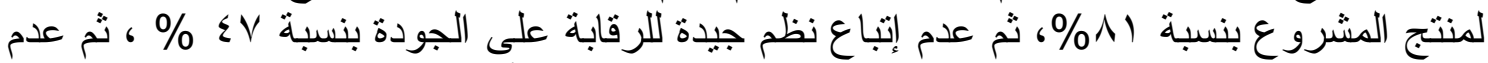

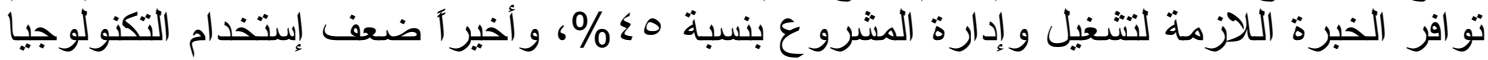

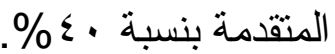
r

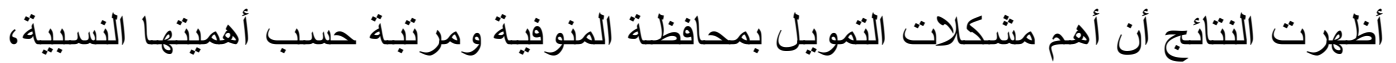

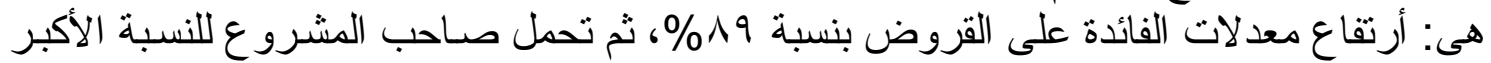

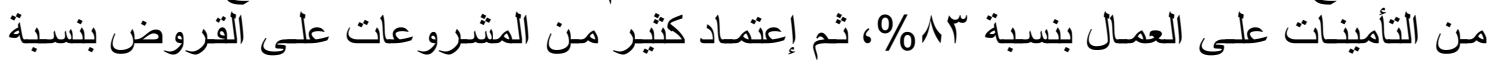

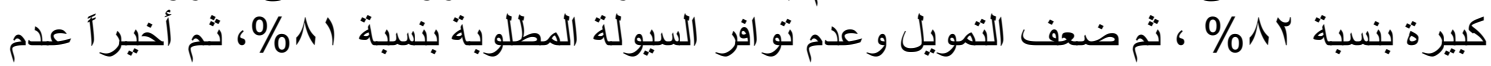

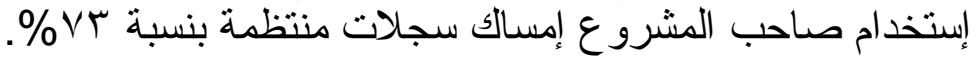




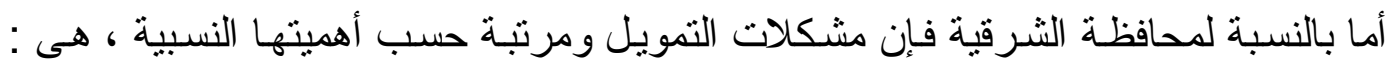

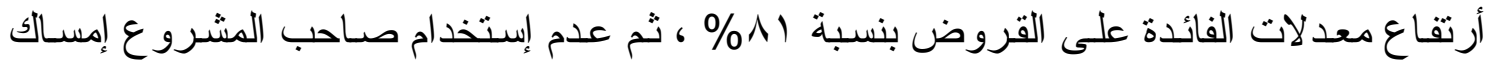

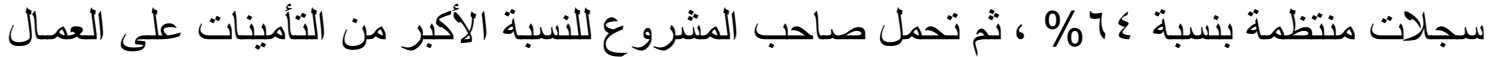

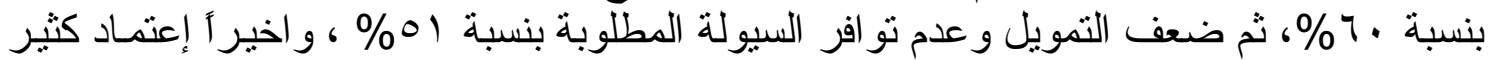

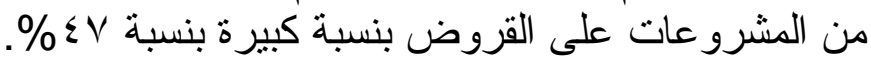
r - المشكلات المرتبطة بإختبار ات وتقيبيم العمالة:

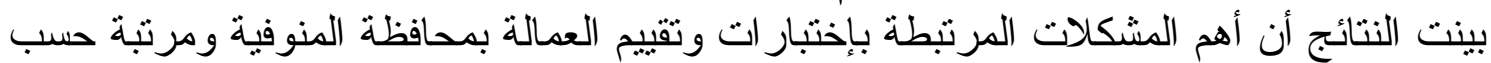

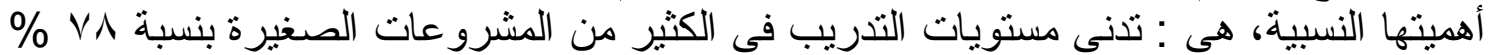

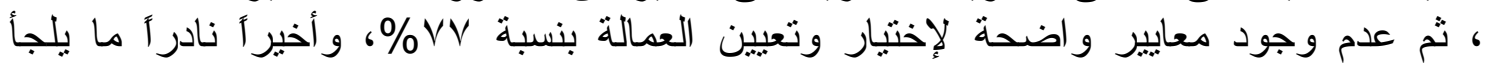

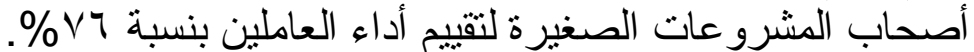

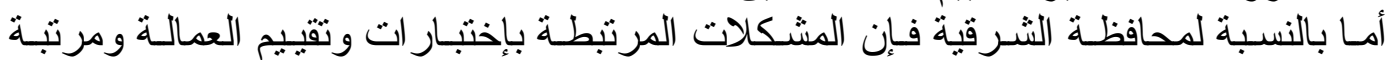

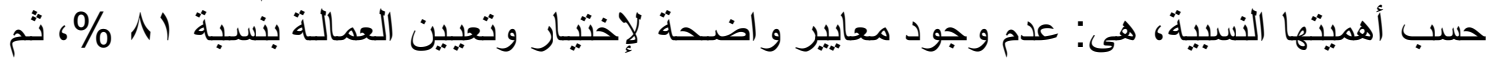

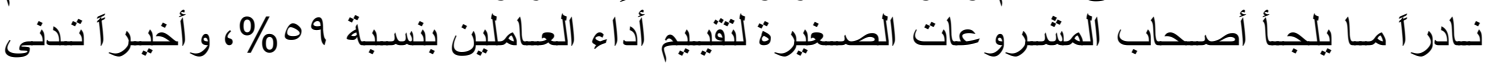

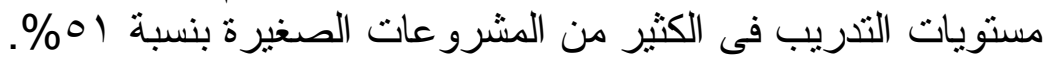
؛ - المشكلات المتعلقة بالتسويقي:

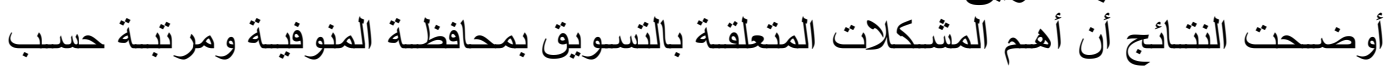

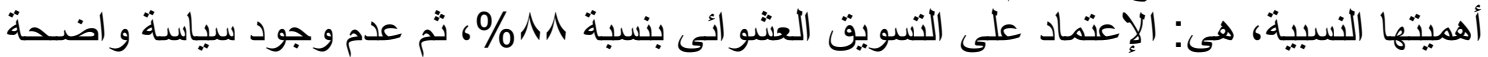

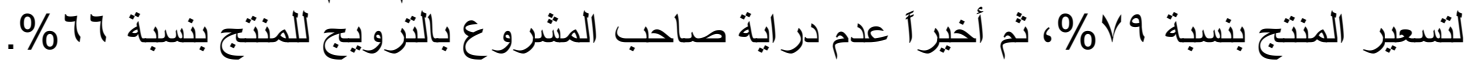

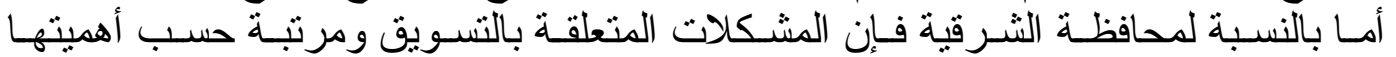

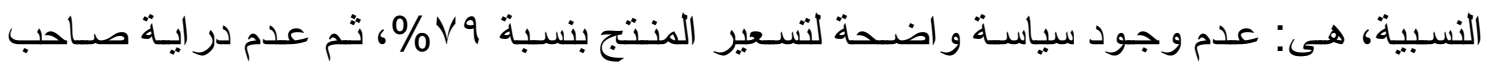

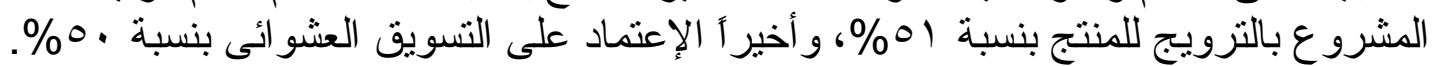

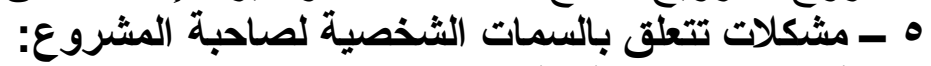

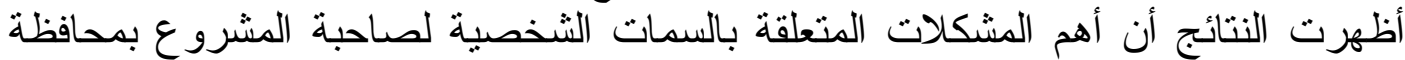

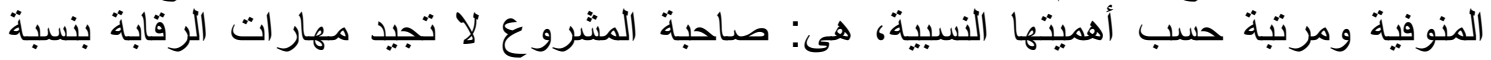

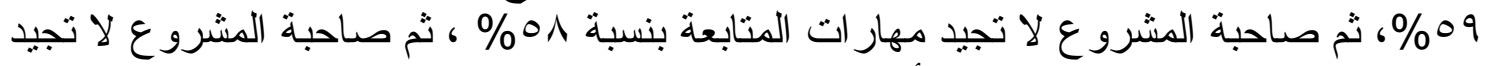

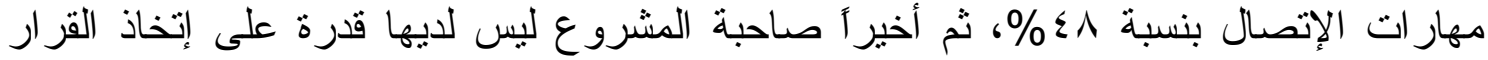

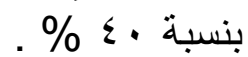

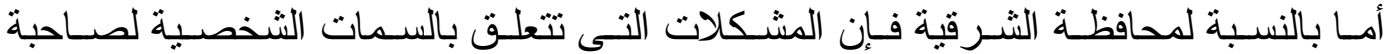

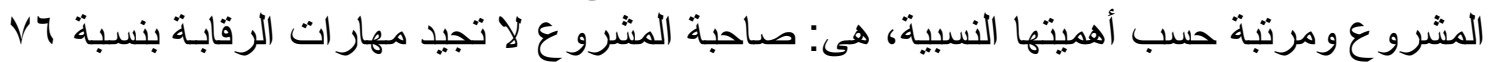

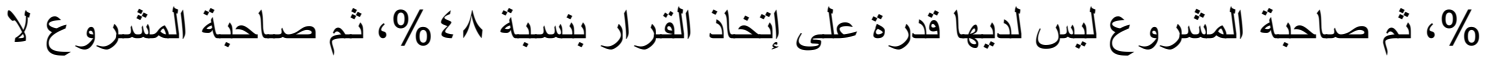

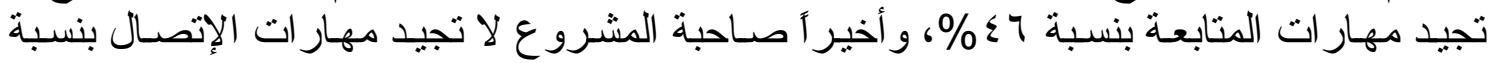
\% Tr 
جدول 1 ـ. المشكلات التى واجهت الريفيات عند تنفيذ مشروعاتهن الصغيرة بمحافظتى الدراسة

\begin{tabular}{|c|c|c|c|c|c|c|c|c|c|}
\hline \multicolumn{4}{|c|}{ محافظة الثرقية } & \multicolumn{4}{|c|}{ محافظة المنوفية } & \multirow{2}{*}{ |المشكلات التى واجهت الريفيات عند تنفيذ مشروعاتهن } & \\
\hline \multicolumn{2}{|r|}{$y$} & \multicolumn{2}{|c|}{ نعم } & \multicolumn{2}{|c|}{$y$} & \multicolumn{2}{|c|}{ نعم } & & \\
\hline$\%$ & عدد & $\%$ & عدد & $\%$ & عدد & $\%$ & عدد & |أولاٍ : مشكلات الموارد والأسعار & \\
\hline 00 & $1 \% 1$ & $\leqslant 0$ & 1.9 & $2 v$ & 115 & or & rᄉ & عدم تو افر الخبرة اللازمة لنشغيل و إدارة المشروع. & 1 \\
\hline iv & $\varepsilon Y$ & $\Lambda T$ & 191 & 10 & rV & 10 & 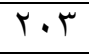 & أرتفاع أسعار المو اد الخام. & r \\
\hline 19 & $\Sigma 7$ & A) & $19 \varepsilon$ & rq & 94 & 71 & $1 \leq V$ & المشروم در ايـة صـاحب المشـروع بالتسـعير المناسـب لمنتـتج & $\bar{r}$ \\
\hline or & ITV & $\sum V$ & $11 \pi$ & r & $\Lambda$. & $7 \mathrm{~V}$ & 17. & عدم إتباع نظم جيدة للرقابة على الجودة. & $\varepsilon$ \\
\hline$V \varepsilon$ & 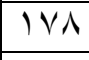 & $r 7$ & TY & $\sum r$ & $1 \cdots$ & $0 \wedge$ & $1 \leqslant$. & ضعف إستخدام التكنولوجيا المتقدمة. & 0 \\
\hline & & & & & & & & |ثانياً : مشكلات التمويل: & \\
\hline$\varepsilon 9$ & $11 \mathrm{~V}$ & 01 & ITr & 19 & $\leqslant 0$ & A) & 190 & ضعف التمويل وعدم تو افر السيولة المطلوبة. & 1 \\
\hline 19 & $\leqslant 7$ & 人) & $19 \varepsilon$ & 11 & Y4 & 19 & $1 \leq \varepsilon$ & أرتفاع معدلات الفائدة على القروض. & r \\
\hline 4 & $\Lambda V$ & $7 \varepsilon$ & 104 & YV & 70 & $\mathrm{VT}$ & 180 & عدم إستخدام صاحب المشروع إمساك سجلات منتظمة. & 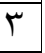 \\
\hline r & IYA & $\varepsilon V$ & 114 & 11 & $\varepsilon \varepsilon$ & Ar & 197 & إعتماد كثير من المشرو عات على القروض بنسبة كبيرة & $\varepsilon$ \\
\hline$\varepsilon$. & $9 \mathrm{~V}$ & 7. & $1 \leq r$ & IV & $\varepsilon Y$ & $\Lambda \mu$ & 191 & |العمال. ـماحل صشرو ع للنسبة الأكبر من التأمينات على & \\
\hline & & & & & & & & |ثالثاً : مشكلات مرتبطة بإختبار ات وتقييم العمالة : & \\
\hline «1 & 91 & 09 & $1 \leqslant r$ & $r \varepsilon$ & 01 & V & IAr & 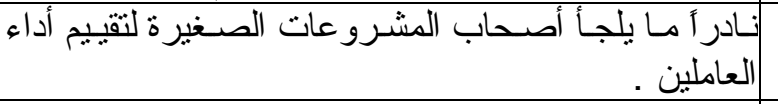 & \\
\hline 19 & $\leqslant 7$ & NI & $19 \varepsilon$ & TT & 07 & VV & $\Lambda \varepsilon$ & عدم وجود معايير و اضحة لإختيار وتعيين العمالة. & r \\
\hline$\varepsilon 9$ & $11 \mathrm{~V}$ & 01 & Tr & TY & $0 \leqslant$ & AV & $1 \wedge 7$ & 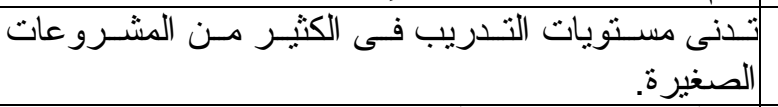 & r \\
\hline & & & & & & & & |رابعاً : مشكلات متعلقة بالتسويق : & \\
\hline 0 . & $|r|$ & 0 . & 119 & IT & rᄉ & $\Lambda \Lambda$ & rit & الإعتماد على التسويق العثو ائى. & \\
\hline Y) & 01 & Vq & 119 & TI & 0. & 19 & 19. & عدم وجود سياية واضحة لتسعير المنتج. & r \\
\hline$\varepsilon 9$ & 111 & 01 & Mr & ए乏 & Ar & 77 & 101 & |عدم در اية صاحب المشروع بالتزويج للمنتج. & $r$ \\
\hline & & & & & & & & |لمشروعـاً: مشـكلات تتعلـق بالســـات الشخصـية لصـاحبة & \\
\hline$v T^{\mu}$ & $1 \mathrm{VI}$ & rV & $7 \varepsilon$ & or & IrE & $\varepsilon \wedge$ & 117 & صاحبة المشروع لا تجيد مهار ات الإتصال . & \\
\hline $0 \leqslant$ & 149 & $\sum 7$ & 111 & $\sum r$ & $1 \cdot 1$ & 01 & 1199 & صاحبة المشروع لا تجيد مهار ات المتابعة. & r \\
\hline$r \varepsilon$ & 01 & VT & INY & $\varepsilon$ & 99 & 09 & $1 \leq 1$ & صاحبة المشروع لا تجيد مهار ات الرقابة. & \\
\hline or & $1 \times 4$ & $\leqslant \wedge$ & $11 \varepsilon$ & 7. & $1 \leq \varepsilon$ & $\varepsilon$. & 97 & |صاحبة المشروع ليس لديه قدرة على إتخاذ القر ار . & \\
\hline
\end{tabular}

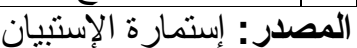

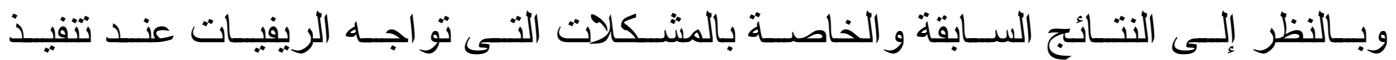

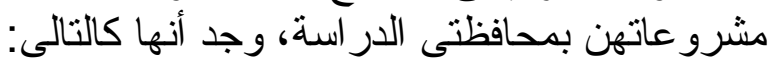

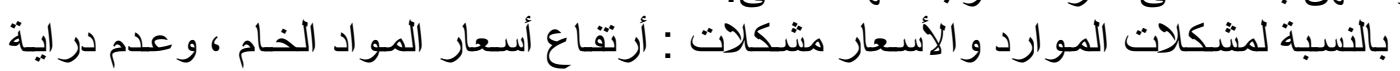

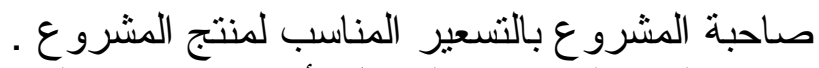

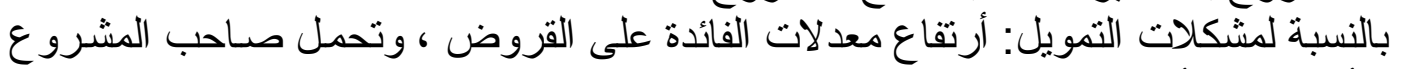

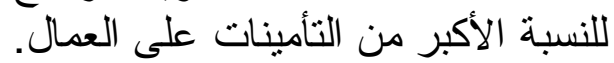

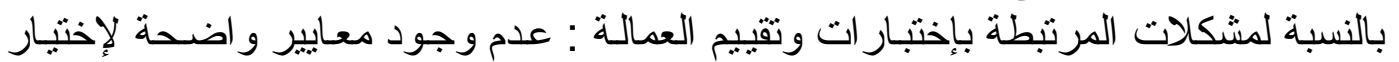
وتعيين العمالة ، ونادر آ ما يلجأ أصحاب المشرو عات الصات الصغيرة لتقييم أداء العاملين .

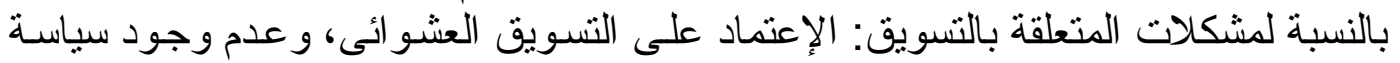
و اضحة لتسعير المنتج، و عدم در اية صاحب الفئل المشروع باللترويج للمنتج. 


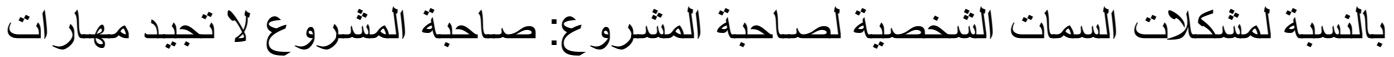

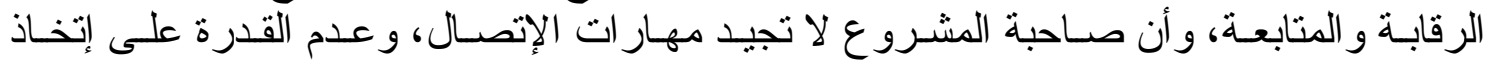

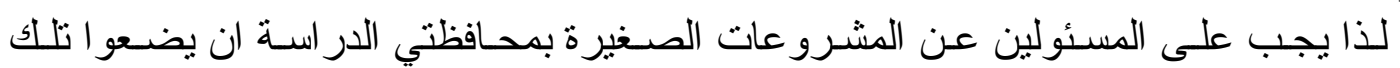

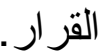

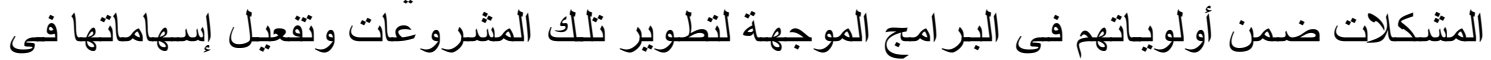

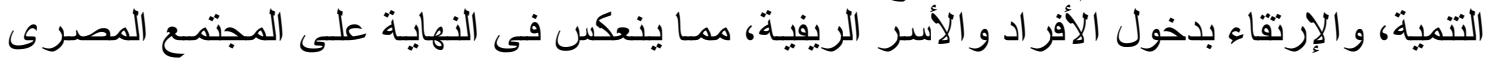

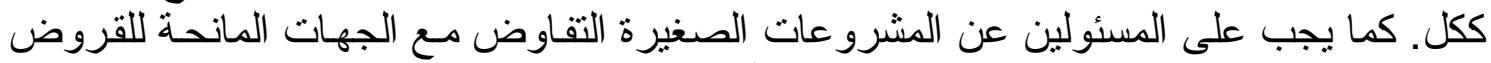

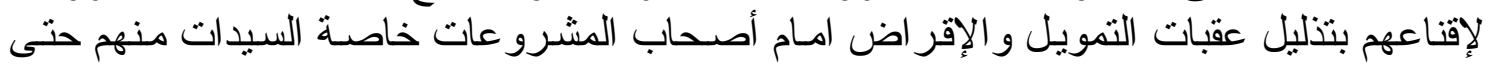

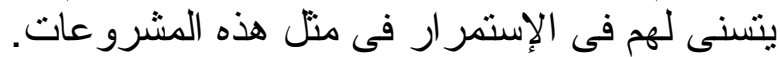
رابعاً : المتطلبات اللازمة لنجاح المشروعات النات الصغيرة:

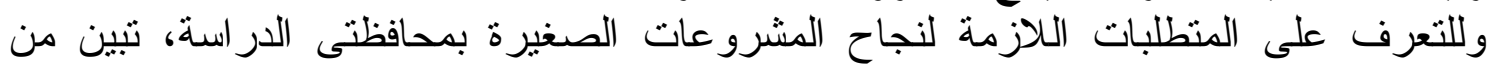

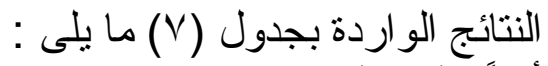

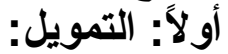

أظهرت النتائج أن أهم منطلبات التمويل بمحافظة المنوفية ومرتبـة حسب أهميتها النسبية،

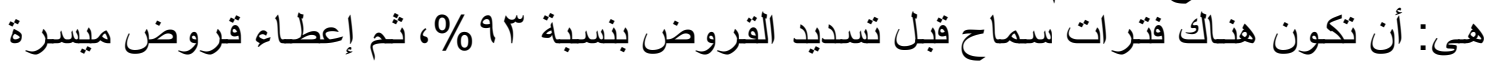

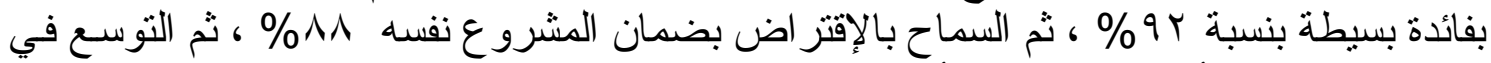

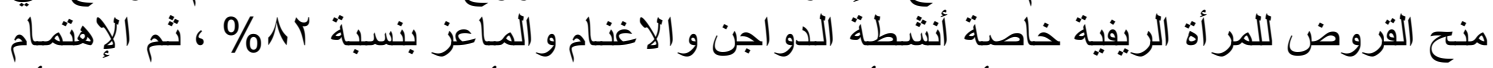

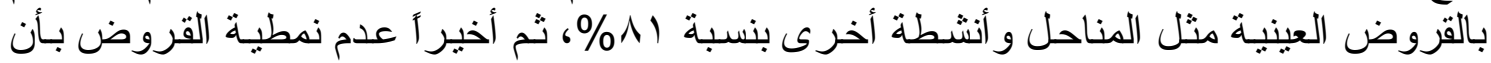

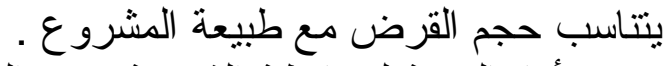

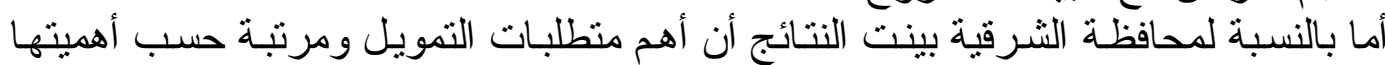

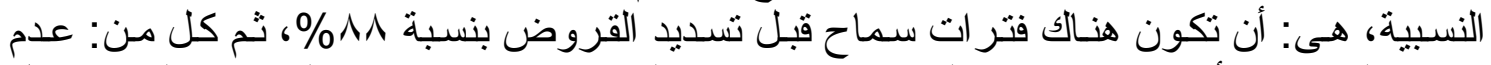

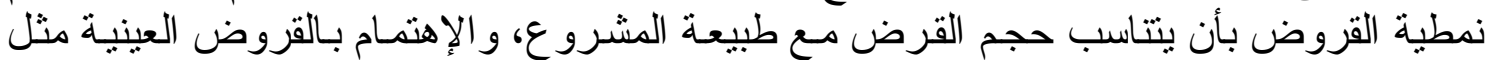

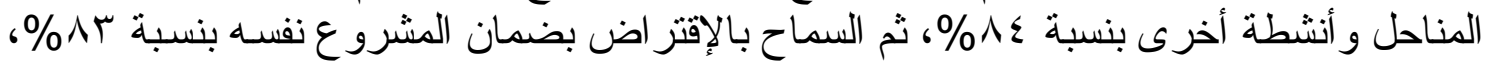

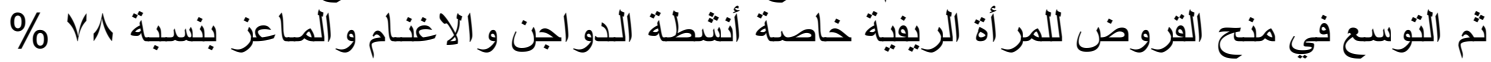

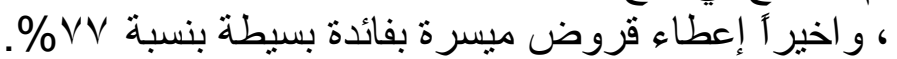

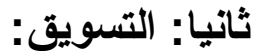
أظهرت النتائج أن أهم منطلبات التسويق بمحافظة المنوفيـة ومرتبة حسب أهميتها النسبية،

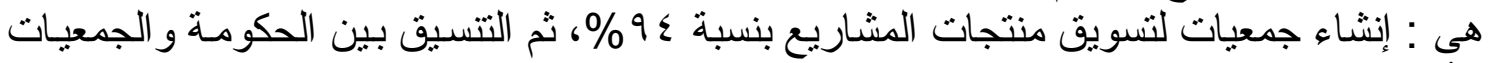

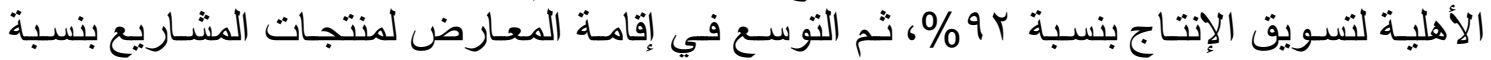

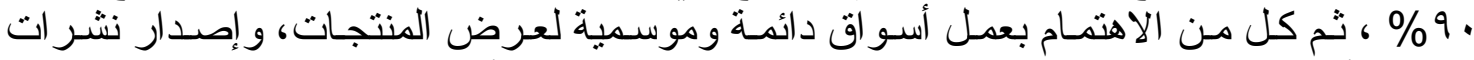

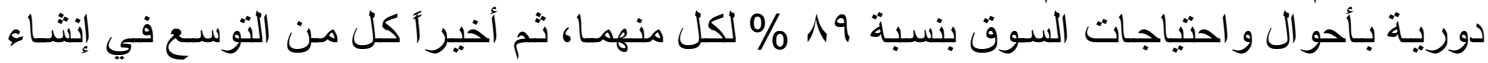

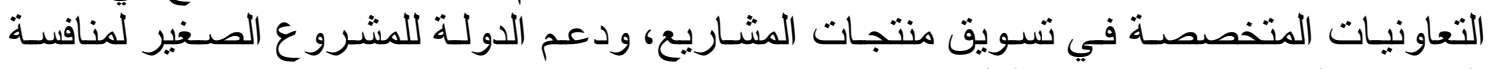

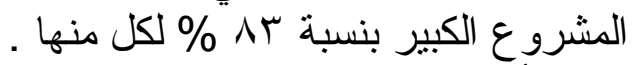
أما بالنسبة لمحافظة الثرقية بئة بينت النتائج أن أهم متطلبات النسويق ومرنبة حسب أهميتها

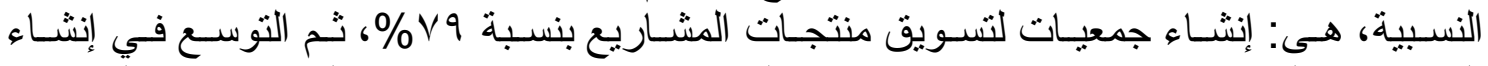

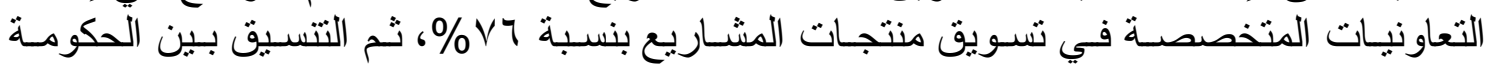

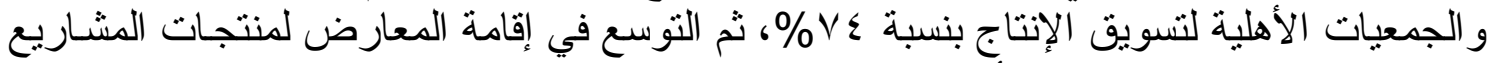

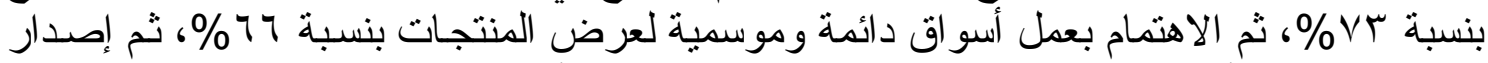

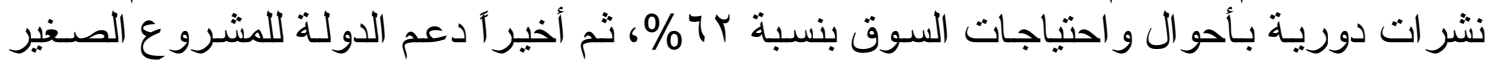
لمنافسة المشروع الكبير بنسبة 09\%. 


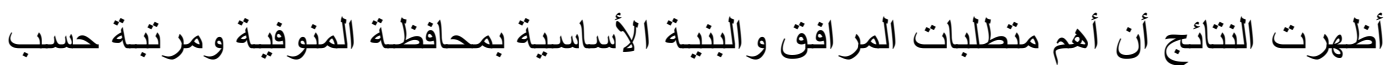

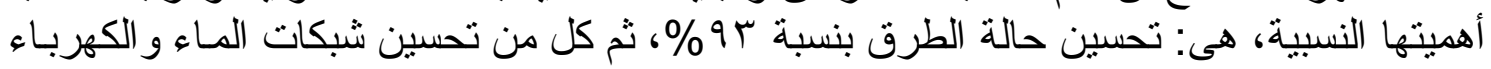

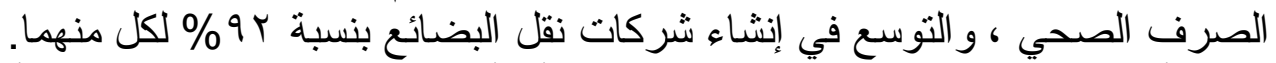

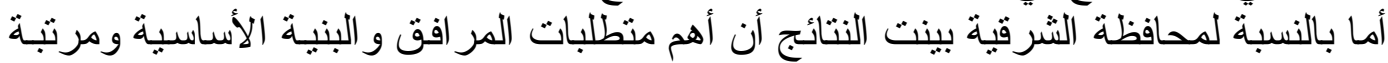

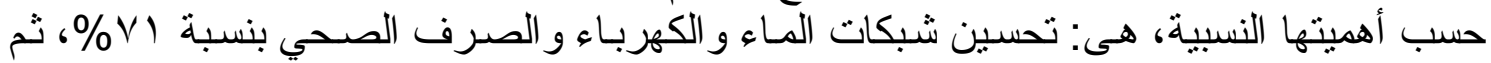

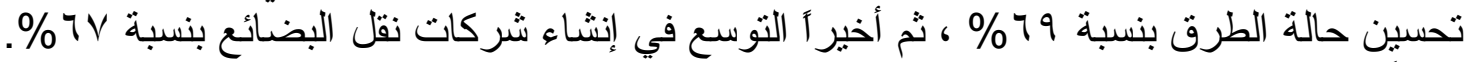

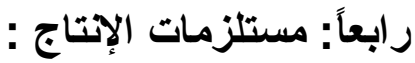

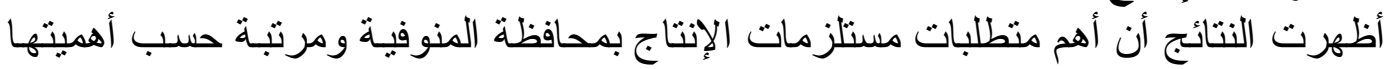

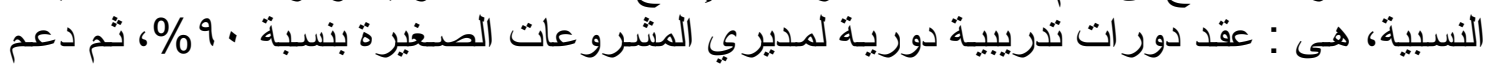

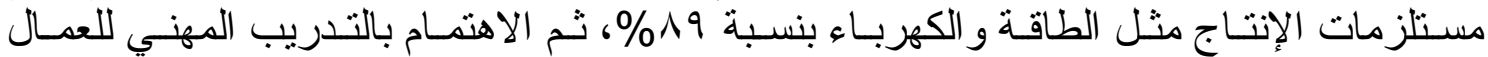

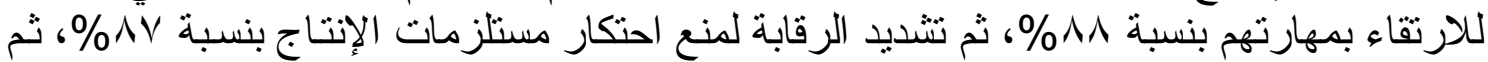

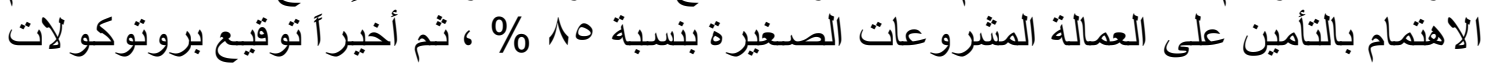

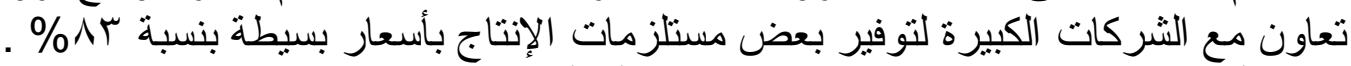

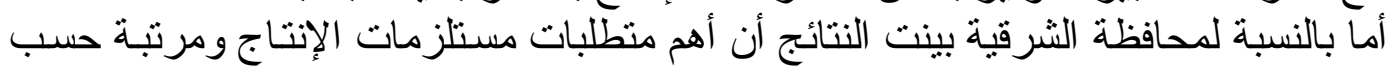

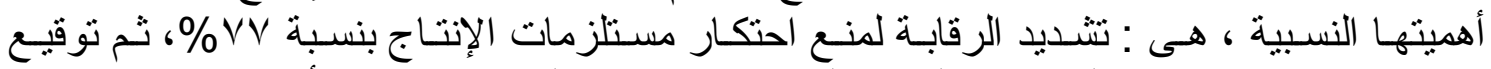

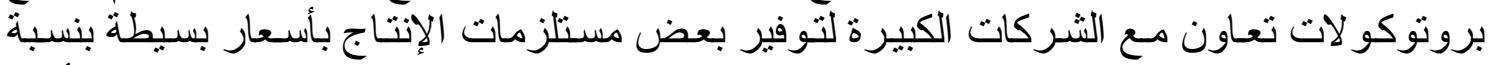

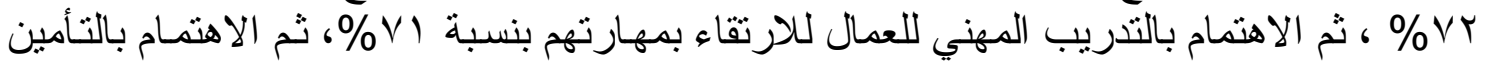

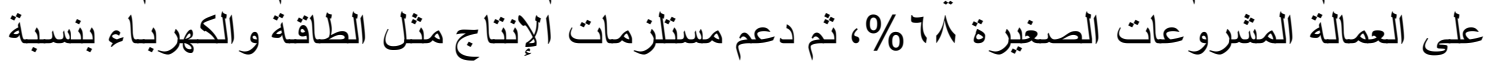

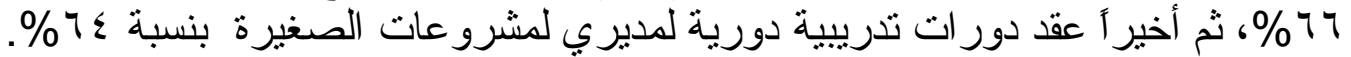
خامساً: التر اخيص :

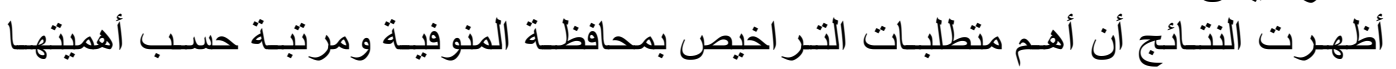

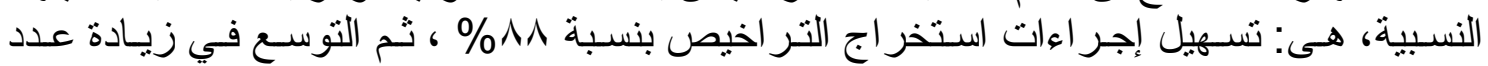

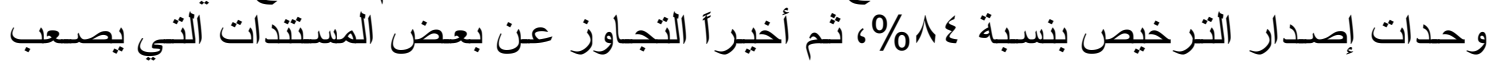

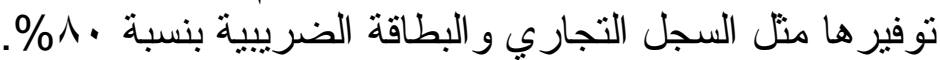

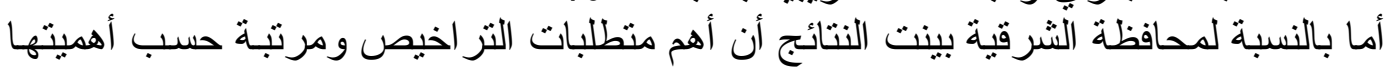

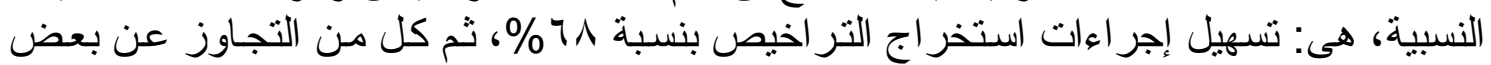

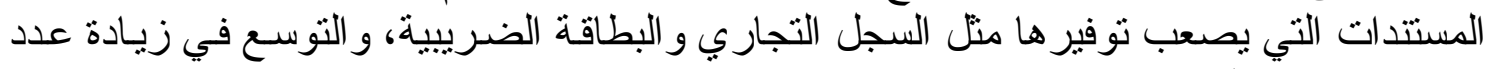

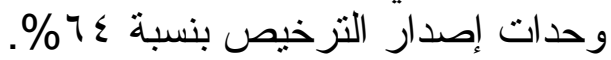

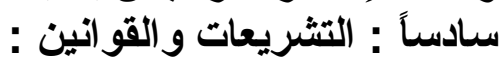

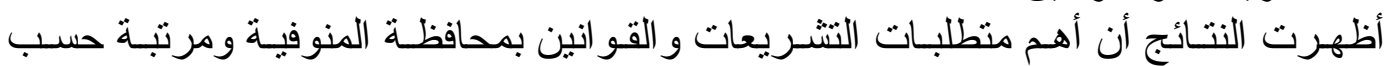

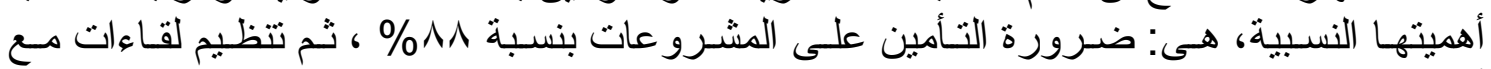

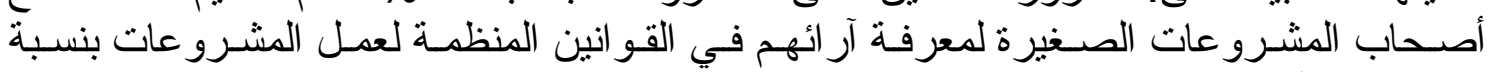

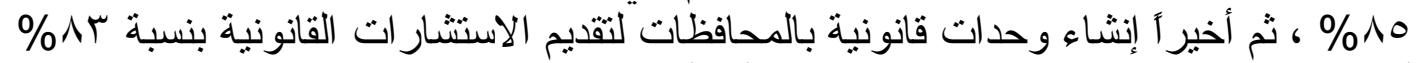

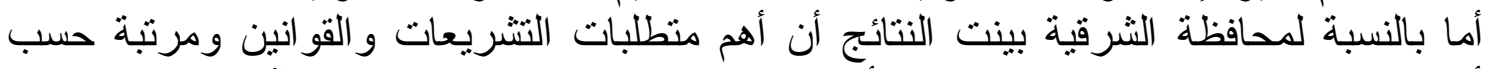

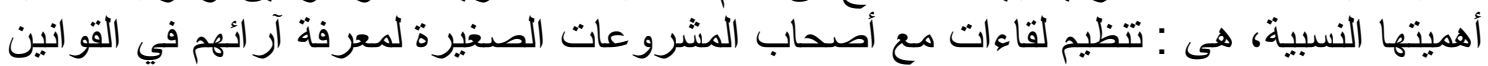

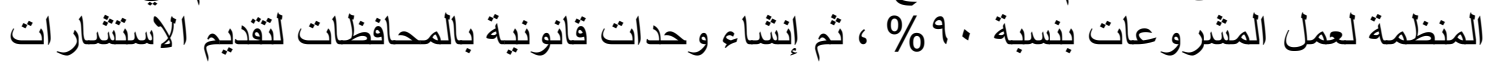

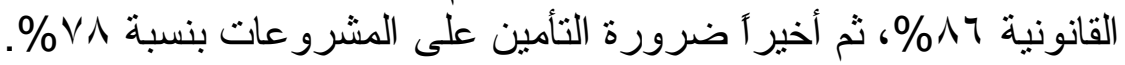

جدول V. المتطلبات اللازمة لنجاح المشروعات الصغيرة من وجهة نظر الريفيات بمحافظتى الدراسة

\begin{tabular}{|c|c|c|c|c|c|c|c|c|c|}
\hline \multirow{2}{*}{\multicolumn{4}{|c|}{ محافظة الشرقية }} & \multirow{2}{*}{\multicolumn{4}{|c|}{ محافظة المنوفية }} & \multirow{3}{*}{ المتطلبات الللزمة لنجاح المشروعات الصغيرة } & \\
\hline & & & & & & & & & \\
\hline \multicolumn{2}{|c|}{$y$} & \multicolumn{2}{|c|}{ نعم } & \multicolumn{2}{|c|}{$y$} & \multicolumn{2}{|c|}{ نعم } & & \\
\hline$\%$ & عدد & $\%$ & عدد & $\%$ & عدد & $\%$ & عدد & |أولاً : التمويل : & \\
\hline$\overline{Y T}$ & 07 & $V V$ & $1 \wedge \varepsilon$ & $\Lambda$ & 19 & 94 & TYI & إعطاء قروض ميسرة بفائدة بسيطة & 1 \\
\hline
\end{tabular}


Assiut J. Agric. Sci., 50 (4) 2019 (265-291)

ISSN: 1110-0486

Website: www.aun.edu.eg/faculty_agriculture/journals_issues_form.php E-mail:ajas@aun.edu.eg

\begin{tabular}{|c|c|c|c|c|c|c|c|c|c|}
\hline 17 & rᄉ & $\Lambda \varepsilon$ & r & זr & 00 & VV & 110 & علدم نمطية القروض بأن يتناسب حجم القرض مع طبيعة المشروع & r \\
\hline Tr & rq & & 1 & $\mathrm{~V}$ & IV & 9 & Tr & أن تكون هناك فتر ات سماح قبل تسديد القروض & \\
\hline 17 & $r \wedge$ & & r & 9 & 7 & (1) & $9 \varepsilon$ & الإهتمام بالقروض العينية منل المناحل و أنشطة أخرى. & $\xi$ \\
\hline IV & \&1 & & 99 & Tr & $r$ r. & 1 & 1. & اللسماح بالإقتر اض بضمان المشروع نفسه & 0 \\
\hline \multirow[t]{2}{*}{ rY } & r & & $\overline{\Lambda N}$ & $\Lambda$ & $\varepsilon$ & Tr & 97 & 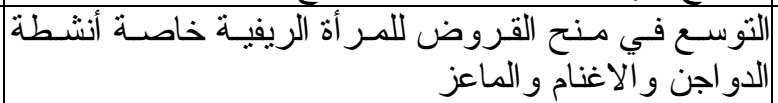 & 7 \\
\hline & & & & & & & & |ثانياً : التسويق : & \\
\hline rT & T & $\varepsilon$ & NV & $\Lambda$ & . & 94 & Tr. & الالتتسيق بين الحكومة و الجمعيات الأهلية لتسويق الإنتاج & 1 \\
\hline TV & 70 & & Vo & $1 \cdot$ & 10 & 9. & $\$ 10$ & اللتوسع في إقامة المعارض لمنتجات المشاريع & $r$ \\
\hline Y) & 0 . & & 9. & 7 & $1 \leqslant$ & $9 \leq$ & rq & إنشاء جمعيات لتسويث منتجات المشاريع & $r$ \\
\hline$T \xi$ & ov & & $\overline{\Lambda T}$ & IV & \& & & 91 & |المشاريع في إنشاء التعاونيات المتخصصة في تسويق منتجات & $\varepsilon$ \\
\hline$\Gamma \varepsilon$ & r & & $2 \wedge$ & & & & 14 & الاهتمام بعمل أسو اق دائمة وموسمية لعرض المنتجات & 0 \\
\hline$\Sigma 1$ & 99 & & «1 & IV & \&1 & "גו & 99 & دعم الدولة للمشروع الصغير لمنافسة المشروع الكبير & 7 \\
\hline \multirow[t]{2}{*}{ rᄉ } & $r$ & & $\varepsilon \wedge$ & & & & & إصدار نشر ات دورية بأحو ال و احتياجات السوق & $\mathrm{V}$ \\
\hline & & & & & & & & |ثالثاً : المرافق والبنية الأساسية : & \\
\hline rq & 79 & & V) & $\Lambda$ & $r$. & 94 & $r$ r. & تحسين شبكات الماء و الكهرباء و الصرف الصحي & 1 \\
\hline r) & $V \varepsilon$ & & 17 & $\mathrm{~V}$ & 17 & qu & $r \varepsilon$ & تحسين حالة الطرق & r \\
\hline \multirow[t]{2}{*}{ r } & $\mathrm{vq}$ & $\mathrm{V}$ & 7) & $\Lambda$ & 19 & 94 & Y & التوسع في إنشاء شركات نقل البضائع & r \\
\hline & & & & & & & & |رابعاً : مستلزمات الإتتاج : & \\
\hline$r \varepsilon$ & Al & 77 & 109 & 11 & YV & 19 & 14 & دعم مستلزمات الإنتاج منل الطاقة و الكهرباء & 1 \\
\hline TA & $7 V$ & r & $v^{\top}$ & IV & $\sum Y$ & Nr & 91 & |توضيع برونتوكو لات الإنتاج بأسعار مع الثركات الكبيرة لتوفير & r \\
\hline rT & 00 & & 10 & & & V & & تشنديد الرقابة لمنع احتكار مستلزمات الإنتاج & $r$ \\
\hline rq & 79 & 1 & VI & IT & rq & $\wedge \wedge$ & 11 & الالهتمام بالتدريب المهني للعمال للارتقاء بمهارتهم & $\varepsilon$ \\
\hline rT & $\bar{\Lambda} \mathrm{V}$ & & Or & $1 \cdot$ & ro & 9. & 10 & عقد دور ات تدرييية دورية لمدير ي المشرو عات الصغير & 0 \\
\hline \multirow[t]{2}{*}{ rr } & $\vee \wedge$ & 1 & Tr & 10 & ro & 10 & .0 & الاهتمام بالتأمين على العمالة المشروعات الصغيرة & 7 \\
\hline & & & & & & & & |خامساً : التراخيص : & \\
\hline rr & VV & $7 \Lambda$ & r & 15 & ra & $\lambda \wedge$ & & تنسهيل إجر اءات استخر اج التز اخيص & 1 \\
\hline r & 1 & $7 \varepsilon$ & $10 \leqslant$ & $r \cdot$ & $\varepsilon V$ & $\Lambda$. & 94 & |التجاوز عن بعض النجاري والبطاقة الضريبية التي يصعب توفير ها منل & r \\
\hline \multirow[t]{2}{*}{ rq } & $\Lambda 7$ & $7 \varepsilon$ & פ & 16 & 19 & $\lambda z$ & & التوسع في زيادة عدد وحدات إصدار التزخيص & $r$ \\
\hline & & & & & & & & سادساً : التثريعات و القو انين : & \\
\hline YY & or & N & IV & 15 & r. & $\lambda \wedge$ & 11. & ضرورة التأمين على المشرو عات & 1 \\
\hline $1 \cdot$ & ro & 9. & Y10 & 10 & ro & 10 & Y.O & 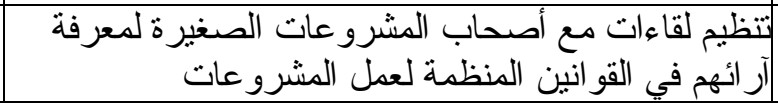 & \\
\hline $1 \varepsilon$ & $r \varepsilon$ & 17 & $r . T$ & IV & 21 & $\Lambda r$ & 191 & |أنشاءونية. & \\
\hline
\end{tabular}

المصدر: إستمارة الإستيبان

وبـالنظر إلى النتائج السـابقة و الخاصـة بمتطلبـات نجـاح المشـرو عات الصــيرة بمحسافظتى

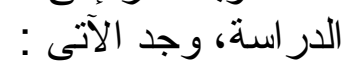
ـ أن أهم منطلبـات التمويل: أن تكون هناك فتر ات سماح قبل تسديد القروض، و إعطاء قروض

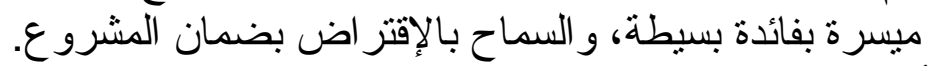

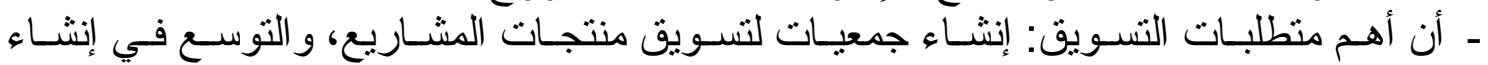

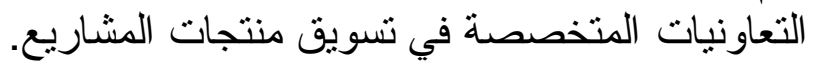


ـ أن أهــ متطلبـات المر افـق و البنيـة الأساسـية: تحسـين حالـة الطـرق، وتحسـين شـبكات المـاء

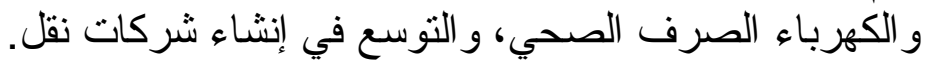

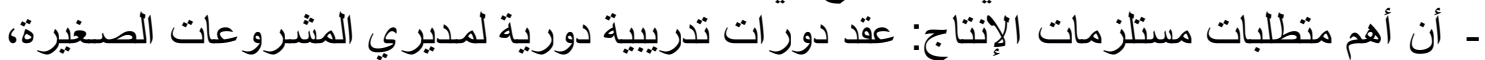

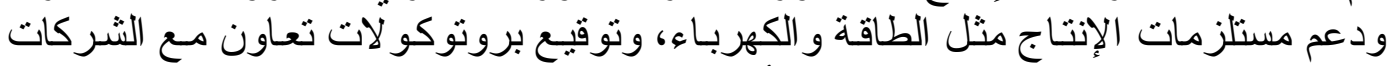

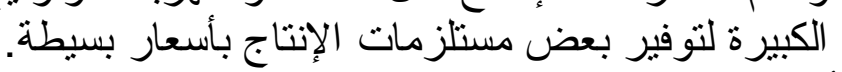

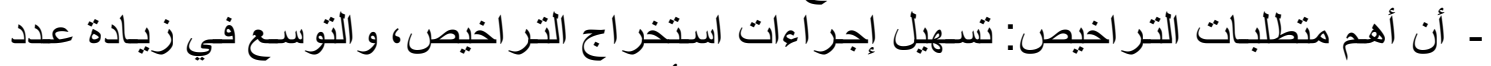

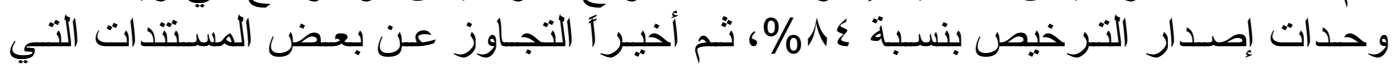
يصعب توفير ها مثل السجل التجاري و البطاقة الضريبية.

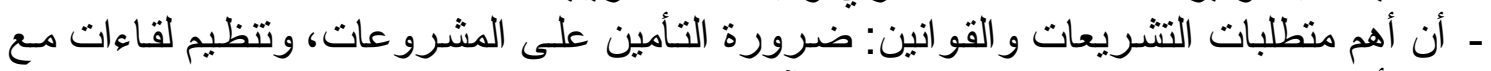

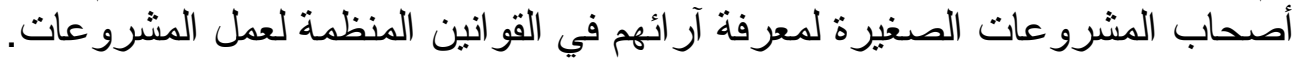

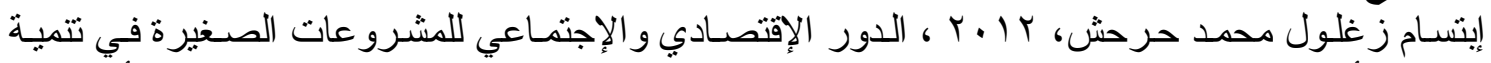

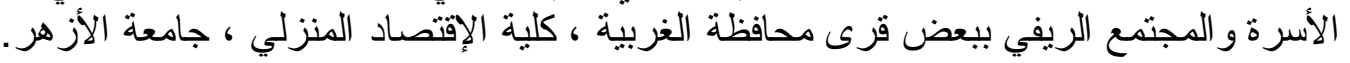

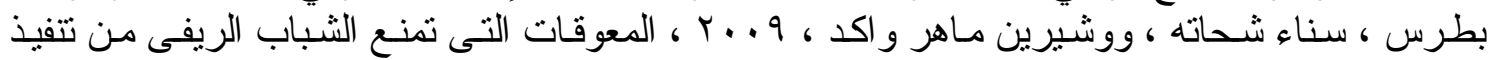

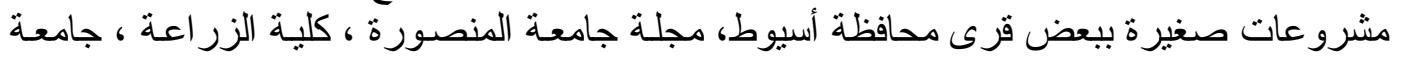

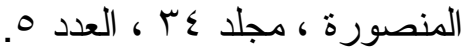

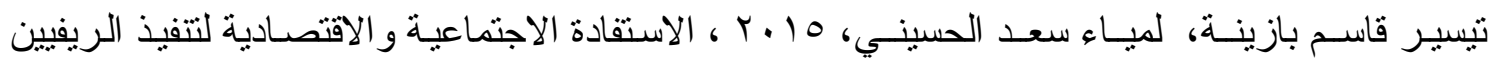

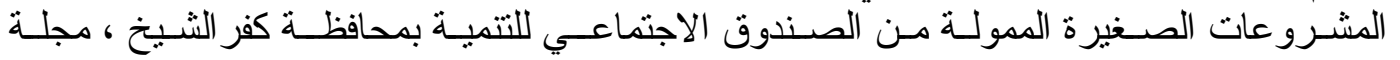

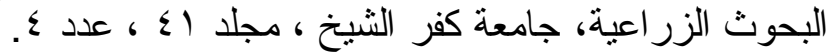

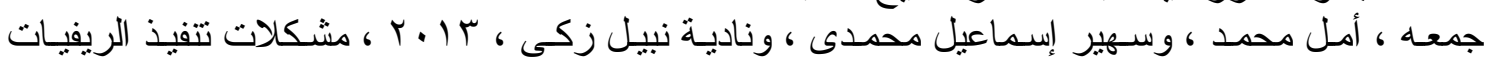

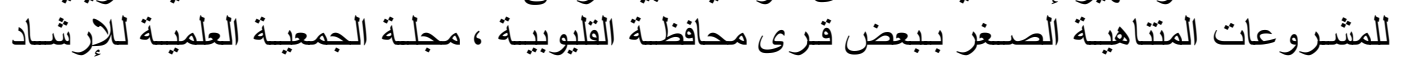

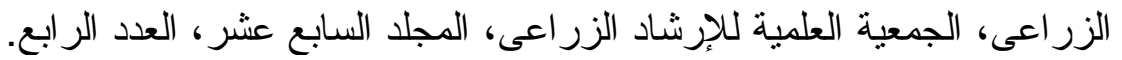

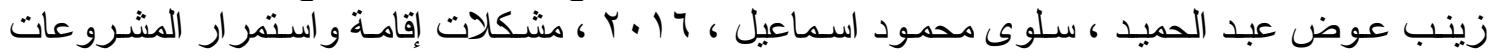

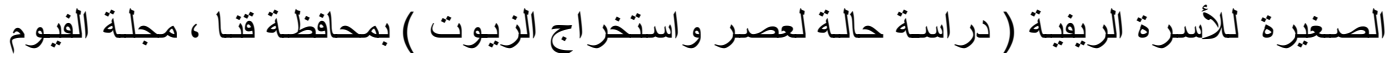

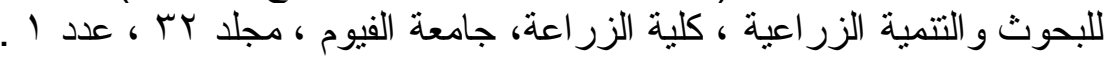

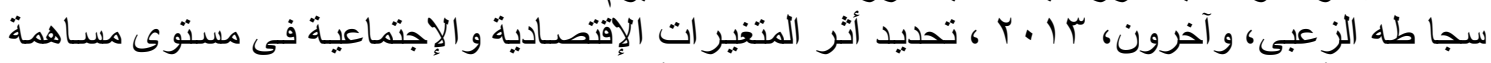

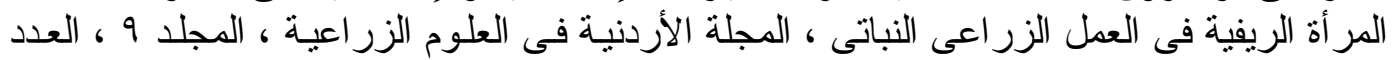

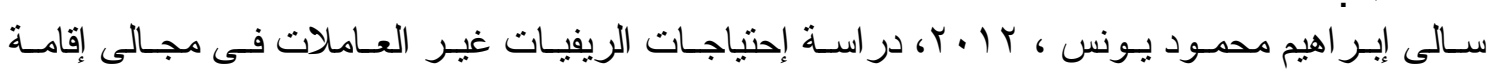

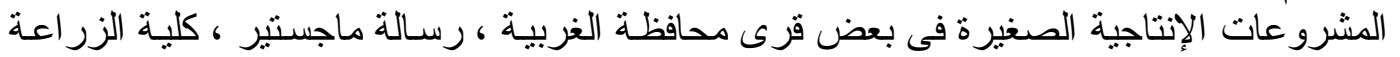

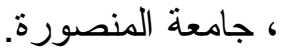

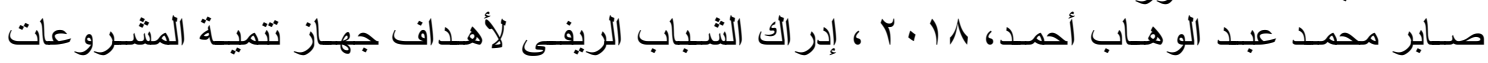

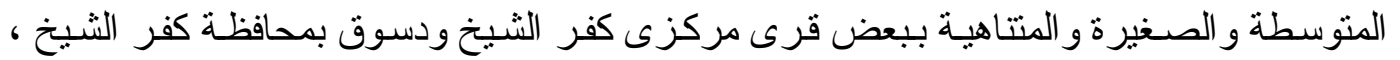

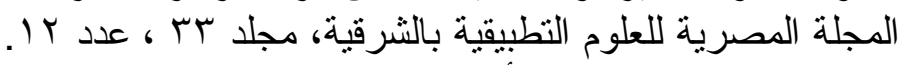

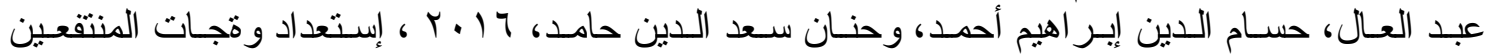

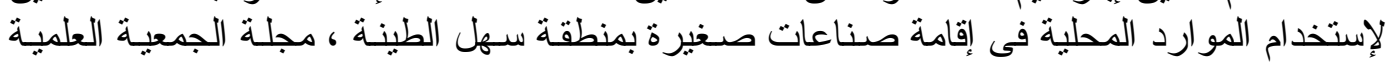

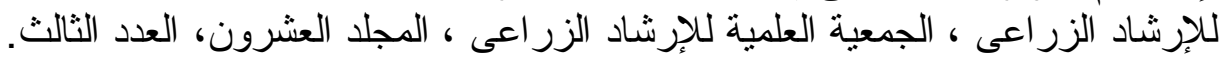

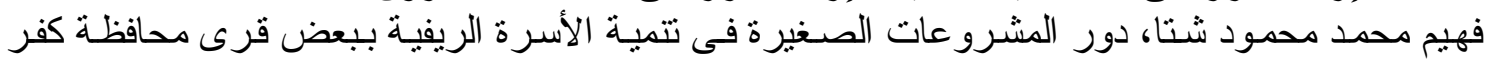

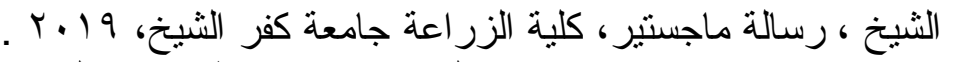

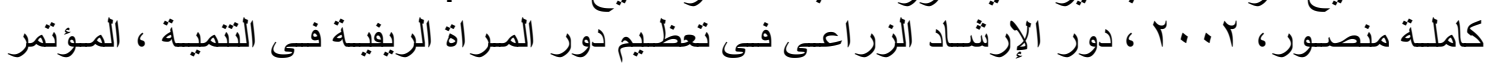

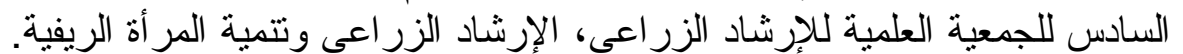

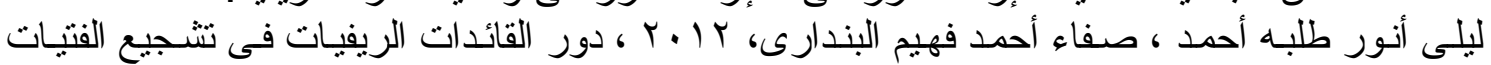

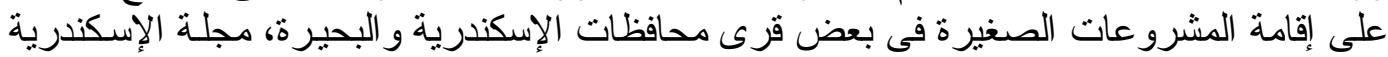

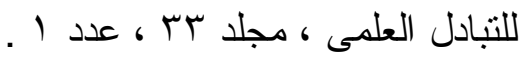




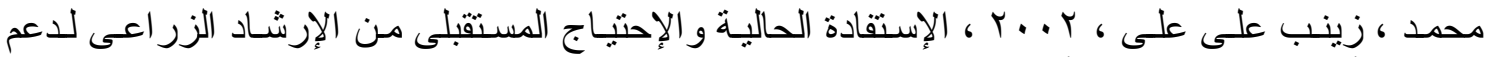

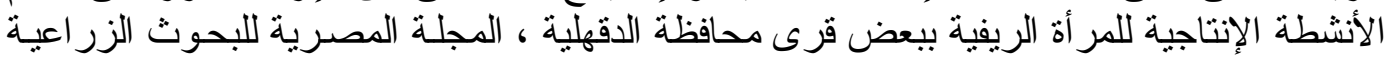

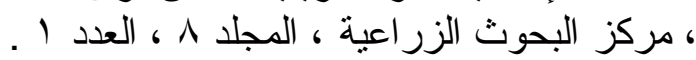

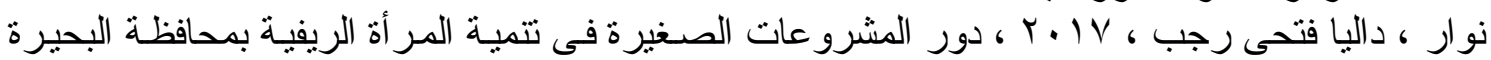

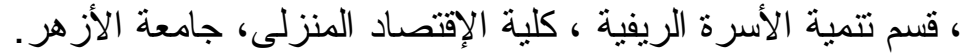

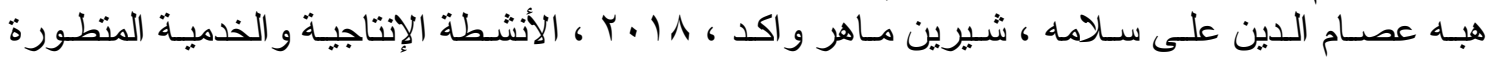

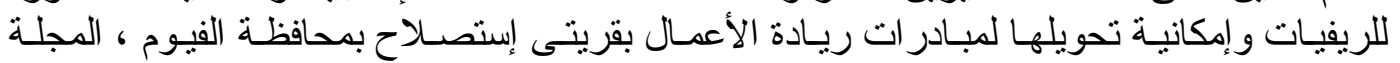

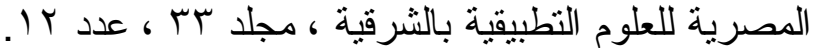

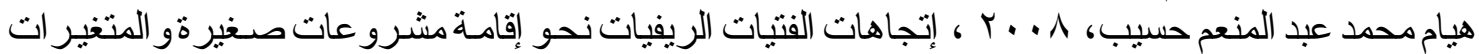

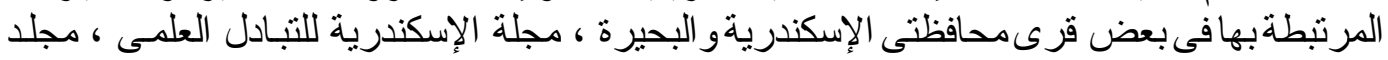
(

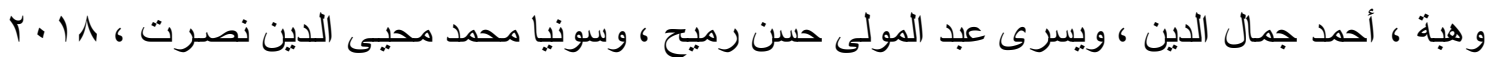

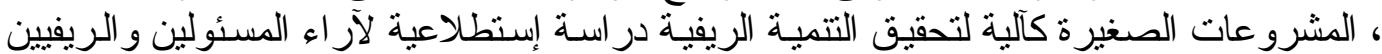

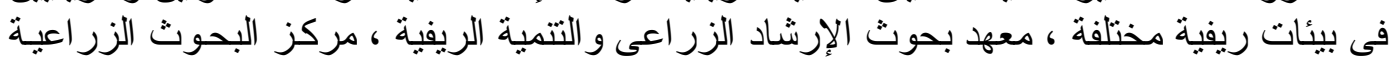
، وزارة الزر اعة و إستصلاح الأر اضى .

Website,http://www.youm7.com,retrieved Aug.15-2018

Website,http://wwwmeemmagazine,retrieved march.20-2018 


\title{
Benefit of Rural Women from Small Projects at Menoufia and Sharqia Governorate
}

\section{Amoura Hassan Aboutaleb}

Department of Rationalization of Rural Women, Agricultural Extension and Rural Development Research Institute, Agricultural Research District

\begin{abstract}
The research aimed at identify the level of benefit of rural women from the small projects they implement in the study area, determine the level of satisfaction of rural women respondents to their projects, and identify the problems facing rural women in the implementation of their projects, and finally to identify the requirements of the success of small projects from the perspective of rural respondents In the study area.

This research was conducted in the Governorates of Menoufia and Sharqia, where they are one of the most Governorates of the Republic that are carrying out small projects, in the villages of Samadoun and Sakiet Abu Sha'ara from Ashmoun District, and Shanawan and Salka from Shebin El-Kom District in Menoufia Governorate, and the villages of Arab Darwish and Ghazali from the district of Faqous, Talbaneh and Bishat Amer from the district of Minya Alkameh Sharqia. The study sample was a purposive sample based on the informants, consisting of 480 projects, a total of nearly $40 \%$, by 240 projects from each Governorate. Frequencies, percentages, weighted mean were used to analyze and describe the data of this research.
\end{abstract}

The results of the study were as follows:

- The majority of rural respondents in Menoufia Governorate had a high level of economic, social, community, and environmental benefit, while the majority of rural respondents in Sharqia Governorate had an average level of economic, social and community benefit, while their environmental level of benefit was low.

- The level of satisfaction of rural respondents with small projects in the two Governorates was average.

- As for the problems faced by rural women in implementing their projects in the two governorates, they were found to be: high prices of raw materials, high interest rates of loans, and the lack of clear criteria for the selection and recruitment of labor, and rely on random marketing, the owner of the project does not have the skills of control and follow-up.

- As for the requirements of the success of small projects in the two focused Governorates, it was found that the most important ones are: There should be grace periods before repaying loans, establishing associations to market project products, improving the condition of roads, improving water and electricity sewage networks, expanding the establishment of transport companies, and holding periodic training courses. For managers of small projects, bypassing some documents that are difficult to provide such as the commercial register and tax card when licensing the establishment of small enterprises, and insurance on projects.

Keywords: Rural Women, Small Projects, The unemployment 